UNIVERSIDADE DE SÃO PAULO

ESCOLA DE ENFERMAGEM

PAULA DE SOUSA E CASTRO

AFERIÇÃO DE CUSTOS EM UNIDADES BÁSICAS DE SAÚDE:

REVISÃO INTEGRATIVA DA LITERATURA

SÃO PAULO

2011 
PAULA DE SOUSA E CASTRO

\section{AFERIÇÃO DE CUSTOS EM UNIDADES BÁSICAS DE SAÚDE: REVISÃO INTEGRATIVA DA LITERATURA}

Dissertação apresentada à Escola de Enfermagem da Universidade de São Paulo para obtenção do título de Mestre em Ciências

Área de Concentração: Fundamentos e Práticas de Gerenciamento em Enfermagem e em Saúde

Orientadora:

Prof $^{\mathrm{a}}$. Dr ${ }^{\mathrm{a}}$. Valéria Castilho

\section{SÃO PAULO}




\section{AUTORIZO A REPRODUÇÃO E DIVULGAÇÃO TOTAL OU PARCIAL DESTE TRABALHO, POR QUALQUER MEIO CONVENCIONAL OU ELETRÔNICO, PARA FINS DE ESTUDO E PESQUISA, DESDE QUE CITADA A FONTE.}

Assinatura:

Data:

Catalogação na Publicação (CIP)

Biblioteca "Wanda de Aguiar Horta"

Escola de Enfermagem da Universidade de São Paulo

Castro, Paula de Sousa e

Aferição de custos em unidades básicas de saúde:

revisão integrativa da literatura / Paula de Sousa e Castro. -São Paulo, 2011.

138p.: il.

Dissertação (Mestrado) - Escola de Enfermagem da Universidade de São Paulo.

Orientadora: $\operatorname{Prof}^{\mathrm{a}} \mathrm{Dr}^{\mathrm{a}}$ Valéria Castilho

1. Economia da saúde 2. Economia da enfermagem 3. Serviços de saúde - Custos 4. Serviços de saúde Gerenciamento 5. Custos e análise de custo 6. Custos em enfermagem I. Título. 
FOLHA DE APROVAÇÃO

\author{
PAULA DE SOUSA E CASTRO
}

\title{
AFERIÇÃO DE CUSTOS EM UNIDADES BÁSICAS DE SAÚDE: REVISÃO INTEGRATIVA DA LITERATURA
}

Dissertação apresentada à Escola de Enfermagem da Universidade de São Paulo para obtenção do título de Mestre em Ciências.

Aprovado em:

\section{Banca Examinadora}

Prof. Dr.

Julgamento:

Prof. Dr.

Julgamento:

Prof. Dr.

Julgamento:
Instituição:

Assinatura:

Instituição:

Assinatura:

Instituição:

Assinatura: 


\section{Dedicatória}

Dedico este trabalho a Deus, força de amore perseverança que sempre me guiou e me fortaleceu.

Em especial, dedico ao meu marido Angelo, sempre presente a meu lado, compreendendo minhas angústias e meus medos, me incentivando e me motivando nessa jornada, com todo seu amor e carinho.

Ao meu filho Pedro Henrique, minha inspiração para ser uma pessoa melhor.

Aos meus pais, Nilson e Gilda, pelos valores e ensinamentos que me passaram, e que com muito amor e carinho sempre se dedicaram à minha instrução. 


\section{AGRADECIMENTOS}

A minha professora Valéria Castilho, pela orientação pautada na dedicação e amizade. Sempre presente com seu carinho e paciência, estendendo a mão nos momentos mais difíceis, norteando meu caminho com toda a sua competência e conhecimento.

A minha irmã Zilda, pelo amor, carinho e incentivo.

Aos meus queridos amigos, que sempre acompanharam a minha trajetória pessoal $e$ profissional, pelo carinho, força e incentivo.

A minha amiga de trabalho Fernanda dos Santos Fernandez, que com muito carinho e disposição fez a revisão ortográfica deste trabalho.

As minhas amigas Julieta e Simone, que sempre compreenderam meus momentos de ausência no trabalho, e sempre me incentivaram com muito carinho.

As professoras Raquel e Fernanda, pelas valiosas contribuições no Exame de Qualificação.

A todos o meu amor, carinho e gratidão. 
"Pode ser que um dia deixemos de nos falar... Mas, enquanto houver amizade, Faremos as pazes de novo.

Pode ser que um dia o tempo passe...

Mas, se a amizade permanecer, Um de outro se há-de lembrar.

Pode ser que um dia nos afastemos...

Mas, se formos amigos de verdade, A amizade nos reaproximará.

Pode ser que um dia não mais existamos...

Mas, se ainda sobrar amizade,

$\mathcal{N}$ asceremos de novo, um para o outro.

Pode ser que um dia tudo acabe... Mas, com a amizade construiremos tudo novamente, Cada vez de forma diferente.

Sendo único e inesquecível cada momento Que juntos viveremos e nos lembraremos para sempre.

Há duas formas para viver a sua vida: Uma é acreditar que não existe milagre. A outra é acreditar que todas as coisas são um milagre" 


\section{RESUMO}

Castro, PS. Aferição de custos em unidades básicas de saúde: revisão integrativa da literatura. [dissertação]. São Paulo: Escola de Enfermagem, Universidade de São Paulo: 2011.

O objetivo deste estudo foi analisar, a partir da revisão integrativa da literatura nacional, o conhecimento cientifico sobre a aferição de custos em unidades básicas de saúde. Para a coleta de dados realizou-se um levantamento bibliográfico, com busca online, nas bases de dados Portal de Evidências da Biblioteca Virtual em Saúde (BVS), LILACS, Banco de teses USP, Google. A amostra desta pesquisa foi constituída por 10 trabalhos. Os locais estudados foram compostos por municípios de todo o território nacional, com população de 5 mil a mais de 1 milhão de habitantes. Os resultados mostraram que o método mais utilizado (80\%) foi a aferição de custos por absorção. Os resultados dos estudos não puderam ser comparados devido à aplicação de conceitos e métodos de aferição de custos com interpretações diversas pelos autores. No entanto, citamos alguns dados aferidos nesses trabalhos. O custo mensal per capita variou de $R \$ 3,27$ a $R \$ 10,99$. As equipes de saúde da família ampliadas com odontólogo podem ter custos até $77,7 \%$ maiores que as equipes básicas. Os municípios podem arcar com até $90 \%$ dos gastos totais em saúde. Dos custos totais, os gastos com recursos humanos representam em média $75 \%$. Dos trabalhos que aferiram o custo por procedimento os valores variaram de $R \$$ 8,35 a $R \$ 34,20$. Este trabalho mostrou a importância da aplicação de um sistema de custeio na atenção básica, para identificar os principais custos e otimizá-los, buscando melhorar a eficiência e eficácia dos serviços de saúde. Recomenda-se para trabalhos futuros a utilização correta dos princípios dos sistemas de custeio pelos autores, buscando aprimorar a utilização de 
ferramentas para o gerenciamento de custos na atenção primária à saúde e possibilitando comparações.

Palavras-chave: Custos e análise de custos, custos de cuidados de saúde, atenção primária à saúde, saúde da família, avaliação em saúde. 


\begin{abstract}
Castro, PS. Cost analysis in primary health care services: an integrative literature review. [thesis]. São Paulo (SP), Brasil: Escola de Enfermagem, Universidade de São Paulo: 2011.

This study aimed to analyze, through an integrative review of the Brazilian literature, scientific knowledge about the measurement of costs in primary health care services. An online literature search was carried out for data collection, in the databases Evidence Portal of the Virtual Health Library (VHL), LILACS, University of São Paulo bank of theses and Google. The sample consisted of 10 studies. The study sites were various cities across Brazil, with populations ranging from 5 thousand to over 1 million inhabitants. Results showed that the most used method (80\%) was absorption costing. The results of the studies could not be compared due to the use of concepts and methods for measuring costs with different interpretations by the authors. However, the study presents some data obtained in these studies. The monthly cost per capita ranged from $R \$ 3.27$ to $R \$ 10.99$. Family health teams with dentists may cost up to $77.7 \%$ more than the basic teams. Cities can afford up to $90 \%$ of total spending on health care. Expenses on human resources account for an average of $75 \%$ of the total costs. Of the studies which measured the cost per procedure, values ranged from $R \$ 8.35$ to $R \$ 34.20$. This study showed the importance of applying a costing system in primary health care, in order to identify the main costs and optimize them, seeking to improve the efficiency and effectiveness of health care services. The correct use of the principles of costing systems by the authors is recommended for future studies, as to enhance the use of tools for cost management in primary health care and to enable comparisons.
\end{abstract}

Key words: cost and cost analysis, health care costs, primary health care, family health, health evaluation. 


\section{LISTA DE QUADROS}

Quadro 1 - Identificação dos trabalhos analisados. São Paulo - 201065

Quadro 2a - Síntese das características metodológicas da amostra do estudo identificado

Quadro 2b - Síntese das características metodológicas da amostra do estudo identificado

Quadro 2c - Síntese das características metodológicas da amostra do estudo identificado

Quadro 2d - Síntese das características metodológicas da amostra do estudo identificado

Quadro 2 e - Síntese das características metodológicas da amostra do estudo identificado

Quadro $2 f$ - Síntese das características metodológicas da amostra do estudo identificado

Quadro $2 \mathrm{~g}$ - Síntese das características metodológicas da amostra do estudo identificado

Quadro 2h - Síntese das características metodológicas da amostra do estudo identificado

Quadro 2i - Síntese das características metodológicas da amostra do estudo identificado

Quadro 2j - Síntese das características metodológicas da amostra do estudo identificado

Quadro 3 - Conceito de custos. São Paulo - 2010.

Quadro 4 - Apresentação dos custos das equipes. 


\section{LISTA DE TABELAS}

Tabela 1 Gasto total (público e privado) com saúde em relação ao PIB e gasto público em relação ao gasto total com saúde em países selecionados - 2005

Tabela 2 Distribuição dos autores segundo a formação. São Paulo 2010.

Tabela 3 Distribuição conforme tipo de publicação. São Paulo - 2010. 69

Tabela 4 Distribuição conforme fonte de publicação. São Paulo 2010.

Tabela 5 Distribuição conforme ano de publicação. São Paulo 2010.

Tabela 6 Distribuição dos objetos de custo conforme tipo de atenção à saúde. São Paulo - 2010.

Tabela 7 Distribuição pelo método de custeio utilizado. São Paulo 2010.

Tabela 8 Valor do custo com saúde per capita/mensal de acordo com os estudos - R\$1,00. São Paulo - 2010.

Tabela 9 Distribuição do aumento do custo per capita para equipes ampliadas. São Paulo - 2010.

Tabela 10 Distribuição de acordo com o gasto do município com os serviços de saúde. São Paulo - 2010.

Tabela 11 Distribuição dos trabalhos de acordo com o gasto com recursos humanos em relação ao custo total. São Paulo 2010.

Tabela 12 Valor encontrado por procedimento realizado. São Paulo 2010. 


\section{LISTA DE ABREVIATURAS}

\begin{tabular}{|c|c|}
\hline ABC & Activity-based Costing (Custos Baseados em Atividades) \\
\hline ACD & Auxiliar de consultório dentário \\
\hline ACS & Agente Comunitário de Saúde \\
\hline APS & Atenção primária à Saúde \\
\hline BVS & Biblioteca Virtual em Saúde \\
\hline CD & Cirurgião Dentista \\
\hline CS & Centro de Saúde \\
\hline DeCS & Descritores em Ciências da Saúde \\
\hline EC & Emenda Constitucional \\
\hline ESF & Equipe Saúde da Família \\
\hline IBGE & Instituto Brasileiro de Geografia e Estatística \\
\hline LILACS & Literatura Latino-Americana e do caribe em Ciências e Saúde \\
\hline LOAS & Leis Orgânicas da Saúde \\
\hline MS & Ministério da Saúde \\
\hline NOAS & Norma Operacional da Assistência à Saúde \\
\hline NOB & Norma Operacional Básica \\
\hline OMS & Organização Mundial da Saúde \\
\hline OPAS & Organização Pan-Americana da Saúde \\
\hline PAB & Piso de Atenção Básica \\
\hline PACS & Programa de Agentes Comunitários de Saúde \\
\hline PIB & Produto Interno Bruto \\
\hline PSF & Programa Saúde da Família \\
\hline SES & Secretaria Estadual da Saúde \\
\hline SIA & Sistema de Informações Ambulatoriais \\
\hline SMS & Secretaria Municipal de Saúde \\
\hline SUS & Sistema Único de Saúde \\
\hline THD & Técnico de Higiene Dental \\
\hline UBS & Unidade Básica de Saúde \\
\hline USF & Unidade de Saúde da Família \\
\hline
\end{tabular}




\section{SUMÁRIO}

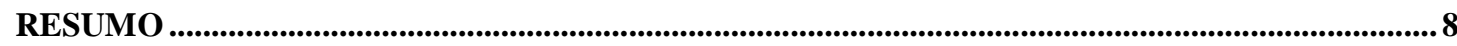

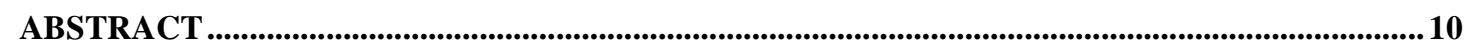

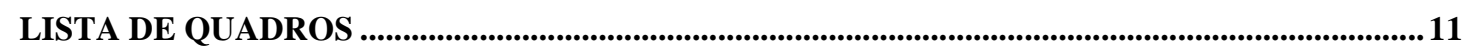

LISTA DE TABELAS................................................................................................................................... 12

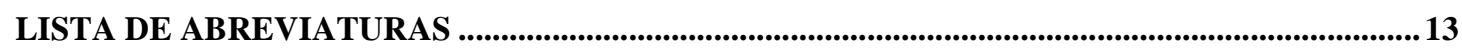

SUMÁRIO ................................................................................................................................................... 14

APRESENTAÇÃO.................................................................................................................... 16

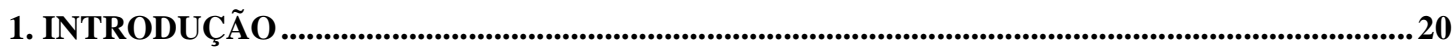

2. JUSTIFICATIVA....................................................................................................................................... 23

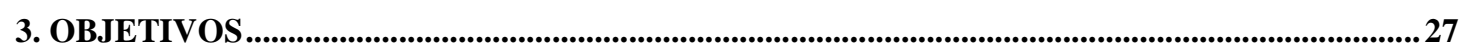

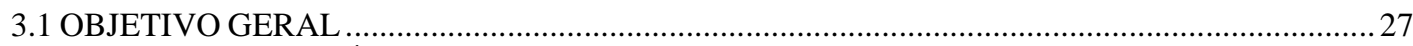

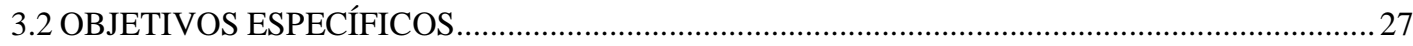

4. BASES CONCEITUAIS ............................................................................................................................28

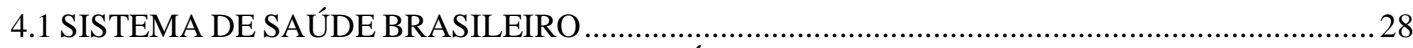

4.2 O FINANCIAMENTO NO SISTEMA DE SAÚDE BRASILEIRO …………………....................... 31

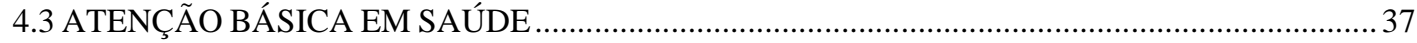

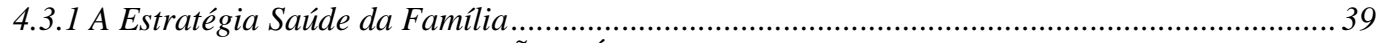

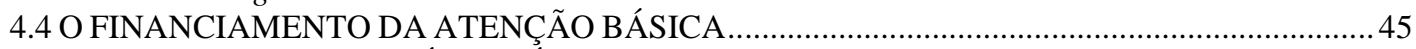

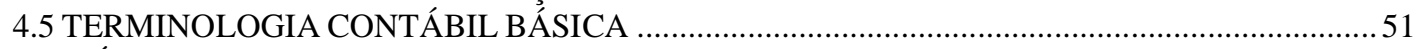

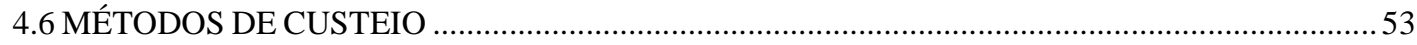

4.6.1 Custeio por absorção............................................................................................... 53

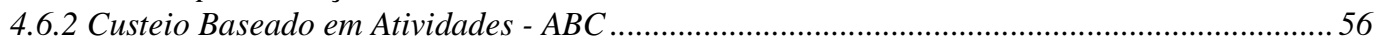

5. MÉTODO .................................................................................................................................58

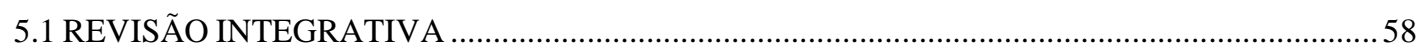

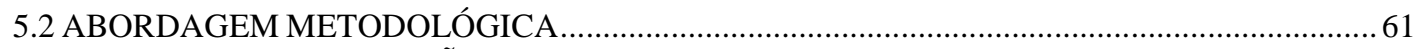

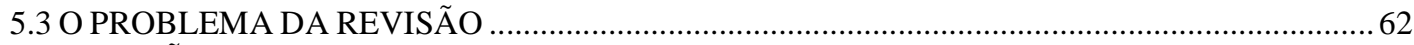

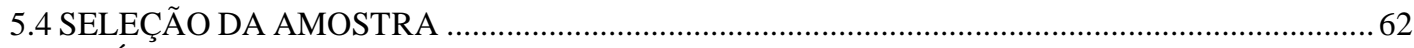

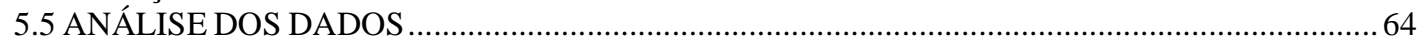

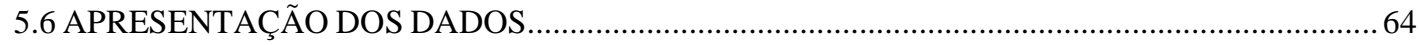

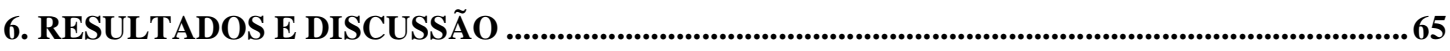

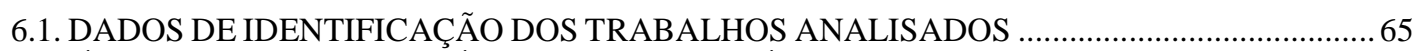

6.2 SÍNTESE DAS CARACTERÍSTICAS METODOLÓGICAS ………………………………….....73

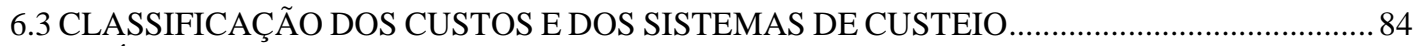

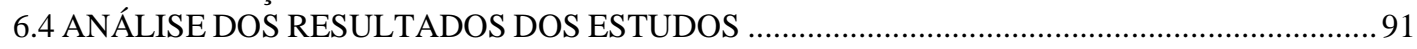

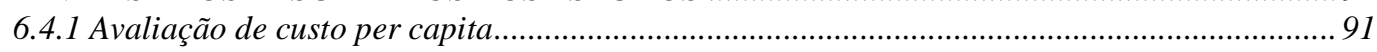

6.4.2 Avaliação de repasse das verbas financeiras e do gasto municipal......................................... 95

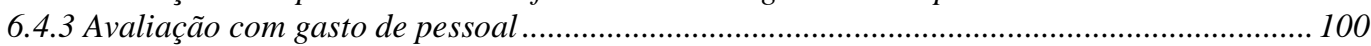

6.4.4 Avaliação do custo de procedimentos................................................................................. 102

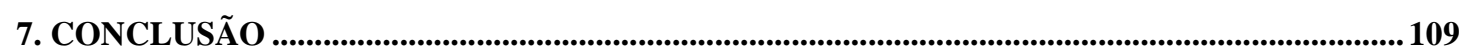

8. CONSIDERAÇÕES FINAIS ......................................................................................11 
9. REFERÊNCIA BIBLIOGRÁFICA...................................................................................113

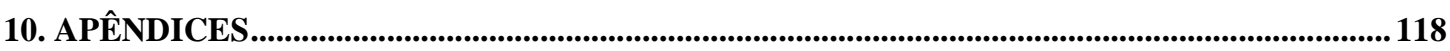

10.1 APÊNDICE A - PLANILHA DE ANÁLISE DOS ESTUDOS ..................................................................... 118

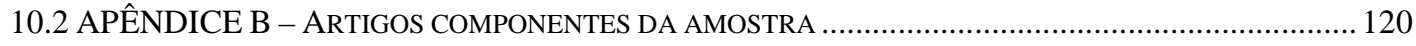

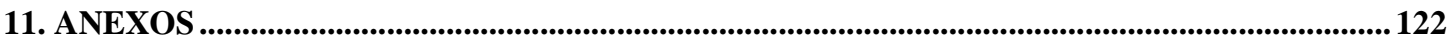

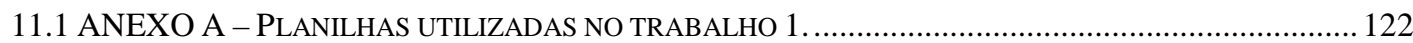

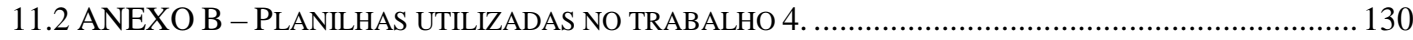




\section{APRESENTAÇÃO}

A escolha do tema, relacionado a custos na atenção básica, vem ao encontro de uma série de questionamentos feitos por mim durante minha vida profissional.

Após a graduação, minha atuação como enfermeira hospitalar foi de apenas 1 ano. Por motivos pessoais, deixei de exercer a profissão para montar um negócio próprio e então vivenciei pela primeira vez a necessidade de conhecimentos básicos em contabilidade, mais especificamente em custos.

Para voltar a exercer a profissão após 3 anos de afastamento, fiz em 2001 o curso de Aprimoramento em Saúde Pública, na Faculdade de Medicina de Botucatu, que me fez apaixonar pela saúde coletiva e nunca mais deixar de exercer a enfermagem na atenção básica.

Concluído o aprimoramento atuei como enfermeira de Saúde da Família por 3 anos, e nesse período fiz minha primeira especialização em Gerenciamento de Serviços de Enfermagem. Neste curso percebi a ausência de conhecimentos específicos de administração aplicada à Saúde Coletiva. Já naquela ocasião houve discussões sobre a importância, do profissional enfermeiro, ter conhecimentos sobre questões econômicas e financeiras, mas havia pouca ou quase nenhuma literatura direcionada para a atenção básica.

Após a conclusão desta pós-graduação, recebi minha primeira promoção profissional, para atuar como gestora de uma unidade básica de saúde, que tinha como característica o fato de ser uma unidade mista, ou seja, parte de sua população cadastrada era atendida pela estratégia saúde da família, e parte era atendida pelo modelo tradicional. Essa unidade funcionava através de uma parceria entre a Secretaria Municipal de São Paulo e um Hospital de grande porte da região onde estava localizada. 
Com o contrato de gestão ou de parceria, a prefeitura repassa uma verba financeira para a Organização Social e esta fica responsável pela contratação de profissionais para a prestação dos serviços.

Assim, um dos meus desafios era conduzir uma equipe com múltiplos tipos de contrato de trabalho (celetistas, municipalizados, funcionários estaduais, funcionários federais), cumprindo diversas cargas horárias e recebendo diferentes remunerações, o que deixava os profissionais com alguns desconfortos. Aqueles que ganhavam menos se achavam no direito de não cumprir sua carga horária total, e até mesmo de escolher qual paciente iriam atender.

Diante disso, começou a minha necessidade de entender a lógica do município, que não podia melhorar os salários de seus funcionários concursados, em razão das limitações impostas pela Lei de Responsabilidade Fiscal, porém os funcionários contratados através das parcerias recebiam salários mais altos, sendo na proporção de 1:2 até 1:4 vezes.

Com o intuito de buscar ferramentas gerenciais que me auxiliassem a enfrentar esses desafios com mais competência, ingressei no curso de especialização em Saúde da Família e, paralelamente, fiz outra especialização à distância em Autogestão em Saúde.

No curso de Saúde da Família, o direcionamento era para a parte prática da estratégia, em como atender a população de maneira mais adequada, mas quase nada foi apresentado sobre gestão. Claro que todos os princípios universalidade, equidade e integralidade - da atenção foram muito discutidos, sendo que o da equidade gerava mais confrontos, uma vez que as unidades básicas, por não terem recursos suficientes para atender as demandas da população, necessitam priorizar os atendimentos.

Após quase dois anos como gestora de unidade básica de saúde nesta estratégia, mudei de modelo de atenção e fui trabalhar em uma unidade ambulatorial de assistência médica - AMA. Este é outro programa do município, 
direcionado para a atenção básica que tem por objetivo diminuir a demanda pela rede básica e os pronto-socorros realizando consultas de urgência de baixa complexidade. Ou seja, atender a população prontamente, nas queixas que não seriam de pronto-socorro hospitalar, mas que não poderiam aguardar pelo agendamento.

Mais uma vez, senti necessidade e interesse em saber: Qual o montante financeiro repassado pela prefeitura as Organizações Sociais? Qual o custo desses serviços? Por que não se ampliar a própria rede municipalizada, melhorando as unidades já existentes para este tipo de atendimento e aumentando o quadro de funcionários? Qual o custo da atenção básica? Com a implantação do PSF, houve uma melhora na atenção e diminuição de custos da atenção básica?

Em busca de esclarecimentos para estas questões passei a procurar artigos e pesquisas relacionadas ao assunto, constatando a escassez de material sobre o tema.

Com o meu ingresso no Mestrado do Programa de Pós-graduação em Gestão em Enfermagem da Escola de Enfermagem da Universidade de São Paulo, surgiu à oportunidade de desenvolver esta pesquisa, após dez anos de trabalho como enfermeira da rede básica de Saúde do município de São Paulo.

A seguir, apresento a organização deste trabalho, para facilitar o acompanhamento do estudo. Esta dissertação está organizada em sete capítulos:

- Capítulo 01 - Introdução: apresentando os temas que norteiam a pesquisa como um todo, traçando um referencial teórico, possibilitando ao leitor familiarizar-se com o tema, explicitando os conceitos necessários para o entendimento do estudo.

- Capítulo 02 - Justificativa. 
- Capítulo 03 -Objetivos.

- Capítulo 04 - Bases Conceituais.

- Capítulo 05 - Método - apresentação da sistemática metodológica adotada para o desenvolvimento da pesquisa.

- Capítulo 06 - Resultados e discussão, que compreende a caracterização da amostra dos estudos utilizados e analisados.

- Capítulo 07 - Conclusão - apresentação dos principais resultados.

- Capitulo 08 - Considerações finais. 


\section{INTRODUÇÃO}

Os processos de definição e redefinição de políticas sociais e econômicas têm colocado a saúde como uma questão de extrema importância, sendo esse setor objeto de análise tanto em países desenvolvidos como nos países em desenvolvimento.

A política social implementada em diversos países ocidentais no pósguerra foi caracterizada por um modelo de proteção social orientado a assegurar direitos sociais. Porém, ele vem sofrendo contestações há alguns anos, por ser o protecionismo considerado a principal causa de crise no setor saúde, devido à incapacidade do Estado em sustentar o aumento crescente de gastos, e, conseqüentemente, dos custos dos serviços de atenção a saúde ${ }^{1}$.

O Brasil, assim como esses países, vêm passando pelos mesmos problemas por ter adotado um modelo universalista de atenção. O sistema de saúde vigente em nosso país - denominado Sistema Único de Saúde (SUS) foi estabelecido pela Constituição Federal de 1988, e regulamentado pelas Leis no 8.080 e no 8.142, ambas de $1990^{2 ;} 3 ; 4$, e tem como princípios a universalidade, a equidade e a integralidade da atenção, e como diretrizes organizacionais a descentralização e da participação da sociedade, dentre outros.

Para a consecução dos objetivos desses sistemas de saúde o financiamento tem sido objeto de crescente preocupação em quase todos os países. Nos países desenvolvidos, que já investem uma parcela considerável e crescente do seu Produto Interno Bruto (PIB) em saúde, aumenta a preocupação com a eficiência, efetividade e equidade nos gastos, uma vez que o incremento nos dispêndios médico-assistenciais, por si só, não gera melhores condições de saúde coletiva, nem reduz eventuais iniqüidades no acesso aos serviços. Por isso, tem sido apontada a necessidade de implementação de novas práticas gerenciais. 
Nos países em desenvolvimento, além das preocupações citadas estão presentes desafios adicionais, como a extensão da cobertura a toda a população, a melhoria da qualidade dos serviços e as exigências do financiamento setorial em concorrência com outras necessidades de desenvolvimento social e econômico ${ }^{5}$.

Assim, com o marcante crescimento dos gastos em saúde, associado à restrição de recursos orçamentários, identifica-se a necessidade de desenvolvimento de mecanismos e instrumentos voltados para o controle de gastos. Para isso, é necessário gerenciar os custos, iniciando pela sua mensuração e monitoramento nos serviços de saúde.

A existência de instrumentos de avaliação de custos pode também permitir o aperfeiçoamento de técnicas de planejamento, sendo uma ferramenta importante para analisar e estabelecer prioridades ${ }^{6}$.

Assim, é cada vez mais importante para o gestor conhecer e controlar a estrutura de custos de sua unidade, de forma a garantir o atendimento de saúde para a população, levando em conta os princípios do SUS (universalidade, integralidade e equidade) e identificando desperdícios, desorganização e falta de planejamento ${ }^{6}$.

Pensando nessas questões, acreditou-se que o passo mais importante para a transformação das práticas na assistência à saúde da população foi construir o consenso em torno da necessidade de mudar o modelo da assistência, desenvolvendo uma porta de entrada acessível para uma população de referência conhecida, com seus problemas de saúde conhecidos e avaliados de forma a fundamentar um planejamento e um programa de ações ${ }^{7}$. Assim, o Programa de Saúde da Família (PSF) foi concebido como uma estratégia para mudança do modelo de atenção à saúde, para efetivar os princípios do SUS ${ }^{8}$.

Segundo relatórios da Organização Pan-Americana da Saúde OPAS/OMS, alguns estudos demonstravam existir maior equidade e eficiência, 
melhor efetividade de custos e maior satisfação dos usuários nos sistemas que possuíam por base a atenção primária a saúde. Com esse argumento, se justificou o investimento na implantação da Estratégia Saúde da Família, como consolidação dos princípios do SUS ${ }^{9}$. 


\section{JUSTIFICATIVA}

O custo da atenção à saúde está se tornando cada vez mais elevado, e os recursos sempre escassos frente ao crescimento quantitativo das necessidades de atenção à saúde, o que torna cada vez mais urgente o conhecimento sobre a formação dos custos nesse setor, a fim de possibilitar intervenções que melhorem a produção dos serviços a menores custos ${ }^{10}$. Outro aspecto, é a necessidade de maior capacitação dos gestores para o exercício de sua função ${ }^{11}$.

Porém, a gestão dos serviços de saúde tem sido um dos setores mais atrasados no que se refere à utilização de instrumentos de gestão financeira, ocasionando elevados desperdícios de recursos e o desconhecimento do custo real dos procedimentos ${ }^{11}$.

Estudos de descrição e análise de custos de programas e serviços de saúde constituem importante ferramenta para a análise de viabilidade financeira - um dos componentes fundamentais do planejamento - e para um melhor gerenciamento do sistema de saúde. A despeito da importância dos estudos de custos, os municípios - mesmo os que apresentam maior nível de organização ainda não estão preparados para produzir informações que possibilitem sua utilização como instrumento aplicado para conferir maior eficiência ao sistema de saúde, visto a inexistência de centros de custeio organizados nos municípios $^{12}$.

Cabe aos gestores criar as alternativas que viabilizem a reestruturação da rede básica de atenção à saúde, sem que seja necessário optar por soluções que reduzam a oferta de serviços. Por isso, o conhecimento de custos, nessas circunstâncias, é uma necessidade para aqueles que pretendem realizar uma gestão mais eficiente e eficaz ${ }^{6}$.

A discussão dos custos dos serviços públicos de saúde e a criação de instrumentos que permitam fazer essa análise são um tópico essencial, para 
orientar novas políticas, que poderão ser implementadas pelos gestores de forma a ampliar a oferta dos serviços com qualidade e com os recursos financeiros disponíveis ${ }^{13}$.

Para uma análise econômica correta do sistema, é preciso que toda a cadeia de trabalho seja envolvida, e o gestor local é a pessoa mais indicada para fornecer os dados necessários para a análise do todo. Apesar de não ter governabilidade para mudar decisões financeiras, no âmbito local ele pode melhorar a distribuição da aplicação financeira de acordo com as suas necessidades.

$\mathrm{Na}$ prática, o desconhecimento da estrutura de custos inviabiliza a análise estratégica da gestão, apesar das apurações de custos serem citadas como ferramenta importante para o gerenciamento dos serviços de saúde, dada sua potencialidade em gerar um elenco de informações necessárias ao processo de tomada de decisão, como a de racionalizar o uso dos insumos, e utilizar estas informações para apoiar o planejamento a médio e longo prazo.

Dessa forma, se faz necessário enfrentar a discussão da eficiência do gasto como uma questão ética. Os instrumentos econômicos de gerenciamento dos custos permitem conhecer melhor alguns aspectos da realidade dos serviços e, conseqüentemente, viabilizam a construção de soluções para cada situação-problema encontrada ${ }^{6 ; 12}$.

Para a efetivação de políticas sociais, a gerência em saúde é fundamental como ação intencional voltada para a concretização de objetivos, já que o gerente tem caráter articulador e integrativo, sendo essas características determinantes no processo de organização dos serviços de saúde ${ }^{14}$.

A gerência em saúde pública compreende o apoio à liderança do setor, seja para uma supervisão técnica, município ou estado; a compreensão da estrutura organizacional e sua relação com a prática profissional; a formulação, realização e monitoramento do desempenho de programas; o gerenciamento de 
sistemas de informação para coleta, recuperação e uso de dados para a tomada de decisão; a negociação e o desenvolvimento de contratos e outros documentos para a provisão de serviços à população e a condução de análises de custo-efetividade, custo-benefício e custo-utilidade ${ }^{14}$.

Com todas essas necessidades, se vê a importância do preparo teórico sobre gestão de serviços para o profissional que assume essa responsabilidade.

$\mathrm{Na}$ prática, nos deparamos com gestores locais de diversas formações acadêmicas: medicina, enfermagem, odontologia, nutrição, administradores, algumas profissões com mais representatividade do que outras. Mas é fato que o número de enfermeiras gestoras locais de serviços de saúde na atenção básica vem crescendo.

A predominância das atividades administrativas no trabalho de enfermeiras no Brasil, em todas as áreas, leva a um consenso de que as enfermeiras possuem competência para assumir a gerência e gestão de serviços de saúde, por estarem aptas a tomar iniciativas, fazer o gerenciamento e administração, tanto da força de trabalho quanto dos recursos físicos, materiais e de informação ${ }^{14}$.

A administração da assistência de enfermagem e a administração do serviço de enfermagem têm sido responsáveis pelo preparo da enfermeira para - gerenciamento de serviços de saúde. A equipe de saúde percebe e reconhece a enfermeira como o profissional que detém mais informações sobre o funcionamento do serviço, pois suas atividades na atenção básica extrapolam a responsabilidade pelas atividades ligadas à equipe de enfermagem e de agentes comunitários, assumindo, na ausência da autoridade sanitária local, as suas funções ${ }^{14}$.

Diante do exposto acima, este estudo tem por escopo analisar a utilização de modelos de aferição de custos, bem como avaliar sua aplicabilidade em unidades básicas de saúde. Sintetizando os vários motivos 
que justificam o interesse em se desenvolver esta pesquisa, seriam: levantar a produção de trabalhos sobre o tema, analisar os seus achados e ampliar a divulgação dos resultados dessas pesquisas em nível nacional.

Um trabalho científico desta natureza poderá, também, contribuir com o desenvolvimento de metodologias específicas para a aferição e avaliação de custos de um serviço de saúde.

Assim, os objetivos propostos dessa pesquisa estão descritos a seguir. 


\section{OBJETIVOS}

\subsection{OBJETIVO GERAL}

- Analisar, a partir de uma revisão integrativa da literatura nacional, o conhecimento científico sobre a aferição de custos em unidades básicas de saúde.

\subsection{OBJETIVOS ESPECÍFICOS}

- Identificar as pesquisas desenvolvidas sobre aferição de custos em unidades básicas de saúde;

- Descrever os estudos caracterizando-os quanto ao desenho metodológico e quanto aos sistemas de custeio utilizados para a aferição de custos;

- Identificar os avanços e as dificuldades encontradas para a utilização de sistemas de custeio e a aferição dos custos. 


\section{BASES CONCEITUAIS}

\subsection{SISTEMA DE SAÚDE BRASILEIRO}

O sistema de serviços de saúde no Brasil, nas suas origens hegemonicamente privado e ancorado na medicina liberal e na filantropia, evoluiu, a partir da criação do seguro social na segunda década do século $X X$, para um modelo no qual a saúde passou a ser um direito inerente à cidadania $\mathrm{e}$ garantido pelo Estado 5 .

Antes disso, com o aumento da oferta de bens e serviços de saúde, sobretudo a partir dos anos 60, o perfil do sistema de saúde brasileiro foi se tornando mais nítido, sobressaindo então quatro principais características: exclusão, segmentação, hegemonia privada na oferta e ênfase nas ações de recuperação da saúde ${ }^{5}$.

Exclusão, porque o crescimento da assistência médica se deu mediante a incorporação gradual de categorias profissionais do mercado de trabalho formal urbano, ignorando o resto da população. Essa característica foi sendo atenuada com a implementação de sucessivas políticas públicas que estenderam a assistência médica previdenciária aos grupos desprotegidos, e a partir da criação do Sistema Único de Saúde (SUS), a assistência se estendeu a todos os brasileiros.

A segmentação ocorria em duas vertentes: a institucional e a de clientela. A primeira ligada ao Ministério da Saúde, com a vinculação da assistência médico-hospitalar ao sistema previdenciário e das funções de saúde pública. A segunda decorria da existência de cinco categorias: a) os clientes particulares; b) os portadores de algum plano de saúde, incluindo aqui os servidores públicos; c) os previdenciários urbanos; d) os previdenciários rurais e e) o resto da população dependente da filantropia. 
Na prática existiam dois subsistemas estatais. Um, de direito, o Ministério da Saúde propriamente dito, dependente de recursos orçamentários sempre escassos e oriundos de impostos gerais. E outro - o da previdência social relativamente autônomo graças à receita proveniente da taxação da folha de salário e com saldos orçamentários expressivos, em virtude do ainda baixo peso relativo de seus compromissos securitários (pensões e aposentadorias) ${ }^{5}$.

Essa situação de relativo conforto financeiro possibilitou, até o final dos anos 70, o custeio de um modelo médico-assistencial seletivo, ancorado na livre demanda e na oferta predominante privada ${ }^{5}$.

Hoje, o sistema de saúde vigente em nosso país, denominado Sistema Único de Saúde (SUS), foi estabelecido pela Constituição Federal de 1988, estando regulamentado pelas Leis no 8.080 e no 8.142 , ambas de 1990 .; 3; 4

$\mathrm{Na}$ sua formulação, estabelece princípios como a universalidade, a equidade e a integralidade da atenção, bem como as diretrizes organizacionais da descentralização e da participação da sociedade.

Com a sua criação, o SUS fundou novas bases institucionais, gerenciais e assistenciais para o provimento das ações e dos serviços de saúde no país ${ }^{15}$.

Sob o lema "Saúde direito de todos, dever do Estado", seus princípios podem ser resumidos em alguns pontos básicos: as necessidades individuais e coletivas de saúde são consideradas de interesse público e seu atendimento um dever do Estado; a assistência médico-sanitária integral passa a ter caráter universal e destina-se a assegurar a todos o acesso aos serviços, que devem ser hierarquizados segundo parâmetros técnicos, e a sua gestão deve ser descentralizada ${ }^{2}$.

Com base no art. $7^{0}$ da Lei 8.080/90, as ações e serviços públicos de saúde e os serviços privados contratados ou conveniados que integram o SUS são desenvolvidos de acordo com as diretrizes previstas no art. 198 da Constituição Federal, obedecendo ainda aos seguintes princípios:

I - universalidade de acesso aos serviços de saúde em todos os níveis de assistência; 
II - integralidade de assistência, entendida como conjunto articulado e contínuo das ações e serviços preventivos e curativos, individuais e coletivos, exigidos para cada caso em todos os níveis de complexidade do sistema;

III - preservação da autonomia das pessoas na defesa de sua integridade física e moral;

IV - igualdade da assistência à saúde, sem preconceitos ou privilégios de qualquer espécie;

$V$ - direito à informação, às pessoas assistidas, sobre sua saúde;

VI - divulgação de informações quanto ao potencial dos serviços de saúde e a sua utilização pelo usuário;

VII - utilização da epidemiologia para o estabelecimento de prioridades, a alocação de recursos e a orientação programática;

VIII - participação da comunidade;

IX - descentralização político-administrativa, com direção única em cada esfera de governo:

a) ênfase na descentralização dos serviços para os municípios;

b) regionalização e hierarquização da rede de serviços de saúde;

$X$ - integração em nível executivo das ações de saúde, meio ambiente e saneamento básico;

$X I$ - conjugação dos recursos financeiros, tecnológicos, materiais e humanos da União, dos Estados, do Distrito Federal e dos Municípios na prestação de serviços de assistência à saúde da população;

XII - capacidade de resolução dos serviços em todos os níveis de assistência; e

XIII - organização dos serviços públicos de modo a evitar duplicidade de meios para fins idênticos.

Baseado nestas diretrizes, a noção de proteção social como uma necessidade das populações, a universalização do acesso aos serviços de saúde surgiu em resposta à crescente desigualdade social, ao consumo indiscriminado e mercadológico do sistema de saúde, já que a sustentabilidade dos sistemas baseados nos modelos médico-hospitalocêntricos demonstravam sinais de esgotamento ${ }^{16}$.

A implantação do SUS criou a necessidade de reorganização dos serviços de saúde no Brasil, especialmente em função da descentralização.

Desde o início da década de 2000, os municípios brasileiros com mais de 100 mil habitantes têm sido priorizados pelo Ministério da Saúde em sua estratégia de expansão e consolidação da atenção básica, devido à grande concentração populacional em grandes centros urbanos e às baixas coberturas apresentadas pelo Programa Saúde da Família (PSF). 
Contudo, pouco ainda se sabe a respeito das condições financeiras que esses municípios apresentam para assumir sua responsabilidade plena na atenção básica.

Considera-se que decisões críticas dos governos municipais em relação às formas de organização e prestação do cuidado à saúde são condicionadas pela disponibilidade de recursos e pela importância relativa das várias fontes de receitas vinculadas à saúde em seus orçamentos. Isso porque, devido à importância relativa dos diferentes tipos de recursos vinculados, as variações na composição orçamentária refletem a diversidade na disponibilidade de receitas voltadas para saúde; oportunidades diferenciadas de obtenção e expansão de receitas e relações intergovernamentais predominantes; tipos de despesa que podem ser efetivadas e maior ou menor autonomia na alocação dos recursos ${ }^{17}$.

Nesse contexto, o principal desafio, principalmente para os municípios, foi e é até hoje a garantia dos princípios básicos da universalidade, da integralidade e da equidade, uma vez que não há correspondente transferência de recursos financeiros, principalmente dos Estados para os municípios.

Esse cenário, agravado pela contínua absorção de novas e caras tecnologias, a entre outros fatores, traz à tona a discussão sobre custos como um dos temas primordiais do setor ${ }^{18}$.

\subsection{O FINANCIAMENTO NO SISTEMA DE SAÚDE BRASILEIRO}

De acordo com estimativas da Organização Mundial de Saúde (OMS), o Brasil gastou cerca de 7,9\% do PIB com saúde em 2005. Desse montante, o gasto privado (das famílias e das empresas) respondeu por $55,9 \%$ do gasto total; o desembolso no ato (gasto out-of-pocket), isoladamente, atinge $30 \%$ do total. Apesar do Brasil despender de uma parcela do PIB, com valores próximos aos países da Organização e Cooperação para o Desenvolvimento Econômico 
(OCDE), ainda ao contrário destes, a participação do gasto público, como percentual do gasto total, é muito menor ${ }^{5}$.

Tabela 1 - Gasto total (público e privado) com saúde em relação ao PIB e gasto público em relação ao gasto total com saúde em países selecionados - 2005

\begin{tabular}{l|c|c}
\hline \multicolumn{1}{c|}{ Países } & \% do PIB & \% do Gasto Público \\
\hline Alemanha & 10,7 & 76,9 \\
Austrália & 8,8 & 67,0 \\
Bélgica & 9,6 & 71,4 \\
Brasil & 7,9 & $\mathbf{4 4 , 1}$ \\
Canadá & 9,7 & 70,3 \\
Espanha & 8,2 & 71,4 \\
Estados Unidos & 15,2 & 45,1 \\
Inglaterra & 8,2 & 87,1 \\
\hline
\end{tabular}

Fonte: World Health Statistics 2008. Disponivel em: www.who.int whosis

O sistema de saúde do Brasil é pluralista, tanto em termos de modalidades de atenção à saúde, quanto de fontes de financiamento. Essa pluralidade se expressa nas quatro vias básicas de acesso da população aos serviços de saúde: o Sistema Único de Saúde, de acesso universal, gratuito e financiado com recursos públicos (impostos e contribuições); o segmento de planos e seguros privados de saúde, de vinculação eletiva, financiado com recursos das famílias e/ou empregadores; o segmento de atenção aos servidores públicos, civis e militares, de acesso restrito a essas clientelas, financiado com recursos públicos e dos próprios servidores, majoritariamente, atendidos na rede privada; e, o segmento de provedores privados autônomos de saúde, de acesso direto mediante pagamento no ato ${ }^{19}$.

O financiamento do SUS é compartilhado entre as três esferas do governo $^{16}$. A Lei $n^{0} 8.080$ define os papéis de cada esfera governamental, no plano da gestão, na estrutura de financiamento e nas regras de transferência de recursos entre os diferentes níveis de governo, deixando clara a utilização de critérios para orientar o estabelecimento de valores das transferências para estados e municípios, no art. $35^{3}$ :

Para o estabelecimento de valores a serem transferidos a estados, Distrito Federal e municípios, será utilizada a combinação dos seguintes critérios, segundo a análise técnica de programas e projetos: I - perfil demográfico da região: II - perfil epidemiológico da 


\begin{abstract}
população a ser coberta; III - características quantitativas e qualitativas da rede de saúde na área; IV - desempenho técnico, econômico e financeiro do período anterior; $V$ - níveis de participação do setor saúde nos orçamentos estaduais e municipais; VI - previsão do plano qüinqüenal de investimento da rede; VII - ressarcimento do atendimento de serviços prestados a outras esferas de governo; Parágrafo $1^{\circ}$ - Metade dos recursos destinados a estados e municípios será distribuído segundo o quociente de sua divisão pelo número de habitantes, independentes de qualquer procedimento prévio;Parágrafo $2^{\circ}$ - Nos casos de estados e municípios sujeitos a notório processo de migração, os critérios demográficos mencionados nesta Lei serão ponderados por outros indicadores de crescimento populacional, em especial o número de eleitores registrados. Parágrafo $6^{0}-0$ disposto no parágrafo anterior não prejudica a atuação dos órgãos de controle interno e externo e nem a aplicação de penalidades previstas em lei, em caso de irregularidades verificadas na gestão dos recursos transferidos.
\end{abstract}

A Constituição Federal, em seu art. 195, define que os recursos do SUS (enquanto integrante da Seguridade Social) são compostos por receitas provenientes da União, dos Estados, do Distrito Federal e dos municípios, e não apenas por recursos de transferências de uma esfera de governo para outra, além de contribuições sociais² ${ }^{2}$.

Isso é reiterado na Emenda Constitucional (EC) $\mathrm{n}^{\circ}$ 29, art. $7^{\circ}$, parágrafo $3^{\circ}$, que estabelece que todos os recursos transferidos e próprios devem estar no Fundo de Saúde e acompanhados e fiscalizados pelo Conselho de Saúde ${ }^{20}$ :

Os recursos dos Estados, do Distrito Federal e dos Municípios destinados às ações e serviços públicos de saúde e os transferidos pela União para a mesma finalidade serão aplicados por meio de Fundo de Saúde que será acompanhado e fiscalizado por Conselho de Saúde, sem prejuízo do disposto no art. 74 da Constituição Federal.

Dessa forma, todos os recursos do SUS, nas esferas estadual e municipal, devem ser provenientes do Fundo de Saúde e nenhuma despesa com ações e serviços de saúde pode ser realizada sem fazer parte do Fundo de Saúde. O Fundo garante que seus recursos financeiros não se misturem aos outros recursos da administração geral, possibilitando autonomia quanto à utilização dos recursos da área da Saúde em relação às demais, e maior agilidade na sua alocação. 
Os Fundos de Saúde, instituídos no âmbito de cada Estado, Distrito Federal e Municípios, são considerados especiais conforme define a Lei $\mathrm{n}^{\circ}$ 4.320/64. Suas receitas são especificadas e vinculadas à realização de objetos e serviços determinados, no caso, as ações e serviços públicos de saúde ${ }^{20}$.

Os fundamentos legais do Fundo de Saúde estão inscritos no inciso IX do art. 167 da Constituição Federal, e nas Leis Orgânicas da Saúde (LOAS) 8.080/90 e 8.142/90 (art. 33 da Lei no 8.080/90 e incisos I e V do art. 4º da Lei no - 8.142/90), especificando que os recursos financeiros do SUS serão depositados em conta especial, em cada esfera de sua atuação e movimentados sob a fiscalização do Conselho de Saúde ${ }^{2 ; 3 ; 4}$.

Os recursos financeiros são repassados por meio de transferências regulares e automáticas, remuneração por serviços produzidos, convênios, contratos de repasses e instrumentos similares.

A transferência fundo a fundo caracteriza-se pelo repasse de recursos, diretamente do Fundo Nacional de Saúde para os Fundos Municipais de Saúde, observadas as condições de gestão, a qualificação e a certificação aos programas e incentivos do Ministério da Saúde e os respectivos tetos financeiros.

São transferidos recursos fundo a fundo para financiamento de ações e serviços de saúde da:

- atenção básica dos municípios habilitados na Gestão Plena da Atenção Básica e dos municípios não habilitados, quando realizadas por Estados habilitados na Gestão Avançada do Sistema Estadual;

- assistência de média e alta complexidade realizada pela União e por Estados habilitados na Gestão Plena do Sistema Estadual.

O financiamento através do Incentivo de Integração ao Sistema Único de Saúde (INTEGRASUS), do Fator de Incentivo ao Desenvolvimento de Ensino e Pesquisa em Saúde (FIDEPS) e do Incentivo de Apoio e Diagnóstico Ambulatorial e Hospitalar à População Indígena (IAPI), é realizado, 
excepcionalmente por pagamento direto aos prestadores dos respectivos serviços, mesmo que vinculados a estados e municípios habilitados em Gestão Plena de Sistema ${ }^{20}$.

A gestão financeira do SUS, por meio do funcionamento do Fundo de Saúde, é definida nas Portarias do Ministério da Saúde, denominadas Normas Operacionais Básicas (NOB) do SUS. A norma que se encontra em vigor é a NOB $96^{21}$, a qual estabelece obrigatoriedade da existência do Fundo de Saúde para que os estados e municípios se habilitem ao SUS e possam receber recursos transferidos do Ministério da Saúde para o financiamento de suas ações e serviços de saúde.

Essa mesma determinação está exposta na recente Norma Operacional da Assistência à Saúde/SUS (NOAS/SUS 01/2001) ${ }^{22}$. E ainda, o Decreto no 1.232, de 30 de agosto de 1994, dispõe sobre as condições e a forma de repasse regular e automático de recursos do Fundo Nacional de Saúde para os fundos de saúde estaduais e municipais ${ }^{20}$.

A EC n 29 , aprovada ao final de 2000, definiu a participação das esferas federal, estadual e municipal de governo no financiamento das ações e serviços de saúde do SUS, procurando enfrentar as dificuldades de financiamento vividas pelo SUS praticamente desde sua criação.

Definiu a participação das esferas de governo no financiamento do SUS da seguinte forma, de acordo com 0 art. $7^{\circ}$ :

Art 7ㅇ O Ato das Disposições Constitucionais Transitórias passa a vigor acrescido do seguinte art. 77:

"Art. 77 - Até o exercício financeiro de 2004, os recursos mínimos aplicados nas ações e serviços públicos de saúde serão equivalentes.

I - no caso da União:

a) no ano 2000, o montante empenhado em ações e serviços públicos de saúde no exercício financeiro de 1999 acrescido de, no mínimo, cinco por cento;

b) do ano 2001 ao 2004, o valor apurado no ano anterior, corrigido pela variação nominal do Produto Interno Bruto - PIB;

II - no caso dos Estados e do Distrito Federal, doze por cento do produto da arrecadação dos impostos a que se refere o art. 155 e dos 
recursos de que tratam os arts. 157 e 159, inciso I, alínea a, e inciso II, deduzidas as parcelas que forem transferidas aos respectivos Municípios; e

III - no caso dos Municípios e do Distrito Federal, quinze por cento do produto da arrecadação dos impostos a que se refere $o$ art. 156 e dos recursos de que tratam os arts. 158 e 159, inciso I, alínea b e $\S 3$.

$\S 1^{\circ}$ Os Estados, o Distrito Federal e os Municípios que apliquem percentuais inferiores aos fixados nos incisos II e III deverão elevá-los gradualmente, até o exercício financeiro de 2004, reduzida a diferença à razão de, pelo menos, um quinto por ano, sendo que, a partir de 2000, a aplicação será de pelo menos sete por cento.

$\S 2^{\circ}$ Dos recursos da União apurados nos termos deste artigo, quinze por cento, no mínimo, serão aplicados nos Municípios, segundo o critério populacional, em ações e serviços básicos de saúde na forma da lei.

Para os estados e municípios, a EC nำ 29 não deixa dúvidas com relação ao percentual a ser aplicado. O cuidado está em apurar corretamente a receita de imposto, nela compreendidas as transferências constitucionais.

O acesso garantido aos serviços de saúde ampliado para toda a população do país foi um dos grandes avanços dos direitos de cidadania nos últimos anos. Infelizmente, não ocorreu um aumento de recursos financeiros no setor, equivalente ao número de pessoas que passaram a serem atendidas no sistema de saúde.

Outro agravante, é que após sete anos de sua promulgação a regulamentação da EC 29 foi aprovada no Senado em abril de 2008, faltando ainda à assinatura da Presidência da República, para entrar em vigor. Enquanto, a regulamentação não acontece muitos governos ignoram o piso proposto pela Lei.

A regulamentação da EC 29 se faz importante entre outros fatores, principalmente, para aumentar a participação dos estados no financiamento da saúde e criar mecanismos que garantam as transferências financeiras dos estados aos municípios. 


\subsection{ATENÇÃO BÁSICA EM SAÚDE}

A construção do Sistema Único de Saúde avançou de forma substantiva nos últimos anos, e a cada dia se fortalecem as evidências da importância da Atenção Primária à Saúde (APS) nesse processo. Os esforços dos governos nas diferentes esferas administrativas (federal, estadual e municipal), da academia, dos trabalhadores e das instituições de saúde vêm ao encontro do consenso de que ter a Atenção Primária à Saúde como base dos sistemas de saúde é essencial para um bom desempenho dos mesmos ${ }^{23}$.

Teoricamente é fácil sistematizar e apresentar um todo organizado e coerente acerca da atenção primária, com importantes referenciais para a implantação de serviços e projetos. Sabemos que não há prática sem uma teoria que a oriente, porém desenvolver um projeto ou um programa não é uma tarefa apenas técnica, mas principalmente política.

Essa é a principal dificuldade que marca a agenda de construção do SUS, que se desenvolve e avança na medida em que os atores sociais coincidem ou divergem em cada passo ou etapa ${ }^{7}$, além da questão já citadas referentes ao financiamento.

Observamos, então, aparentes atrasos no processo da construção do SUS. E podemos explicar, pelo fato de que a Conferência de Alma Ata, promovida pela Organização Mundial de Saúde (OMS), enunciou as diretrizes da atenção primária em 1978, aprovando por unanimidade, como meta de seus países membros a "saúde para todos no ano 2000", tendo como definição de atenção primária ${ }^{23}$ :

\footnotetext{
"uma atenção à saúde essencial, baseada em métodos e tecnologias práticas, cientificamente comprovadas e socialmente aceitáveis, cujo acesso seja garantido a todas as pessoas e famílias da comunidade mediante sua plena participação, a um custo que a comunidade e o país possa suportar, em todas as etapas de seu desenvolvimento, com espírito de auto-responsabilidade e auto-determinação. A atenção primária é parte integrante tanto do sistema nacional de saúde, do qual constitui-se como função central e núcleo principal, como do desenvolvimento social e econômico global da comunidade. Representa o primeiro nível de contato dos indivíduos, da família e da
} 
comunidade com o sistema de saúde, levando a atenção à saúde o mais próximo possível de onde residem e trabalham as pessoas, constituindo o primeiro elemento de um processo permanente de assistência sanitária."

A APS é uma forma de organização dos serviços de saúde, uma estratégia para integrar todos os aspectos desses serviços, tendo como perspectiva as necessidades em saúde da população, sendo em sua forma mais desenvolvida a porta de entrada ao sistema de saúde.

A atenção primária se diferencia da secundária e da terciária por dedicarse aos problemas mais freqüentes, sejam eles simples ou complexos, que se apresentam, sobretudo em fases iniciais e que são, portanto, menos definidos.

Um serviço é considerado porta de entrada quando uma população o identifica como o primeiro recurso de saúde a ser buscado, sempre que há uma necessidade ou um problema de saúde. A utilização dos serviços primários pela população dependerá da boa resolutividade, do acolhimento, da capacidade de delimitar os recursos necessários para resolver os problemas e de uma prática baseada na pessoa e não na doença ${ }^{23}$.

No decorrer do processo histórico brasileiro, o Programa de Saúde da Família (PSF) começou a ser entendido como estratégia prioritária para o desenvolvimento da APS no SUS.

Com o entendimento sobre a APS como estratégia de reorientação do modelo assistencial, e não como um programa limitado de ações em saúde de baixa complexidade, o PSF começou a ser considerado "uma estratégia de reorientação do modelo assistencial tendo como princípios: a família como foco de abordagem, território definido, descrição de clientela, trabalho em equipe multidisciplinar, co-responsabilização, integralidade, resolutividade, intersetorialidade e estímulo à participação social”. 


\subsubsection{A Estratégia Saúde da Família}

Formulado pelo Ministério da Saúde em 1994, num contexto de mobilização dos secretários municipais de saúde em torno da atenção básica, o governo federal assumiu a implantação do PSF como uma estratégia para a mudança do modelo de assistência à saúde no país, dispondo o programa com diretrizes normativas, objetivos e operações claramente definidos, sendo que sua implantação, quando adequada, traz resultados que extrapolam o nível da atenção primária e repercutem sobre a dinâmica e o funcionamento do sistema de saúde como um todo ${ }^{8}$.

Inicialmente, o governo federal assumiu como prioridade dentro da agenda setorial a implementação do Programa de Agentes Comunitários de Saúde (PACS), existente nos estados da região nordeste desde 1991, visando estender a cobertura do sistema público de saúde, visando, principalmente, a população materno-infantil ${ }^{24}$.

No contexto do Sistema Único de Saúde, o PSF incorpora as bases conceituais de planejamento e programação da oferta de serviços a partir do enfoque epidemiológico, incluindo a compreensão dos múltiplos fatores de risco à saúde, e a possibilidade de intervenção sobre os mesmos com estratégias como promoção da saúde ${ }^{8}$.

O PSF representa uma transformação do modelo de atenção à saúde do município, de acordo com algumas características:

- criar novas oportunidades de acesso aos serviços às comunidades mais vulneráveis;

- estabelecer uma metodologia de organização do trabalho dos profissionais de saúde centrada no indivíduo, sua família e seu ambiente, estreitando os vínculos e permitindo um conhecimento 
mais apropriado da realidade em que vivem as pessoas e de quais são suas necessidades;

- traduzir o conceito de responsabilidade sanitária, criando espaços de construção de cidadania;

- articular-se à rede de saúde, de forma hierarquizada e regionalizada, para garantir o acesso aos serviços de maior complexidade e,

- promover o estabelecimento de relações intersetoriais que possam atender demandas relacionadas às condições de vida das pessoas e famílias residentes em um dado território, através de políticas públicas mais integradas.

O PSF parte de uma proposta de ação que envolve necessariamente as três esferas de governo que devem contribuir para a reorientação do modelo de atenção à saúde no país, visando à organização dos sistemas municipais de saúde, à avaliação e acompanhamento de seu desempenho e ao envolvimento na capacitação e educação permanente dos recursos humanos.

Ao Ministério da Saúde compete a formulação geral do programa e a sua coordenação nacional, revendo permanentemente as suas diretrizes e renegociando pactos na Comissão Intergestores Tripartite, na medida em que forem se acumulando experiências que apontem essa necessidade. Além disso, também deve: garantir fontes de recursos federais para compor o financiamento do programa; regulamentar os mecanismos de cadastramento, inclusão e exclusão das equipes e profissionais para fins de pagamento de incentivos federais; prestar assessoria técnica aos estados e municípios no processo de implantação e expansão do programa; articular instituições, em parceria com Secretarias Estaduais e Municipais de Saúde, para capacitação e garantia de educação permanente aos profissionais de saúde membros das Equipes de Saúde da Família e, promover o intercâmbio de experiências, buscando o aperfeiçoamento e a disseminação de tecnologias e conhecimentos voltados à Atenção Primária. 
Às Secretarias Estaduais de Saúde compete estabelecer, em conjunto com o Ministério da Saúde, as normas e as diretrizes complementares do programa; prestar assessoria técnica aos municípios no processo de implantação/ampliação e monitoramento do programa; disponibilizar aos municípios instrumentos técnicos e pedagógicos que facilitem o processo de formação e educação permanente dos membros das equipes e promover o intercâmbio de experiências entre os diversos municípios, para disseminar tecnologias e conhecimentos voltados à melhoria da Atenção Básica ou Primária, além de participar do financiamento, quer seja através da participação dos Estados no financiamento global da saúde, conforme preconiza a lei, quer seja através de incentivos estaduais para a Saúde da Família.

Às Secretarias Municipais de Saúde compete a operacionalização do PSF, inserindo o mesmo em sua rede de serviços, visando a organização descentralizada do Sistema Único de Saúde. Também compete aos municípios garantir infraestrutura necessária ao funcionamento das Unidades de Saúde da Família, dotando-as de recursos materiais, equipamentos e insumos suficientes para o conjunto de ações preconizadas pelo Programa e selecionar, contratar e remunerar os profissionais que compõem as equipes multiprofissionais, conforme legislação vigente ${ }^{8}$.

A operacionalização do programa tem várias etapas: a territorialização, que não deve ser entendida somente como a divisão geográfica das equipes; o levantamento do perfil demográfico; as principais doenças e agravos diagnosticados e as condições que influenciam esses problemas. Para tanto, é realizado um levantamento de informações a partir do cadastramento de cada família e seus componentes.

Esses dados permitem que as equipes de saúde da família identifiquem a situação de saúde das comunidades e planejem o trabalho a ser feito, buscando as alternativas mais adequadas para a superação dos problemas e promoção da saúde. 
O plano de trabalho das equipes deve contemplar a interação entre seus profissionais, de tal forma que possam acolher a população e resolver, na própria Unidade de Saúde da Família (USF), as questões e os problemas mais freqüentes relacionados à saúde daquela coletividade à qual está vinculada. $\mathrm{A}$ resolutividade das equipes é um dos fatores determinantes para o novo desenho do sistema municipal de saúde.

Ao contrário de uma Unidade de Saúde convencional, em que a maior parte do atendimento às demandas se faz a partir da procura dos usuários aos serviços, na USF o que se pretende é uma relação diferenciada, buscando reorganizar a demanda, isto é, ter uma postura pró-ativa da equipe, a partir, sobretudo, do diagnóstico de situação elaborado ainda na fase de implantação.

As USF's se posicionam na base da organização dos sistemas locais de saúde. Isto quer dizer que considerando seu potencial de resolução dos problemas mais freqüentes e de identificação das situações que requerem intervenções diagnósticas e terapêuticas mais sofisticadas, em termos de recursos humanos e materiais, acabam por atuar como importante orientador de demandas mais complexas.

O Ministério da Saúde, por meio do projeto de Implantação e Consolidação da Saúde da Família (PROESF), tem por objetivos expandir e qualificar o PSF em municípios com população superior a 100 mil habitantes, ampliar a capacitação de profissionais para a saúde da família e aprimorar sistemas de avaliação e monitoramento para todos os municípios brasileiros.

Com o apoio do Banco Mundial, o projeto previa no período de 2001 a 2008 um volume total de recursos de US\$550 milhões, sendo 50\% desses recursos oriundos de empréstimo do Banco e 50\% de contrapartida do governo federal. O acordo de empréstimo foi assinado em Washington pelo Ministro da Fazenda, autorizando o repasse de US\$ 68 milhões ao governo brasileiro para a realização da primeira fase do projeto. 
As linhas de ação previstas encontram-se distribuídas nos seguintes Componentes:

Componente 1 - Apoio à Conversão do Modelo Assistencial para a Estratégia de Saúde da Família nos municípios com população acima de 100 mil habitantes. As linhas de investimento incluem modernização institucional; adequação da rede de serviços; fortalecimento dos sistemas de avaliação e informação e desenvolvimento de recursos humanos (treinamentos e supervisões).

Componente 2 - Desenvolvimento de Recursos Humanos, incluindo: capacitação e educação permanente de recursos humanos; formação de recursos humanos em Saúde da Família e apoio e monitoramento das atividades de desenvolvimento de recursos humanos.

Componente 3 - Monitoramento e Avaliação, incluindo: adequação e consolidação do sistema de monitoramento da atenção básica; avaliação da implementação do PSF e dos Pólos de Capacitação de Recursos Humanos; qualificação das unidades básicas de saúde e instituições formadoras de recursos humanos e projetos de pesquisa e Fundo de Pesquisa em Saúde.

O Projeto contemplava duas vertentes no que diz respeito aos municípios brasileiros. A primeira delas refere-se à conversão do modelo tradicional de organização dos serviços de atenção básica pela Estratégia da Saúde da Família, tendo como objeto potencial os 226 municípios brasileiros com população superior a 100 mil habitantes.

Em vários municípios brasileiros já foi possível verificar que as equipes implantadas não só diminuem as ocorrências de casos urgentes (devido à sua intervenção precoce em situações de maior risco, estabelecendo uma hierarquia entre as demais unidades e serviços, por níveis de complexidade), como também contribuem para um planejamento das ações de saúde e dos investimentos para contemplar as necessidades e prioridades de cada 
município e de cada estado, numa lógica ascendente, ou seja, em perspectiva municipal e regional mais abrangente.

Importante ressaltar a questão do acompanhamento e avaliação das equipes, da atenção básica e do sistema de saúde. O gestor, desde o início da implantação, deve estar atento ao registro e acompanhamento dos sistemas de informação, pois serão deles os dados gerados para avaliação da situação de saúde e do desempenho dos serviços. A produção das informações para o planejamento e gestão, para o controle, avaliação e regulação do sistema só será possível na medida em que os bancos de dados sejam fidedignos.

Infelizmente, a cultura da informação ainda é incipiente no Brasil, mas temos grande potencial para a mudança dessa situação, contando especialmente com o comprometimento dos gestores nesse processo ${ }^{8}$. 


\subsection{O FINANCIAMENTO DA ATENÇÃO BÁSICA}

A Constituição Federal e a Lei Orgânica da Saúde, marcos decisivos na construção do Sistema Único de Saúde (SUS), prevêem a possibilidade de a União, Estados, Distrito Federal e Municípios, como instâncias gestoras do Sistema, proporem a celebração entre si de convênios com vistas ao atendimento prioritário à população. Compete ao Ministério da Saúde (MS), por intermédio de seus órgãos e entidades, dentre os quais o Fundo Nacional de Saúde, prestar cooperação técnica e financeira aos Estados, ao Distrito Federal e aos Municípios para o aperfeiçoamento da atuação institucional de seus níveis de gestão.

Nesse contexto, incluem-se, também, as entidades privadas sem fins lucrativos, que atuam de forma complementar ao poder público na assistência à saúde, conforme preconiza o art. 199 da Carta Magna.

Como já dito anteriormente, as Leis 8.080/90 e 8.142/90, tratam das normas gerais de funcionamento do SUS, especialmente das transferências intergovernamentais de recursos financeiros para a área. Porém, somente três anos após a lei orgânica é que os critérios para o repasse dos recursos do governo federal para os estados e municípios tornaram-se efetivos e sistemáticos, através da Norma Operacional Básica do SUS de 1993 (NOB/93), criada pela Portaria 545 de 20 de maio de $1993^{2 ; 3 ; 4 ; 24 ; 25}$.

A NOB/93 entra em vigor no ano seguinte, estabelecendo um processo flexível, gradual e negociado para assegurar viabilidade política a operacionalização da descentralização. Neste sentido, estabeleceu responsabilidades, requisitos e prerrogativas para a gestão local do SUS, incluindo estados e municípios, sob as três modalidades: gestão incipiente, gestão parcial e gestão semiplena. Sob a regulamentação da NOB/93, a descentralização caminhou a passos lentos. Até o final de 1997, 57\% dos 
municípios estavam enquadrados na gestão incipiente ou parcial e apenas $2 \%$ na condição de gestão semiplena.

O processo de descentralização se acelera a partir de 1996, quando são implementadas medidas de incentivo, através da Norma Operacional Básica 1996 (NOB/96), criada pela Portaria 2.203, de 06 de novembro de 1996, para que os municípios assumam a gestão da rede de serviços locais de saúde, numa política deliberada do governo central em prol da municipalização ${ }^{21 ; 24}$.

A NOB/96 também altera as modalidades da gestão local do SUS, que passam a ser apenas duas: plena da atenção básica e plena do sistema de saúde. Em linhas gerais, podemos dizer que a principal diferença entre essas duas modalidades de gestão é o fato de que, na primeira, o poder público municipal tem governabilidade apenas sobre a rede de atendimento básico; já na segunda, é o município que gerencia todo o atendimento à saúde no seu território, inclusive a rede hospitalar pública e privada conveniada, tendo para tanto repasse direto de recursos do Ministério da saúde para o Fundo Municipal de Saúde, sem intermediação da esfera estadual.

Uma das questões mais importantes, do ponto de vista do gestor federal, foi especificar mecanismos de regulação, de forma a garantir algum controle sobre essas transferências.

A partir de 1998, ano em que a NOB/96 efetivamente entra em vigor, há uma alavancagem importante no ritmo e no alcance do processo descentralizador, já que a principal estratégia do governo é enfatizar e garantir prioridade ao atendimento básico em saúde, com a introdução do PAB - Piso de Atenção Básica, criado através da Portaria GM/MS nº 1882, de 18 de dezembro de $1997^{21 ; 26}$.

O PAB refere-se ao montante de recursos financeiros federais destinados à viabilização de ações de atenção básica à saúde, descritas nos Grupos dos Procedimentos da Atenção Básica, conforme Tabela do Sistema de Informações Ambulatoriais (SIA) do Sistema Único de Saúde (SUS), que 
permanecem como referência para a alimentação dos bancos de dados nacionais. São as ações mínimas descritas no escopo da Atenção Básica:

- consultas médicas em especialidades básicas;

- atendimento odontológico básico;

- atendimentos básicos por outros profissionais de nível superior e médio;

- visita e atendimento ambulatorial e domiciliar da estratégia Saúde da Família;

- vacinação;

- atividades educativas a grupos da comunidade;

- assistência pré-natal e ao parto domiciliar;

- atividades de planejamento familiar;

- pequenas cirurgias;

- atividades dos agentes comunitários de saúde; e

- pronto atendimento em unidade básica de saúde.

O PAB é composto por uma parte fixa, o PAB fixo, destinado a financiamento de atenção básica em geral - estabelecido por um valor per capita/ano, definido de acordo com a base populacional do Censo/IBGE - e uma parte variável, o PAB Variável, relativo aos incentivos para o desenvolvimento de ações específicas na atenção básica ${ }^{23}$.

O recurso referente à parte fixa do $P A B$, em 1998, era de $R \$ 10,00$ habitante/ano, alterado para $R \$ 12,00$ em 2003, e em 2009 para $R \$ 18,00$, de acordo com a Portaria do Ministério da Saúde no. 2007, publicada em 01 de setembro de $2009^{26 ; 27 ; 28}$.

O PAB Variável representa a fração de recursos federais para 0 financiamento de estratégias nacionais de organização da Atenção Básica. É composto de incentivos que o Ministério da Saúde repassa sempre que os municípios se comprometam a realizar práticas determinadas, ou façam adesão 
a "formas de organização" da atenção básica propostas pelo Ministério da Saúde. Os recursos do PAB Variável integram o Bloco da Atenção Básica e devem ter sua utilização definida nos planos municipais de saúde ${ }^{23}$.

As estratégias nacionais que compõe o PAB variável são:

- Saúde da Família;

- Agentes Comunitários de Saúde;

- Saúde Bucal;

- Compensação de Especificidades Regionais;

- Fator de Incentivo de Atenção Básicos aos Povos Indígenas;

- Incentivo para a Atenção à Saúde no Sistema Penitenciário;

- Incentivo para a Atenção Integral à Saúde do Adolescente em conflito com a lei, em regime de internação e internação provisória;

- Outros que venham a serem instituídos por meio de ato normativo específico.

O PAB altera a lógica de repasse dos recursos federais para o sistema de prestação de ações médico-sanitárias e constitui numa medida decisiva na perspectiva da descentralização financeira do sistema de saúde no Brasil, incentivando os municípios a assumirem, progressivamente, a gestão da rede básica de serviços de saúde ${ }^{24}$.

Esse novo mecanismo dissocia a produção do faturamento, característica central do sistema anterior, onde o pagamento através do faturamento com base no número de atendimentos e de procedimentos realizados que perpetuava um modelo de pós-pagamento, incentivando a lógica do aumento crescente de procedimentos e um superfaturamento dos serviços prestados. Procedimentos mais caros usualmente predominavam sobre os mais simples, atuando como um desestímulo à adoção de medidas preventivas e de promoção à saúde. 
O PAB introduz uma outra lógica no financiamento da assistência à saúde, dissociando produção e financiamento. Assim, as prefeituras passam a receber regular e diretamente recursos para investir naqueles procedimentos definidos como prioritários e fundamentais.

Resumidamente o financiamento da atenção básica, é dado de duas formas: caso o município seja habilitado na Gestão Plena, os recursos são transferidos diretamente da União através do PAB Fixo e variável e de outros incentivos. Caso o município não seja habilitado na Gestão Plena, os repasses são transferidos primeiro da União para o Estado, que então repassa para os municípios de acordo com a serviços e programas oferecidos à população ${ }^{20}$.

O financiamento descentralizado do SUS remete a uma complexa relação de interdependência fiscal das três esferas de governo. Entretanto, para a maioria dos governos municipais de grande porte populacional, as principais fontes de financiamento da saúde provêem da União. A possibilidade de interferência das Secretarias Estaduais de Saúde quanto à expansão dos recursos exclusivos da saúde é mais limitada, atrelada aos recursos repassados pela União ${ }^{17}$.

Apesar de toda regulamentação a questão do financiamento ainda é uma preocupação constante dos gestores da atenção básica, considerando que a atenção básica é de responsabilidade dos municípios, aos repasses são quase que exclusivamente da União, baseados na população e nos procedimentos, cabendo aos municípios arcarem com a diferença entre o planejado (orçado) e o real (aferido).

Percebe-se que não há transferência de recursos dos Estados para os municípios, ou quando existe é mínima, visto que os Estados são responsáveis pela atenção em saúde de média e alta complexidade. Os Estados têm contribuído, em média de $0,7 \%$ do gasto total dos municípios nos investimentos em à saúde ${ }^{23}$. Lembrando que sob responsabilidade dos Estados está o monitoramento da qualidade da atenção prestada pelos municípios. 
Análises feitas em 2005 indicam que o PAB Variável propiciou significativa redistribuição recursos na saúde privilegiando municípios situados em regiões carentes. No entanto, o volume de recursos transferido não foi suficiente para romper com as desigualdades inter e intraregionais das receitas públicas municipais, com até 200 mil habitantes. Ambas são decorrentes da menor arrecadação direta de impostos e do volume de apropriação das transferências dos estados. Por outro lado, a possibilidade de redistribuição do PAB Variável associa-se à capacidade de adesão do município às regras estabelecidas pelo Ministério da Saúde. No caso do PSF, se um município já tiver atingido o máximo de cobertura estabelecido, não haverá mais possibilidade de expansão de recursos por esse caminho.

Aqui se configura um dos principais dilemas das regras implantadas para distribuição dos recursos do SUS: quanto maior for a adesão dos municípios aos programas nacionais, cuja implantação é induzida pelo gestor federal por meio de incentivos financeiros, menor será o efeito redistributivo que esses incentivos propiciam. Isso sugere a necessidade da adoção de novas estratégias de equalização fiscal mais permanentes e efetivas no âmbito da atenção básica.

Vimos então, que a discussão do financiamento do SUS nos municípios remete a questões mais amplas inerentes ao federalismo fiscal brasileiro ${ }^{17}$.

Por isso, a necessidade de conhecer os custos da atenção básica e não apenas os seus gastos, pois diante da constatação de que os recursos públicos são escassos e finitos, e que nem sempre atendem as demandas do sistema, é crucial conhecer os seus custos, para assim, determinar onde investir e disponibilizar atividades, programas e serviços bem dimensionados, garantindo a atenção com qualidade à população ${ }^{24}$. 


\subsection{TERMINOLOGIA CONTÁBIL BÁSICA}

A contabilidade de custos pode ser conceituada como o ramo de função financeira que acumula, organiza, analisa e interpreta os custos dos produtos, dos serviços, dos componentes da organização, dos planos operacionais e das atividades de distribuição, para controlar as operações e para auxiliar o administrador no processo de tomada de decisões e de planejamento ${ }^{29}$.

Para a implantação de um sistema de custeio, se faz necessário homogeneizar conceitos normas e rotinas. Porém em toda área do conhecimento encontra-se uma gama de conceitos que convergem para um único sentido.

Para evitarmos um problema de entendimento, descreveremos a seguinte nomenclatura ${ }^{29 ; 30 ; 31}$ :

- Gasto - compra de um produto ou serviço qualquer, que gera sacrifício financeiro para a entidade (desembolso), sacrifício este representado por entrega ou promessa de entrega de ativos (normalmente dinheiro);

- Investimento - gasto ativado em função de sua vida útil ou de benefícios atribuíveis a futuro(s) período(s);

- Custo - gasto relativo à bem ou serviço utilizado na produção de outros bens ou serviços. Estes ainda são classificados em fixos e variáveis, e diretos e indiretos;

- Custo direto: são os que podem ser facilmente quantificados e identificados ao produto, processo ou serviço e valorizados com facilidade. Os custos diretos nas unidades de saúde como na maioria das indústrias, compõem-se basicamente de mão-de-obra, insumos e equipamentos, utilizados diretamente no processo produtivo, ou seja, no processo assistencial. 
- Custos indireto - por não serem perfeitamente identificados aos produtos, processos ou centros de custos, não podem ser apropriados diretamente para essas unidades específicas, e por isso, necessitam da utilização de algum critério de rateio para a sua alocação.

- Custo variável - Os custos variáveis mantêm relação direta com o volume de produção ou de serviço, ou seja, o valor dos custos variáveis aumenta à medida que a produção cresce.

- Custo fixo: Custos fixos são aqueles que permanecem constantes dentro de uma determinada capacidade instalada. Eles independem do volume de produção, ou seja, alterações no volume de produção, para mais ou para menos, não alteram o valor total do custo.

- Custo médio unitário - custo total dividido pela quantidade produzida em um determinado período. Pode ser obtido em relação ao custo direto, indireto e total.

- Centro de custos - setor de uma instituição que possui gastos mensuráveis. Não há a necessidade do centro de custos acompanhar a estrutura formal da instituição, mas às vezes é oportuno agrupar ou separar determinados para a apuração dos custos.

- Tipos de centros de custos - classificação dada, conforme características, ao grupo de centro de custos que executam atividades similares (produtivos ou finais, auxiliares e administrativas).

- Contabilidade de custos - ramo da contabilidade pelo qual a gestão de custos é traduzida em normas, fluxos, papéis e rotinas, tendo por finalidade absorver dados de diversas áreas, manipulá-los e finalmente emitir relatórios gerenciais.

- Gestão de custos - ação de gerir meios e recursos técnicos, metodológicos e funcionais, para gerar informação sobre custos e subsidiar a avaliação de desempenho. 
Os custos são determinados a fim de atingir os seguintes objetivos: determinação do custo, controle das operações, tomada de decisões e elaboração de demonstrações financeiras ${ }^{32}$.

\subsection{MÉTODOS DE CUSTEIO}

A palavra custeio pode ser definida como "metodologia de apuração de custos”. Custeio significa apropriação de custos. Assim, existem diversos modelos de custeio, mas vamos citar os mais tradicionais para serviços de saúde. Os métodos não são necessariamente excludentes, podem ser mutuamente utilizados, cada qual com suas vantagens e desvantagens ${ }^{31}$.

Para a escolha do sistema mais adequado é preciso saber para qual objetivo se quer atingir: controle, fornecimento rápido de informações, tomada de decisões, avaliações de estoques e resultados, entre outros que a própria instituição venha a definir. Para isso um sistema de custos deve estar em conformidade com as necessidades de gestão de cada instituição, pois do contrário, suas informações geradas não serão úteis ao processo decisório ${ }^{29 ;} 32$.

\subsubsection{Custeio por absorção}

Custeio por absorção é o método que consiste na apropriação de todos os custos de produção aos bens elaborados, e só os de produção; todos os gastos relativos ao esforço de produção são distribuídos para todos os produtos ou serviços feitos ${ }^{29}$.

É um sistema mais tradicional e também pode receber a denominação de custeio integral $^{33}$. Sua característica é a apropriação integral de todos os custos (diretos e indiretos ou fixos e variáveis) aos serviços. Estes passam a ter um custo total, uma vez que, além dos custos diretos, absorvem também os custos 
indiretos. Os custos indiretos nesse caso são apropriados por critérios bastante genéricos e convencionais.

O custeio por absorção tem sido utilizado nas organizações de saúde, para a apuração do desempenho ou dos custos por departamentos, que compreende o custo de cada unidade assistencial ou de serviço que integra os diferentes departamentos. Assim, para os produtos e processos são contabilizados os custos diretos, recebendo a parcela que lhes cabe, através de forma de rateio, dos custos indiretos de onde estão sendo realizados.

Um sistema de informação contábil permite a apropriação dos custos à produção ou aos serviços prestados em um período, por meio da utilização da estrutura organizacional das unidades operacionais da empresa.

Essas unidades operacionais se constituem os Centros de Custos onde serão apropriados os custos diretos e indiretos dos produtos fabricados ou dos serviços prestados nesses centros. Esses centros de custos são classificados em produtivos ou finais, auxiliares e administrativos ${ }^{30}$.

O centro de custo produtivo, ou final, é o que desenvolve atividade diretamente relacionada com os objetivos principais da instituição, ou seja, unidade que presta serviço diretamente aos pacientes e que compreendem uma atividade com remuneração pelos serviços prestados, exemplificando, a clinica cirúrgica, médica, centro cirúrgico, unidade de terapia Intensiva, serviço de radiologia e laboratório.

O centro de custo auxiliar é o que executa atividade complementar àquelas desenvolvidas no centro de custo produtivo, compreendendo, por exemplo, o centro de material esterilizado, o serviço de nutrição, o almoxarifado, o serviço de manutenção, entre outros.

O centro de custo administrativo está relacionado com as atividades de natureza administrativa. Compreendem a superintendência, administração, informática, suprimento, o setor de compras, o setor de contabilidade, a educação continuada, etc. ${ }^{30 ; 31}$. 
Para a apuração dos custos dos centros de custos que compõem uma organização deve-se seguir as seguintes fases:

a) distribuição dos custos diretos (pessoal, materiais) aos centros de custos dos serviços produtivos, auxiliares e administrativos;

b) identificação dos custos indiretos e seu rateio aos centros de custos dos serviços produtivos, auxiliares e administrativos (luz, telefone, gases, etc); utilizando a base de rateio mais adequada ao consumo do serviço. Exemplificando, podemos citar a depreciação da estrutura física por $\mathrm{m}^{2}$;

c) apuração do custo total (diretos e indiretos) de todos os centros de custos;

d) rateio dos custos dos centros de custos auxiliares e administrativos aos centros produtivos, por meio de critérios que melhor representem 0 consumo desses custos pelos serviços produtivos. Exemplo: o custo total do centro de custo auxiliar Nutrição será rateado aos centros de custos produtivos pelo número de refeições consumidas em cada um desses centros;

e) apuração do custo total de cada centro produtivo, podendo assim obter o custo de cada departamento pelo soma dos custos de seus centros de custos e o custo total da organização pela soma dos custos dos departamentos.

A utilização desse sistema tem como vantagem assegurar uma visão unitária para o custo total de cada serviço, desde que todos os custos estejam absorvidos, além de poder ser utilizados nas instituições que não possuem condições de informatizar todas as suas informações ${ }^{18 ; 34}$.

Esta metodologia apesar de ser uma das utilizadas pelas empresas, apresenta as seguintes desvantagens gerenciais ${ }^{11}$ :

- a falta de identificação dos custos indiretos aos objetos de custeio, já que os custos quase sempre são distribuídos à base de rateio, utilizando critérios subjetivos, podendo distorcer os resultados, penalizando alguns produtos em benefícios de outros; 
- dificuldade na atualização dos custos para corresponder à agilidade da decisão, pois os custos são calculados ao término do período contábil;

- os gerentes dos centros de custos são avaliados pela habilidade de controlar custos, entretanto, não são todos os que estão sob sua área de controle.

\subsubsection{Custeio Baseado em Atividades - ABC}

Esta metodologia conhecida como Custos Baseados em Atividades Activity-Based Costing - ABC, pressupõe que os serviços ou produtos consomem atividades, e depois, que são essas atividades que consomem os recursos. Em outras palavras, o sistema $A B C$ propõe que atividades consomem recursos para produzir um resultado, uma vez que cada paciente necessita de uma série diferente de atividades para seu tratamento e recuperação ${ }^{33}$.

A primeira etapa para o desenvolvimento do método de custeio $A B C$ é identificar as atividades que são executadas. A atividade pode ser definida como um conjunto de recursos humanos, materiais, tecnológicos e financeiros. A descrição das atividades gera a criação de um dicionário que define cada atividade executada.

Outra etapa deste sistema a ser respeitada é a definição dos direcionadores de custos, que pode ser definido como um evento que influencia o nível e o desempenho de atividades e o consumo resultante de recursos. Os direcionadores seriam responsáveis pela maior "precisão" do sistema, no sentido de exatidão dos números, e pela maior "acurácia", no sentido da utilização dos resultados para auxílio à decisão ${ }^{32}$.

O sistema de custeio ABC permite melhor visualização dos custos por meio da análise das atividades executadas dentro da instituição e suas respectivas relações com os objetos de custos. O princípio básico deste 
sistema é tornar direto maior número possível de custos proporcionais e nãoproporcionais, por meio de direcionadores de custos $^{31}$.

O objetivo do ABC é "rastrear" as atividades mais relevantes, identificando as mais diversas rotas de consumo dos recursos da empresa. É através desta análise das atividades, que se busca planejar e realizar o uso eficiente e eficaz dos recursos das empresas ${ }^{32}$.

Podemos destacar os seguintes benefícios do ABC: melhora as decisões gerenciais; facilita a determinação de custos relevantes; proporciona maior exatidão nos custos de produtos; determina os custos dos serviços, entre outros $^{31}$.

A metodologia $A B C$ pode relacionar custos com medidas de performance e/ou resultados. Gerentes com os dados de custos $A B C$ nas mãos têm melhores condições de conseguir eficiência em seu funcionamento organizacional, sem impactar negativamente a qualidade dos serviços prestados. A metodologia $\mathrm{ABC}$ serve como um sistema para garantir a melhoria contínua de qualidade.

Essas informações de custos são importantes devido à alta competitividade entre organizações de saúde e à necessidade de diminuir despesas sem prejudicar a qualidade. 


\section{MÉTODO}

\subsection{REVISÃO INTEGRATIVA}

A Revisão Integrativa é um método de pesquisa amplo, que permite a inclusão simultânea de pesquisas experimentais e não experimentais, combina dados da literatura teorizada e empírica. O pesquisador, ao definir esse método, irá criar sistematicamente uma base de conhecimentos estando intensamente envolvido no processo de leitura, análise e síntese de um determinado tema, e eventualmente poderá redefini-lo.

Com essa modalidade os pesquisadores esperam apresentar questões importantes que outras pesquisas não elucidaram, através da síntese das conclusões de diversos estudos, separando e direcionando relatos ou identificando hipóteses. A revisão integrativa contém todos os pontos relevantes das outras revisões de literatura, sendo alguns exclusivos deste tipo de estudo ${ }^{35}$.

A revisão integrativa pode ser um catalisador para novas pesquisas sobre um tema, pois tem a capacidade de gerar e direcionar novas idéias em qualquer área.

Ao identificar e obter palavras-chave, sintetizar informações e apresentar resultados de forma descritiva, a revisão integrativa percorre o caminho de uma investigação científica, porém não deve ser uma série de resumos, mas um relatório integrado.

A revisão integrativa da literatura contribui para o processo de síntese e analise de resultados de estudos independentes, em que as informações obtidas são sistematicamente categorizadas e constitui-se em parte valiosa do processo de criação e organização do corpo literário, mantendo os mesmos padrões de clareza, rigor e replicação da pesquisa primária. 
Ao contrário da revisão integrativa, a revisão de literatura típica tem especial importância no desenvolvimento de conceitos. Ela aparece como introduções para divulgar novos dados primários ou trabalhos independentes mais detalhados. Tem como objetivo explicitar o conhecimento, o entendimento profundo de um fenômeno através de dados ou resultados baseados em outros trabalhos. Já a revisão sistemática consiste em sintetizar com rigor todas as pesquisas que têm relação com uma questão especifica, buscando superar vieses que podem ser encontrados; avaliando a relevância dos estudos encontrados; coletando, sintetizando e interpretando os dados obtidos com as pesquisas, seguindo método rigoroso na sua busca e seleção.

Uma revisão integrativa bem feita colabora com a ciência contribuindo com o desenvolvimento de teorias e tem aplicação direta na prática e nas políticas de saúde.

Nesse tipo de estudo deve-se seguir cinco etapas ${ }^{30}$ :

1ํ. Etapa: identificação do problema

2ªpt Etapa: pesquisa na literatura (coleta de dados)

3a. Etapa: avaliação dos dados

4‥ Etapa: análise dos dados

5ª . Etapa: apresentação dos resultados.

$\mathrm{Na}$ primeira etapa o problema ou questão deve estar claramente identificado de forma que as variáveis de interesse (conceitos, população alvo, problemas e cuidados de saúde) e as características das amostras (tipos de estudos, inclusão da literatura teórica) sejam determinadas. A finalidade da pesquisa deve ser bem definida para facilitar a operacionalização da enorme gama de variáveis que serão encontradas, assim como a extração de dados apropriados das pesquisas primárias. A especificação adequada desta fase facilitará a condução das etapas subseqüentes para que a revisão integrativa seja de qualidade. 
$\mathrm{Na}$ segunda, a pesquisa na literatura deve ser realizada com estratégias bem definidas para aumentar o rigor da revisão, devido à possibilidade de obter pesquisas incompletas e enviesadas em bases de dados inadequadas, gerando falhas nos resultados. O ideal é que toda literatura relevante sobre o problema ou tema de interesse, esteja incluída na revisão. Todo o processo de pesquisa na literatura de uma revisão deve ser documentado com clareza, incluindo palavras-chave para buscas, estratégias para pesquisa e critérios de inclusão e exclusão para determinar pesquisas primárias relevantes ${ }^{35}$.

A terceira consiste em avaliar a qualidade dos dados obtidos, tarefa complexa em virtude da diversidade das pesquisas primárias encontradas. Numa revisão integrativa com diversas amostras de pesquisas, tanto empíricas quanto teóricas, deve-se avaliar a sua autenticidade, qualidade metodológica, importância das informações e representatividade das pesquisas primárias disponíveis, as quais devem ser apresentadas e discutidas no final do estudo.

$\mathrm{Na}$ quarta, a análise dos dados das pesquisas primárias requer que estes sejam ordenados, codificados, categorizados e sumarizados dentro de uma conclusão unificada e integrada sobre o problema da pesquisa.

$\mathrm{Na}$ quinta etapa da revisão integrativa da literatura, a pesquisa deve ser apresentada com detalhes das pesquisas primárias, para que a conclusão tenha uma seqüência lógica, permitindo ao leitor verificar que as conclusões não excederam as evidências. Os resultados devem aprofundar e ampliar o tema estudado, contribuindo para um novo entendimento do fenômeno de interesse, com implicações para a prática, pesquisa e iniciativas políticas. As limitações metodológicas da revisão devem estar explicitadas em sua apresentação.

Elaborar uma revisão integrativa consiste num desafio, com resultados compensadores. Todo o processo de elaboração e publicação de uma revisão integrativa promove a aproximação das respostas aos questionamentos dos profissionais em suas praticas, dentro da sua área. 
Além da revisão integrativa da literatura, a fundamentação teórica da análise do conceito do tema é essencial para colaborar com o desenvolvimento do conhecimento na área.

O conceito é a ação de formular uma idéia por meio de palavras, definição e caracterização ${ }^{35}$.

Assim, a clareza dos conceitos é necessária para caracterizar um assunto, descrever situações e estabelecer a comunicação efetiva. Analisar o conceito é uma maneira que o pesquisador tem para identificar o conjunto de atributos que o define e constitui. Quando os atributos que compreendem o conceito não são claros, a habilidade para comunicar o fenômeno fica comprometida.

O uso do conceito expressa o modo como ele deve ser empregado, a situação apropriada para o seu uso, evidenciando os seus atributos essenciais. A análise do conceito está focalizada na fase do uso do seu desenvolvimento, direcionado através da sua clareza e identificação.

\subsection{ABORDAGEM METODOLÓGICA}

A pesquisa será do tipo qualitativo, utilizando como método a revisão integrativa da literatura.

A escolha pela metodologia tem a finalidade de reunir, identificar, analisar e sintetizar o conhecimento científico já produzido sobre o tema custos em serviços de saúde, em especial aferição de custos em unidades básicas de saúde.

Além disso, tem a característica de sumarizar conclusões de estudos anteriores, o que permite obter evidências disponíveis para a sua incorporação na prática, além de permitir a construção de análise da literatura, abordando discussões sobre os métodos e resultados das publicações ${ }^{36}$. Assim, será 
apresentada nessa dissertação uma síntese sobre os trabalhos publicados, e uma análise comparativa entre os resultados e conclusões sobre o tema objeto desta pesquisa.

\subsection{O PROBLEMA DA REVISÃO}

Respeitando o pressuposto de que a pergunta norteadora de um estudo precisa ser clara e específica, e ainda estar relacionada a um raciocínio teórico baseado em definições pré-existentes pelo pesquisador, o presente estudo pretende responder à seguinte questão:

- quais são os sistemas de custeio utilizados para a aferição de custos nos serviços de atenção básica do SUS?

\subsection{SELEÇÃO DA AMOSTRA}

Para a seleção dos trabalhos publicados sobre aferição de custos nos serviços de atenção básica de saúde, foi realizado um levantamento bibliográfico, com busca on-line. As bases de dados consultadas foram: LILACS, Portal de evidências, Banco de teses da USP e Google.

Os critérios de inclusão definidos para a seleção foram:

- artigo original, publicado em periódicos indexados nas referidas bases citadas;

- dissertações de Mestrado e Tese de Doutorado;

- trabalhos científicos com identificação de texto - autor, ano, volume, título;

- relatórios de governo, com publicação on-line.

A LILACS (Literatura Latino-Americana e do Caribe em Ciências e Saúde) é uma base de dados que reúne artigos de revistas conceituadas da 
área da saúde publicados em países latino-americanos e região. A LILACS também indexa outros tipos de literatura científica e técnica como teses, monografias, livros e capítulos de livros, trabalhos apresentados em congressos ou conferências, relatórios, publicações governamentais e de organismos internacionais regionais. Foi acessada através do site da Biblioteca Virtual em Saúde (BVS). Os registros da LILACS são também indexados no Google.

O Portal de Evidências da Biblioteca Virtual em Saúde (BVS) reúne, organiza e oferece acesso integrado a fontes de informação em saúde de melhor nível de evidência, de acordo com a metodologia proposta pela Medicina Baseada em Evidências (MBE), bem como acesso a fontes de informação sobre a própria metodologia MBE.

Tem como objetivo promover o uso da informação de melhor evidência para apoio aos processos de tomada de decisão na atenção e gestão da saúde, assim como ao processo de desenvolvimento de novos estudos baseados em evidências com a aplicação da metodologia MBE.

A coleção do Portal de Evidências da BVS tem como base a Rede de fontes de informação da Biblioteca Virtual em Saúde, utilizando filtros para seleção de conteúdos de acordo com o tipo de estudo. Foram selecionados conteúdos das seguintes fontes de informação: base de dados LILACS, Cochrane Library, La Biblioteca Cochrane Plus, diretrizes clínicas do Ministério da Saúde do Brasil, Sociedade Brasileira de Medicina de Família e Comunidade e National Guideline Clearinghouse (Estados Unidos), Portal de Revistas da BVS, LIS - Localizador de Informação em Saúde, além de sites da Internet avaliados e eventos relacionados à metodologia $\mathrm{MBE}$.

Um dos temas do Portal é sobre Atenção à Saúde, que inclui estudos sobre efetividade, eficiência e segurança das intervenções no cuidado e atenção à saúde, selecionados e organizados por tipo de trabalho: ensaios clínicos controlados; revisões sistemáticas; avaliações econômicas em saúde; 
avaliações de tecnologias sanitárias; diretrizes para a prática clínica baseadas em evidências e informes de evidências.

A utilização da base de dados Google se deu pela dificuldade em encontrar trabalhos publicados na base da BIREME. Os trabalhos encontrados foram incorporados ao estudo, depois de verificada da confiabilidade dos mesmos.

Foram utilizadas terminologias em saúde adotadas pelo DeCS/MeSH. Para definir a amostra deste estudo, foi realizada busca através do cruzamento de palavras-chave relacionadas à aferição de custos em unidades básicas de saúde. Assim, foram selecionadas: CUSTOS E ANÁLISE DE CUSTOS, CUSTOS DE CUIDAdOS DE SAÚdE, ATENÇÃO PRIMÁRIA À SAÚdE, SAÚDE DA FAMÍLIA, AVALIAÇÃO EM SAÚDE, AVALIAÇÃO.

\subsection{ANÁLISE DOS DADOS}

Para a análise dos estudos selecionados, foi elaborado pela autora um instrumento (Apêndice A - planilha de artigos), tomando por base uma estruturação proposta por $\mathrm{Pompeo}^{37}$, e adaptada às características metodológicas desta pesquisa.

\subsection{APRESENTAÇÃO DOS DADOS}

Os dados obtidos dos trabalhos selecionados, após análise, foram apresentados, discutidos e sintetizados de forma clara e explicativa.

No presente trabalho, a síntese dos dados extraídos dos artigos foi apresentada de forma descritiva e por tabelas. 


\section{RESULTADOS E DISCUSSÃO}

\subsection{DADOS DE IDENTIFICAÇÃO DOS TRABALHOS ANALISADOS}

As informações contidas no Quadro 1 e nas Tabelas 1, 2, 3, e 4 apresentam os dados referentes à identificação dos trabalhos que integram a amostra desta pesquisa, a formação dos autores, o tipo de publicação, a ocorrência dos estudos nas bases de dados e a freqüência de publicação.

Durante a discussão dos trabalhos, utilizaremos apenas o número designado ao trabalho conforme a descrição apresentada no Quadro 1.

A referência completa de cada trabalho está descrita no Apêndice B.

Quadro 1- Identificação dos trabalhos analisados. São Paulo, 2010.

\begin{tabular}{|c|c|c|}
\hline $\begin{array}{l}\text { Número } \\
\text { do } \\
\text { trabalho }\end{array}$ & Título & Autor \\
\hline 01 & $\begin{array}{l}\text { A utilização do sistema de custeio por } \\
\text { absorção para avaliar custos da atenção } \\
\text { básica de saúde: reformulações e } \\
\text { aprimoramentos }^{6}\end{array}$ & Castro, JD \\
\hline 02 & $\begin{array}{l}\text { O custo efetividade: uma comparação entre } \\
\text { o modelo "tradicional" e o modelo do } \\
\text { Programa de Saúde da Família }\end{array}$ & $\begin{array}{l}\text { Castro, JD } \\
\text { Rocha, V } \\
\text { Marinho, ME } \\
\text { Pinto, S }\end{array}$ \\
\hline 03 & $\begin{array}{l}\text { Os custos dos PSF do Programa de Saúde } \\
\text { da Família de Porto Alegre - } 1998 \text { e } 2002^{18}\end{array}$ & $\begin{array}{l}\text { Castro, JD } \\
\text { Marinho, ME }\end{array}$ \\
\hline 04 & $\begin{array}{l}\text { Determinação e avaliação do custo do } \\
\text { Programa de Saúde da Família - PSF - } \\
\text { Relatório Final }^{13}\end{array}$ & FGV/MS \\
\hline 05 & $\begin{array}{l}\text { Atividade econômica do Programa de Saúde } \\
\text { da Família (PSF) em municípios do Estado }\end{array}$ & $\begin{array}{l}\text { Santana, EM } \\
\text { E col. }\end{array}$ \\
\hline
\end{tabular}




\begin{tabular}{|c|c|c|}
\hline & da Bahia: um estudo de custos $^{12}$ & \\
\hline 06 & $\begin{array}{l}\text { Análise dos custos e produtividade de } \\
\text { equipes do Programa de Saúde da Família } \\
\text { em Fortaleza-Ceará em } 2004^{39}\end{array}$ & Rocha Filho, FS \\
\hline 07 & $\begin{array}{l}\text { Análise dos custos com pessoal e } \\
\text { produtividade de equipes do programa de } \\
\text { saúde da família em Fortaleza, Ceará }{ }^{10}\end{array}$ & $\begin{array}{l}\text { Rocha Filho, FS } \\
\text { Silva, MGC }\end{array}$ \\
\hline 08 & $\begin{array}{l}\text { O custo do Programa de Saúde da Família: } \\
\text { um estudo de caso no Município de } \\
\text { Sapé/PB }\end{array}$ & $\begin{array}{l}\text { Barbosa, ES } \\
\text { Rego, TF } \\
\text { Rezende, ICC }\end{array}$ \\
\hline 09 & $\begin{array}{l}\text { Sistema de custos na Administração Pública } \\
\text { - análise da implantação do método ABC em } \\
\text { um município de pequeno porte }\end{array}$ & Mello, GS \\
\hline 10 & $\begin{array}{l}\text { Avaliação econômica da atenção básica no } \\
\text { município de Vitória da Conquista - Bahia }\end{array}$ & Couto, PA \\
\hline
\end{tabular}

Os 10 (dez) trabalhos analisados foram escritos por profissionais com diferentes formações, distribuídos na Tabela 2.

Tabela 2 - Distribuição dos autores segundo a formação. São Paulo - 2010

\begin{tabular}{l|l|l}
\hline Formação & Número & $\%$ \\
\hline Contabilidade & 04 & 30,8 \\
Economia & 02 & 15,4 \\
Administração Hospitalar & 02 & 15,4 \\
Medicina & 02 & 15,4 \\
Administração & 01 & 7,7 \\
Psicologia & 01 & 7,7 \\
Tecnólogo & 01 & 7,7 \\
Processamento de Dados & & \\
\hline Total & $\mathbf{1 3}$ & $\mathbf{1 0 0}$ \\
\hline
\end{tabular}


Os trabalhos 1, 2 e 3 foram escritos pela mesma autora, que é formada em economia, com pós-graduação em sociologia, mestrado em economia e doutorado em saúde coletiva.

O trabalho 2 foi escrito pela autora do trabalho 1 , e por mais 3 profissionais: um com graduação como Tecnólogo em Processamento de Dados, especialização em Saúde Pública e mestrado em Administração, e duas administradoras hospitalares, sendo que uma tem especialização em gestão comercial.

O trabalho 3 foi escrito pela autora do trabalho 1, pela segunda autora do trabalho 2 formada como Tecnólogo em Processamento de Dados, com especialização em Saúde Pública e mestrado em Administração.

O trabalho 4 foi realizado por uma equipe multiprofissional, de um Consórcio formado por duas empresas de consultoria especializadas na área da saúde, a Fundação Getúlio Vargas e a EPOS Health Consultoria. Esse consórcio foi firmado por solicitação do Ministério da Saúde, através de um contrato celebrado em agosto de 2000.

O trabalho 5 também foi escrito por uma equipe multiprofissional, mas teve como coordenadora uma profissional graduada em psicologia, com especialização em saúde da família e mestrado em comunicação e cultura contemporânea. Fez parte da equipe da pesquisadora 1 antropóloga, especialista em saúde coletiva, 1 assistente social e 1 economista com especialização em saúde coletiva.

O autor do trabalho 6 é formado em medicina, com especialização em planejamento e administração em saúde, economia da saúde, mestrado em saúde pública.

O trabalho 7 foi escrito pelo mesmo autor do trabalho 6 em conjunto com outro profissional graduado em medicina e ciências econômicas, com mestrado e doutorado em saúde pública, e pós-doutorado em ciências da saúde na especialidade economia da saúde.

A autora do trabalho 8 é formada em administração e em ciências contábeis, com especialização em auditoria e mestrado em ciências contábeis. 
A autora do trabalho 9 é formada em ciências contábeis, com mestrado em engenharia da produção.

A autora do trabalho 10 é formada em economia.

A formação dos autores foi fator relevante nas avaliações dos estudos, pois de acordo com a sua formação o estudo mostrava propósitos diferentes, bem como a forma como cada estudo foi direcionado para a aferição de custos, como veremos ao longo dos resultados da pesquisa.

Foi possível verificar que nos estudos em que os autores têm formação na área de ciências sociais aplicadas (administração, economia e contabilidade), os conceitos de custos são mais detalhados, bem como mostram, com maior detalhamento, como a aferição foi realizada.

Pode-se, ainda, verificar que os autores com formação em Contabilidade foram muito mais criteriosos em realizar a aferição dos custos. Os autores com formação em economia mostraram uma visão mais macroeconômica do estudo, focada na avaliação do impacto financeiro para os municípios.

Nos estudos realizados por autores com formação na área de ciências da saúde, verificamos como característica a importância em relacionar os custos com a qualidade e quantidade dos atendimentos.

No que se refere ao tipo de publicação dos trabalhos analisados, a Tabela 3 evidencia que $30 \%$ são artigos publicados em revista, $20 \%$ são dissertações de mestrado, $20 \%$ são trabalhos apresentados em congressos na forma de artigo, 10\% equivale a uma tese de doutorado, 10\% a um relatório de pesquisa governamental nacional e $10 \%$ um relatório de pesquisa governamental estadual.

Observamos ainda que os trabalhos foram realizados na sua maioria na área de saúde coletiva/pública, sendo em menor escala os relatórios de pesquisa governamental. Os trabalhos publicados e apresentados em congressos revelam o interesse do tema nas áreas de contabilidade $e$ economia. 
Tabela 3 - Distribuição conforme tipo de publicação. São Paulo - 2010

\begin{tabular}{l|c|c}
\hline Tipo de publicação & Número & $\%$ \\
\hline $\begin{array}{l}\text { Artigo publicado em revista - saúde coletiva / } \\
\text { pública }\end{array}$ & 03 & 20 \\
Artigo publicado em congresso - ciências & 02 & 20 \\
$\begin{array}{l}\text { contábeis / economia da saúde } \\
\text { Dissertação de mestrado - saúde pública / } \\
\text { engenharia de produção }\end{array}$ & 2 & 10 \\
Tese de doutorado - saúde coletiva & 1 & 10 \\
Relatório de pesquisa governamental - nacional & 1 & 10 \\
Relatório de pesquisa governamental - estadual & 1 & $\mathbf{1 0 0}$ \\
\hline Total & $\mathbf{1 0}$ & 2 \\
\hline
\end{tabular}

$\mathrm{Na}$ busca dos trabalhos houve certa dificuldade em encontrar os estudos, quando realizada pesquisa apenas nos sites de busca científica. A Tabela 4 evidencia que apenas $20 \%$ dos trabalhos foram selecionados no site LILACS e $80 \%$ dos trabalhos foram selecionados após busca no site Google.

Tabela 4 - Distribuição conforme fonte de publicação. São Paulo - 2010

\begin{tabular}{l|ll}
\hline Ano de publicação & Número & $\%$ \\
\hline Google & 08 & 80 \\
LILACS & 02 & 20 \\
\hline Total & $\mathbf{1 0}$ & $\mathbf{1 0 0}$ \\
\hline
\end{tabular}

As palavras utilizadas para busca no LILACS foram a combinação dos termos custos $x$ atenção básica $x$ programa de saúde da família.

Dois trabalhos foram selecionados através da busca no LILACS, o 01 e 0 07. O trabalho 07 apareceu em duas combinações: custos AND atenção AND básica, e custos AND PSF. O estudo 01 apareceu com a combinação custos AND atenção AND básica. 
Os estudos 02 e 03 foram encontrados através do site de busca Google, e foram incluídos após verificar a citação dos mesmos no currículo lattes da autora do trabalho. O trabalho 03 também foi citado na busca do site Google, com a combinação custos AND programa saúde da família.

O trabalho 04 foi encontrado no site Google, que informou a base governamental como base de referência do mesmo. $O$ trabalho encontra-se disponível no site do Departamento de Atenção Básica do Ministério da Saúde, no seguinte endereço eletrônico:

189.28.100/dab/docs/geral/determinação.pdf

O trabalho 05, também encontrado através da busca no site Google, com a combinação das palavras avaliação AND econômica AND PSF, que direcionou para o seguinte endereço:

portal.saude.gov.br/portal/arquivos/pdf/livro pes.pdf

O trabalho 06 foi selecionado através da referência bibliográfica do trabalho 07, por ser a dissertação que deu origem ao artigo. Com os dados da referência a dissertação foi encontrada no site de busca Google, que direcionou para a biblioteca da universidade na qual a dissertação foi defendida.

O trabalho 08 foi encontrado no site de busca Google, com a combinação das palavras custo AND programa saúde da família, que direcionou para o site da Associação Brasileira de Custos, onde encontrado, por sua vez, o resumo do artigo apresentado no XV Congresso Brasileiro de Custos. Enviei então um email para a autora, que disponibilizou prontamente o artigo na integra.

O trabalho 09 foi encontrado no site de busca Google com a combinação das palavras sistemas de custeio pelo método $A B C$ em municípios, que direcionou para o link direto da dissertação, disponível no seguinte endereço eletrônico:

\section{adm-net-a.unifei.edu.br/phl/pdf/0030357.pdf}

O trabalho 10 foi encontrado também no site Google, com a combinação das palavras custos AND PSF e com a combinação custos AND efetividade no PSF. O trabalho está disponibilizado através do site eletrônico: 
www.abresbrasil.org.br/pdf/11.pdf

A busca para a seleção destes artigos foi árdua, já que pela utilização dos seguintes descritores - CUSTOS E ANÁLISE DE CUSTOS, CUSTOS DE CUIDADOS DE SAÚDE, ATENÇÃO PRIMÁRIA À SAÚDE, SAÚDE DA FAMÍLIA, AVALIAÇÃO EM SAÚDE, AVALIAÇÃO, não houve um resultado adequado.

Isso nos fez procurar através do site de busca Google, que por várias vezes nos direcionava para o site Google Acadêmico, onde pudemos fazer uma busca mais minuciosa sobre os custos na atenção básica.

Para essa busca várias palavras foram utilizadas: CUSTOS, PSF, PROGRAMA DE SAÚDE DA FAMÍLIA, AVALIAÇÃO ECONOMICA EM SAÚDE DA FAMÍLIA, SISTEMAS DE CUSTO EM MUNICÍPIOS, SISTEMAS DE CUSTOS EM SAÚDE, com as mais possíveis e variadas combinações.

A projeção histórica sobre o interesse neste tema pode ser observada na Tabela 5, onde se encontra a distribuição dos trabalhos, conforme o ano de publicação.

Tabela 5 - Distribuição conforme ano de publicação. São Paulo - 2010

\begin{tabular}{l|ll}
\hline Ano de publicação & Número & $\%$ \\
\hline 2005 & 2 & 20 \\
2007 & 2 & 20 \\
2000 & 1 & 10 \\
2001 & 1 & 10 \\
2002 & 1 & 10 \\
2003 & 1 & 10 \\
2006 & 1 & 10 \\
2009 & 1 & 10 \\
\hline Total & 10 & 100 \\
\hline
\end{tabular}


Todos os trabalhos foram publicados entre 2000 e 2009, porém 1 autor utilizou dados do final da década de 1990 em dois estudos.

Observa-se que, somente após quase uma década, houve o interesse ou necessidade de conhecimento sobre os gastos com os serviços de saúde na atenção básica.

De qualquer forma, a análise dos estudos evidenciou a produção científica de 1 ou 2 trabalhos sobre o tema por ano, o que é muito pouco para um país com as dimensões geográficas do Brasil, e que tem como meta a estruturação do sistema de saúde com a gestão plena dos municípios, e a implantação e consolidação da estratégia de saúde da família. 


\subsection{SÍNTESE DAS CARACTERÍSTICAS METODOLÓGICAS}

Os dados apresentados a seguir são a descrição dos objetivos de cada trabalho, bem como a metodologia para a seleção da amostra, determinação do custo, resultados e conclusões.

Quadro 2a - Síntese das características metodológicas da amostra do estudo identificado.

\begin{tabular}{|c|c|}
\hline Estudo & Castro, JD, 2000. \\
\hline Objetivos & $\begin{array}{l}\text { Identificar os sistemas de custeio através de revisão bibliográfica. Reformular, aprimorar, } \\
\text { aperfeiçoar e adequar o sistema de custeio por absorção, como metodologia para a } \\
\text { apuração de custos no programa de saúde da família do município selecionado. }\end{array}$ \\
\hline Local do estudo & $\begin{array}{l}\text { O estudo foi realizado em um município de mais de } 1 \text { milhão de habitantes, com } 8 \% \text { da } \\
\text { população atendida pelo PSF, cobrindo } 25 \% \text { da população de baixa renda da cidade. O } \\
\text { serviço de saúde do município contava, com } 49 \text { unidades básicas de saúde, onde estavam } \\
\text { inseridas } 28 \text { unidades de PSF, } 13 \text { serviços de atenção especializada, } 21 \text { hospitais, } 03 \\
\text { pronto-atendimentos e SAMU. }\end{array}$ \\
\hline Objeto de custo & $\begin{array}{l}\text { Para a análise dos custos foram selecionadas como objeto de custo } 28 \text { unidades de PSF } \\
\text { inseridas no sistema de saúde do município, e que tinham mais de } 01 \text { ano de implantação. }\end{array}$ \\
\hline $\begin{array}{l}\text { Determinação do } \\
\text { custo }\end{array}$ & $\begin{array}{l}\text { A metodologia utilizada foi de custeio por absorção, onde a autora utilizou para a aferição } \\
\text { do custo total, a somatória do custo direto do PSF mais o custo indireto do PSF, com a } \\
\text { somatória do custo administrativo. }\end{array}$ \\
\hline Resultados & $\begin{array}{l}\text { Neste estudo o custo médio per capita anual do município foi de } R \$ 55,82 \text {, que na época } \\
\text { do estudo equivalia a US } \$ 48,12 \text {, sendo o valor médio mensal em torno de } R \$ 4,00 \text {. O } \\
\text { custo médio por procedimento foi de } R \$ 12,36 \text {. }\end{array}$ \\
\hline Conclusões & $\begin{array}{l}\text { O estudo concluiu que para a maioria dos serviços de atenção básica, o instrumento de } \\
\text { apuração de custos por absorção pode ser bastante útil para aprender sobre as suas } \\
\text { estruturas de custos e assim realizar as alterações necessárias para construir um sistema } \\
\text { de saúde mais eficiente, tendo condições de ser um sistema mais equânime, uma vez que } \\
\text { a gestão de custos deve ser vista como uma maneira de buscar eficácia, equidade e } \\
\text { universalidade no acesso ao sistema de saúde. }\end{array}$ \\
\hline
\end{tabular}




\section{Quadro 2b - Síntese das características metodológicas da amostra do estudo identificado.}

\begin{tabular}{|c|c|}
\hline Estudo & Castro, JD et al., 2002. \\
\hline Objetivos & $\begin{array}{l}\text { Fazer uma análise de custo-efetividade da atenção básica, comparando duas alternativas } \\
\text { de provisão de serviços de atenção básica - modelo "tradicional" e o programa de saúde } \\
\text { da família, a partir de um estudo de caso de duas unidades de atenção básica de saúde. }\end{array}$ \\
\hline Local de estudo & $\begin{array}{l}\text { Foram selecionadas } 02 \text { unidades de saúde de um município de mais de } 1 \text { milhão de } \\
\text { habitantes, } 01 \text { unidade básica de saúde (tradicional) e } 01 \text { unidade de PSF. As duas } \\
\text { unidades atendiam cerca de } 7000 \text { pessoas cada uma. }\end{array}$ \\
\hline Objeto de custo & $\begin{array}{l}\text { Foi aferido o custo de } 02 \text { unidades, sendo } 01 \text { unidade básica de saúde (tradicional) e } 01 \\
\text { unidade de PSF. }\end{array}$ \\
\hline $\begin{array}{l}\text { Método de aferição } \\
\text { de custo }\end{array}$ & $\begin{array}{l}\text { Foi determinada a utilização da metodologia de custeio por absorção, pois foi considerado } \\
\text { pelos pesquisadores como um sistema de custeio integral, e por ser um sistema fácil de } \\
\text { ser adaptado à estrutura do orçamento do município. Para a análise dos custos foram } \\
\text { identificados os seguintes indicadores de efetividade considerados confiáveis para a } \\
\text { avaliação, nas duas unidades. Os indicadores analisados foram: a) indicador de oferta: } \\
\text { total de atendimentos per capita; b) indicador de qualidade: total de atendimentos de pré- } \\
\text { natal realizados; c) indicador de acesso/utilização: cobertura vacinal. }\end{array}$ \\
\hline Resultados & $\begin{array}{l}\text { Os valores encontrados foram: custo total anual de } R \$ 733.170,43 \text { para a unidade de PSF } \\
\text { e de } R \$ 852.046,06 \text { para a unidade tradicional. O custo per capita anual de } R \$ 103,82 \text { e de } \\
R \$ 120,12 \text {, respectivamente. O estudo ainda identificou que o modelo tradicional realizou } \\
2,3 \text { atendimentos per capita, enquanto o modelo PSF realizou } 3,75 \text { atendimentos per } \\
\text { capita ano. Em relação à cobertura vacinal o indicador foi a porcentagem das crianças } \\
\text { cobertas, e nesse caso o indicador foi maior para a unidade tradicional para todas as } \\
\text { vacinas. }\end{array}$ \\
\hline Conclusões & $\begin{array}{l}\text { O estudo reflete o que o modelo de atenção do PSF parece indicar a prestação de serviços } \\
\text { com menor custo e maior efetividade. No entanto deve-se levar em consideração ser uma } \\
\text { pesquisa piloto, que avaliou apenas duas unidades, durante } 01 \text { ano, utilizando apenas três } \\
\text { indicadores. }\end{array}$ \\
\hline
\end{tabular}




\section{Quadro 2c - Síntese das características metodológicas da amostra do estudo identificado.}

\begin{tabular}{|c|c|}
\hline Estudo & Castro, JD, Marinho, ME, 2007. \\
\hline Objetivos & $\begin{array}{l}\text { Identificar as tendências na aplicação dos recursos e a evolução dos custos nos serviços } \\
\text { de saúde nos anos de } 1998 \text { e 2002, no município selecionado. }\end{array}$ \\
\hline Local de estudo & $\begin{array}{l}\text { O local foi o mesmo do trabalho } 01 \text {, um município de mais de } 01 \text { milhão de habitantes, } \\
\text { comparando a evolução dos custos no período de } 1998 \text { a } 2002 \text {. Para a análise deste } \\
\text { estudo, foram excluídas as unidades do estudo de } 1998 \text { que passaram a ter mais de duas } \\
\text { equipes do PSF e as unidades criadas a partir de } 1998 \text {, ficando assim uma amostra de } 22 \\
\text { unidades de PSF, que atendiam em média } 3.281 \text { pessoas. }\end{array}$ \\
\hline Objeto de custo & Foi aferido o custo de 22 unidades de PSF. \\
\hline $\begin{array}{l}\text { Método de aferição } \\
\text { de custo }\end{array}$ & $\begin{array}{l}\text { Utilização da metodologia de custeio por absorção, utilizando dados disponíveis na } \\
\text { secretaria de saúde (gastos). }\end{array}$ \\
\hline Resultados & $\begin{array}{l}\text { A pesquisa identificou que os custos totais passaram de } R \$ 87,34 \text { per capita para } R \$ \\
131,86 \text { per capita, e a receita do SUS aumenta de } R \$ 9,48 \text { per capita para } R \$ 25,57 \text { per } \\
\text { capita. Os recursos de origem federal pagavam em } 199811 \% \text { dos custos e em } 2002 \text { estes } \\
\text { recursos conseguiam pagar } 19,39 \% \text {. Apesar do aumento da parcela financiada pelo } \\
\text { governo federal, recaía para o município uma carga de } 80 \% \text { do financiamento do } \\
\text { programa. }\end{array}$ \\
\hline Conclusões & $\begin{array}{l}\text { Sugere que mais trabalhos desta natureza sejam realizados por um número maior de } \\
\text { municípios. Desta forma será possível identificar as diferenças e semelhanças entre eles, } \\
\text { estabelecer alguns parâmetros importantes de custos e aprimorar os indicadores. Afirma } \\
\text { ainda, que o conhecimento das estruturas de custos das instituições de saúde é } \\
\text { fundamental para que o gestor possa viabilizar algumas alterações no modelo de atenção } \\
\text { que poderão garantir maior universalidade e integralidade da atenção. }\end{array}$ \\
\hline
\end{tabular}




\section{Quadro 2d - Síntese das características metodológicas da amostra do estudo identificado.}

\begin{tabular}{|c|c|}
\hline Estudo & FVG/EPOS, 2001. \\
\hline Objetivos & $\begin{array}{l}\text { Determinar os custos reais para o ano de } 2000 \text { e potenciais do PSF e calcular os custos do } \\
\text { PSF, nas equipes básicas e ampliadas. O objetivo foi levantar os custos totais por equipe, } \\
\text { per capita e por atendimento. }\end{array}$ \\
\hline Local de estudo & $\begin{array}{l}\text { Foram selecionados } 51 \text { municípios com equipes básicas e ampliadas de saúde da família, } \\
\text { sendo } 10 \text { da região norte, } 11 \text { da região nordeste, } 11 \text { da região sudeste, } 10 \text { da região sul e } \\
9 \text { da região centro oeste. A divisão destes municípios pelas faixas populacionais foi da } \\
\text { seguinte forma: } 6 \text { municípios com menos de } 5 \text { mil habitantes; } 6 \text { com } 5 \text { mil a } 10 \text { mil } \\
\text { habitantes; } 8 \text { com } 10 \text { mil a } 30 \text { mil habitantes; } 7 \text { com } 30 \text { mil a } 50 \text { mil habitantes; } 9 \text { com } 50 \text { mil a } \\
100 \text { mil habitantes e } 15 \text { mais de } 100 \text { mil habitantes. Para essa seleção os municípios } \\
\text { deveriam ter mais de } 01 \text { ano de implantação do programa em julho de } 2000 \text {, equipes } \\
\text { completas e dados do SIAB atualizados. }\end{array}$ \\
\hline
\end{tabular}

\section{Objeto de custo}

Método de aferição do custo

\section{Resultados}

\section{Conclusões}

Os objetos de cálculo dos custos foram as equipes básicas de saúde da família e equipes ampliadas de saúde da família, dos municípios selecionados.

A pesquisa cita a metodologia de custeio por absorção, definindo os custos diretos e indiretos. Para o estudo, os custos do PSF foram definidos pelo conjunto de todos os gastos do programa, independente da fonte de financiamento. Para o cálculo do custo por atendimento, somaram-se os custos totais de todas as equipes, básicas e ampliadas, dividindo essa somatória pelo número médio de atendimentos mensais realizados.

O custo médio mensal de cada equipe básica de PSF foi de $R \$ 17.903,00$, e o per capita mensal foi de $R \$ 5,11$. O custo médio mensal da equipe ampliada foi de $R \$ 28.322,00$, e o per capita mensal foi de $R \$ 7,99$. Já o custo médio por atendimento foi de $R \$ 13,85$.

O estudo constatou que as diferenças regionais são tão acentuadas quanto as diferenças entre equipes do mesmo município e entre municípios da mesma região. Outra observação é que, apesar do programa ser um modelo único, as equipes não são homogêneas em termos de salários e número de integrantes. O grau de controle administrativo dos recursos materiais também explica parte das diferenças existentes entre os custos das equipes. $\mathrm{O}$ estudo conclui que todos os municípios devem possuir uma estrutura adequada para calcular seus custos, não somente do PSF, mas de todos os programas de saúde, e até de todas as suas atividades em geral. 


\section{Quadro 2e - Síntese das características metodológicas da amostra do estudo identificado.}

\begin{tabular}{|c|c|}
\hline Estudo & Santana et al., 2003 \\
\hline Objetivos & $\begin{array}{l}\text { Estimar os custos médios de funcionamento da equipe de saúde da família - básica e } \\
\text { ampliada com odontólogo, incluindo custo per capita e custo por atendimento em } \\
\text { municípios de diferentes portes. }\end{array}$ \\
\hline Local de estudo & $\begin{array}{l}\text { Para a seleção os municípios deveriam ter o PSF implantando há mais de } 01 \text { ano, com } \\
\text { equipes de odontologia, fossem de macrorregiões diferentes e de diferentes portes. Foram } \\
\text { selecionados } 03 \text { municípios: um município de pequeno porte que tinha uma população } \\
\text { menor de } 5 \text { mil habitantes e com } 100 \% \text { da população coberta pelo PSF; um município de } \\
\text { médio porte que se encontrava na faixa de } 50 \text { mil a } 100 \text { mil habitantes, com } 70 \% \text { da } \\
\text { população coberta pelo PSF, e um município de grande porte com mais de } 100 \text { mil, com } \\
40 \% \text { da população coberta pelo PSF. }\end{array}$ \\
\hline Objeto de custo & $\begin{array}{l}\text { Para a aferição dos custos foram considerados como objeto de custo as equipes } \\
\text { ampliadas de saúde da família, com odontólogo, nos } 3 \text { municípios selecionados. }\end{array}$ \\
\hline $\begin{array}{l}\text { Método de } \\
\text { aferição do custo }\end{array}$ & $\begin{array}{l}\text { O estudo utilizou como metodologia de apuração de custos o sistema de custeio por } \\
\text { absorção, utilizando para a coleta de dados instrumentos adaptados de outro estudo. }\end{array}$ \\
\hline Resultados & $\begin{array}{l}\text { A pesquisa identificou os seguintes valores de custo médio mensal por equipe do PSF: } R \$ \\
19.111,00 \text { no município de grade porte; } R \$ 17.092,00 \text { no município de médio porte, e } R \$ \\
14.489,00 \text { no município de pequeno porte. Os custos per capita/mês foram } \\
\text { respectivamente nos mesmos municípios de } R \$ 5,42 \text {, } R \$ 6,21 \text { e } R \$ 4,53 \text {. Os custos por } \\
\text { atendimento/mensal foram de } R \$ 13,47 \text {, de } R \$ 11,89 \text { e de } R \$ 8,35 \text {, respectivamente nos } \\
\text { municípios de grande, médio e pequeno porte. }\end{array}$ \\
\hline Conclusões & $\begin{array}{l}\text { A pesquisa identifica que estudos de descrição e análise de custos de programas e } \\
\text { serviços de saúde constituem importante ferramenta para a análise de viabilidade } \\
\text { financeira e para um melhor gerenciamento do sistema de saúde. Verificou ainda a } \\
\text { inexistência de centros de custeio organizados, identificando que mesmo os municípios } \\
\text { com maior nível de organização ainda não estão preparados para a produção de } \\
\text { informações que possibilitem sua utilização para a composição dos custos de PSF. O } \\
\text { estudo finaliza identificando a necessidade de fortalecer, junto aos municípios, uma cultura } \\
\text { de apuração de custos que permita monitorar, acompanhar e avaliar a aplicação dos } \\
\text { recursos em saúde, criando condições necessárias para uma maior eficiência dos sistemas } \\
\text { municipais, seu gerenciamento e gestão. }\end{array}$ \\
\hline
\end{tabular}




\section{Quadro $2 f$ - Síntese das características metodológicas da amostra do estudo identificado.

\begin{tabular}{l|l}
\hline \hline Estudo & Rocha Filho, S, 2005. \\
\hline Objetivos & Levantamento dos custos da produção das principais atividades de saúde das equipes do \\
& PSF, considerando os recursos humanos empregados na produção destas atividades. \\
& $\begin{array}{l}\text { Verificar se a produção está de acordo com as metas estipuladas, identificando as equipes } \\
\text { com a maior produção e com menor custo, além de identificar alternativas para melhorar a } \\
\text { produtividade, otimizando desempenho, custos e utilização de recursos. }\end{array}$
\end{tabular}

Local de estudo

Objeto de custo

Método de aferição do custo

\section{Resultados}

\section{Conclusões}

O estudo foi realizado em um município com aproximadamente 2,2 milhões de habitantes, com cobertura populacional pelo PSF de até $16 \%$, que equivale a 349.000 habitantes.

Foram aferidos os custos de 02 unidades de saúde da família, que totalizavam 08 equipes de PSF.

Foi utilizada a metodologia de custeio por absorção, identificando os recursos envolvidos e divididos em: centro de custos assistenciais; centro de custos de apoio assistencial; centro de custos de apoio geral; centro de custos administrativos e de gastos gerais.

Como resultado foi encontrado o valor de $\mathrm{R} \$ 3,93$ de custo médio per capita/mensal, e o valor de $R \$ 15.719,00$, como custo médio mensal de cada equipe de saúde da família. Os gastos mais volumosos nas equipes com PSF foram com recursos humanos $(75 \%)$, sendo o segundo maior gasto com medicamentos (18\%). O estudo identificou um custo médio de $\mathrm{R} \$ 150,74$ para visita domiciliar médica, sendo que este custo poderia ter sido de $\mathrm{R} \$$ 25,91 , ou seja, $17,91 \%$ do custo ocorrido, caso a meta de visita do mês tivesse sido atingida. No caso de consulta de pré-natal realizada por enfermeiro, identificou um custo de $R \$ 34,20$, e o valor de $R \$ 7,48$ caso a meta fosse atingida. Identificou ainda que 0 repasse mensal de verbas federais por equipe foi de $R \$ 9.543,33$, e o gasto mensal foi de $R \$ 15.719,00$.

As informações disponibilizadas pela pesquisa permitem que o planejamento da instalação de novas equipes do PSF seja realizado com mais precisão, detectando alternativas para otimização do desempenho das equipes, evitando a ociosidade. Os resultados podem subsidiar a atuação de gerentes e gestores nos vários níveis, a participação da população usuária através de seus conselhos de saúde, e a própria reflexão e autogerenciamento de funcionários. 


\section{Quadro $2 \mathrm{~g}$ - Síntese das características metodológicas da amostra do estudo identificado.}

\begin{tabular}{|c|c|}
\hline Estudo & Rocha Filho, S, 2009. \\
\hline Objetivos & $\begin{array}{l}\text { Identificar e analisar os custos com pessoal na produção das atividades de saúde de oito } \\
\text { equipes do PSF que atuavam em duas unidades básicas de saúde da família. }\end{array}$ \\
\hline Local de estudo & $\begin{array}{l}\text { O estudo foi realizado em um município com aproximadamente } 2,2 \text { milhões de habitantes, } \\
\text { com cobertura populacional pelo PSF de até } 16 \% \text {, que equivale a } 349.000 \text { habitantes. }\end{array}$ \\
\hline Objeto de custo & $\begin{array}{l}\text { Foram identificados os custos de } 02 \text { unidades de saúde da família, que totalizavam } 08 \\
\text { equipes de PSF. }\end{array}$ \\
\hline $\begin{array}{l}\text { Método de aferição } \\
\text { do custo }\end{array}$ & $\begin{array}{l}\text { Utilizou-se o método de custeio por absorção para o calculo do custo global da atuação de } \\
\text { cada equipe do PSF, definiu-se cada equipe como um centro de custos produtivo dentro } \\
\text { das unidades básicas. }\end{array}$ \\
\hline Resultados & $\begin{array}{l}\text { O estudo identificou que após o calculo com pessoal de apoio e da própria equipe do PSF, } \\
\text { aproximadamente } 82 \% \text { refere-se ao gasto com os integrantes da equipe do PSF. } \\
\text { Identificou ainda que das oito equipes do estudo, metade teve produtividade abaixo de } \\
30 \% \text { da meta esperada, } 25 \% \text { entre } 30 \text { a } 40 \% \text { da meta, e apenas } 25 \% \text { ultrapassaram } 40 \% \text {, } \\
\text { mas não superaram } 50 \% \text { da meta. Fica clara a ociosidade das equipes em } 50 \% \text { de sua } \\
\text { capacidade. A pesquisa identificou que os repasses federais por equipe foram de R } \$ \\
9.543,33 \text {, e o gasto com uma equipe foi de } \mathrm{R} \$ 15.719,00 \text {, identificando que o repasse } \\
\text { federal cobre } 60 \% \text { do gasto com uma equipe. Esse repasse cobre } 97,57 \% \text { com o gasto } \\
\text { com profissionais da equipe, e cobre } 80,49 \% \text { se somado o gasto da equipe de PSF com a } \\
\text { equipe de apoio. }\end{array}$ \\
\hline Conclusões & $\begin{array}{l}\text { Após a verificação e análise dos dados, o estudo detectou alternativas para otimização do } \\
\text { desempenho das equipes do município selecionado. O estudo possibilitou maior precisão } \\
\text { na avaliação e no planejamento do curto ao longo prazo, sobre a manutenção e atuação } \\
\text { das equipes existentes e daquelas a serem instaladas. }\end{array}$ \\
\hline
\end{tabular}




\section{Quadro $2 \mathrm{~h}$ - Síntese das características metodológicas da amostra do estudo identificado.}

\begin{tabular}{|c|c|}
\hline Estudo & Barbosa, et al., 2005 \\
\hline Objetivos & $\begin{array}{l}\text { Avaliar e acompanhar, monitorando os gastos do PSF, identificando diferenças e } \\
\text { semelhanças entre os valores transferidos e com o que é efetivamente gasto para a } \\
\text { realização das atividades. }\end{array}$ \\
\hline Local de estudo & $\begin{array}{l}\text { O estudo foi realizado em um município com população na faixa de } 30 \text { a } 50 \text { mil } \\
\text { habitantes, com cobertura de } 85 \% \text { da população pelo PSF }\end{array}$ \\
\hline Objeto de custo & 19 equipes de PSF, atendendo cada uma média de 600 famílias por mês. \\
\hline $\begin{array}{l}\text { Método de aferição } \\
\text { do custo }\end{array}$ & $\begin{array}{l}\text { As autoras fizeram um levantamento sobre os custos do município divididos em custos } \\
\text { diretos e indiretos. Após análise dos dados utilizando a metodologia de custeio ABC, } \\
\text { identificaram que nos gastos com salários estavam ausentes os gastos com encargos } \\
\text { sociais. Após a análise correta dessas informações aplicando a metodologia do sistema } \\
\text { de custeio ABC, verificaram que o município estava avaliando os custos de } \\
\text { manutenção do programa de forma errônea. }\end{array}$ \\
\hline Resultados & $\begin{array}{l}\text { A conclusão do estudo foi a identificação de que o município arcou com } 42,23 \% \text { de } \\
\text { recursos próprios no ano de } 2005 \text {, e em } 2006 \text { com } 46,01 \% \text {. O estudo ainda identificou } \\
\text { que o custo anual por equipe do Programa de Saúde da Família foi } R \$ 95.730,69 \text { em } \\
2005 \text {, e de } R \$ 98.513,57 \text { em } 2006 \text {. Já o custo unitário por família atendida foi de } R \$ \\
16,67 \text { em } 2005 \text {, e de } R \$ 17,04 \text { em } 2006 \text {. }\end{array}$ \\
\hline Conclusões & $\begin{array}{l}\text { A relevância do estudo centra-se na possibilidade de sanar as necessidades } \\
\text { preeminentes do administrador de prestar contas à sociedade sobre os serviços } \\
\text { operacionalizados e custeados com os recursos públicos, advindos dos pagamentos de } \\
\text { impostos pelos cidadãos, que vislumbram a melhoria dos serviços essenciais à } \\
\text { sociedade. }\end{array}$ \\
\hline
\end{tabular}




\section{Quadro 2i - Síntese das características metodológicas da amostra do estudo identificado.}

\begin{tabular}{l|l}
\hline \hline Estudo & Mello, GS, 2006 \\
\hline Objetivos & $\begin{array}{l}\text { Analisar a implantação da apuração de custos através da metodologia ABC adaptada a um } \\
\text { município de pequeno porte. }\end{array}$ \\
Local de estudo & $\begin{array}{l}\text { Município de pequeno porte com menos de 5mil habitantes, sendo que a secretaria } \\
\text { municipal de saúde é composta por } 1 \text { unidade básica de saúde e } 2 \text { postos de saúde, } \\
\text { localizados na zona rural da cidade. }\end{array}$ \\
Método de aferição & $\begin{array}{l}\text { Atilização da metodologia custeio baseado em atividades - ABC, para exemplificar a } \\
\text { aplicabilidade do método ao programa de imunização, por se tratar de um programa } \\
\text { independente de outros, e pelo fato do município tê-lo como sua maior ação pactuada com } \\
\text { a União, onde as metas são cobradas anualmente pelo ministério da saúde, além de ter } \\
\text { sido identificado como a melhor estrutura de forma mais organizada. Para o uso da } \\
\text { metodologia, a pesquisa teve as seguintes fases de ação: a) levantamento do dicionário de } \\
\text { atividades; b) definição dos direcionadores de custos; c) rastreamento dos custos e d) } \\
\text { alocação dos custos da subfunção administração ao programa de imunização. }\end{array}$
\end{tabular}

\section{Resultados}

\section{Conclusões}

Após a aplicação da metodologia, a pesquisadora chegou ao custo de $R \$ 17,97$ para a realização de cada procedimento do Programa Imunização, sendo $R \$$ 6,87 efetivamente para o procedimento do programa, e $\mathrm{R} \$ 11,10$ para a alocação de custos da subfunção administração.

A pesquisa apontou a importância de cada atividade envolvida nos procedimentos realizados no objeto de estudo, além de algumas dificuldades a serem superadas, como a carência de informações pelos sistemas operacionais da contabilidade e a inexistência de praticas de controle de custos, pois o estudo concluiu que o sistema baseado em atividades pode ser aplicado em um município de pequeno porte, mas que deve ter um alto comprometimento do gestor público, já que a implantação de novos sistemas é de suma importância e favorece a tomada de decisão. 


\section{Quadro 2j - Síntese das características metodológicas da amostra do estudo identificado.}

\begin{tabular}{|c|c|}
\hline Estudo & Couto, PA, 2007. \\
\hline Objetivos & $\begin{array}{l}\text { Fazer uma avaliação econômica de unidades selecionadas da atenção básica de saúde, } \\
\text { objetivando a apuração do custo médio mensal e anual, custo per capita, custo por } \\
\text { famílias cadastradas e o custo por procedimentos dos serviços prestados nesta } \\
\text { modalidade de atenção. }\end{array}$ \\
\hline Local de estudo & $\begin{array}{l}\text { Município considerado como de grande porte com mais de } 100 \text { mil habitantes, que } \\
\text { contava em seu serviço de saúde com } 07 \text { unidades básicas tradicionais e } 26 \text { unidades de } \\
\text { saúde da família, com } 37 \text { equipes de saúde da família e } 27 \text { equipes de saúde bucal }\end{array}$ \\
\hline Objeto de custo & $\begin{array}{l}\text { Foram selecionados para a aferição de custos: } 02 \text { centros de saúde, } 03 \text { unidades de } \\
\text { saúde da família na zona urbana e } 05 \text { unidades de saúde da família na zona rural. }\end{array}$ \\
\hline $\begin{array}{l}\text { Método de aferição } \\
\text { do custo }\end{array}$ & $\begin{array}{l}\text { A aferição dos custos foi realizada através da metodologia de custeio por absorção, por } \\
\text { ser considerada uma metodologia que assegura uma visão unitária para o custo total de } \\
\text { cada serviço, desde que todos os custos sejam absorvidos. }\end{array}$ \\
\hline Resultados & $\begin{array}{l}\text { Após a análise das dez unidades, foi apurado um custo médio mensal equivalente a } R \$ \\
53.359,95 \text { para um Centro de Saúde; } R \$ 48.059,72 \text { para uma unidade de saúde da família } \\
\text { de zona urbana e } R \$ 31.519,72 \text { para uma unidade de saúde da família da zona rural. O } \\
\text { estudo demonstrou que os custos com pessoal absorvem } 82,68 \% \text { dos custos totais de } \\
\text { centro de saúde, } 91,58 \% \text { de USF zona urbana e } 88,22 \% \text { de uma USF zona rural. Com } \\
\text { base nas informações do SIAB, apurou-se um custo médio per capita de } R \$ 4,54 \text {, um } \\
\text { custo médio de } R \$ 8,35 \text { por procedimento ambulatorial realizado e um custo de } R \$ 14,66 \\
\text { por família cadastrada. }\end{array}$ \\
\hline Conclusões & $\begin{array}{l}\text { A avaliação econômica dos serviços da atenção básica demonstrou que o determinante } \\
\text { dos custos totais das unidades é a conta com pessoal, e quando somado aos salários, } \\
\text { encargos e benefícios, podem representar até } 91,58 \% \text { dos custos totais. O estudo aponta } \\
\text { que o financiamento adequado é imprescindível para a integralidade do SUS, no sentido } \\
\text { de que a eficiência alocativa e técnica dependem do envolvimento e contribuição de uma } \\
\text { equipe multidisciplinar da área administrativa e técnica da saúde, de forma a articular } \\
\text { propostas viáveis para identificação e correção de ineficiências alocativas, promovendo } \\
\text { melhorias significativas no planejamento, com impactos sensíveis na qualidade da } \\
\text { assistência à população. }\end{array}$ \\
\hline
\end{tabular}


Após essa síntese, observa-se na Tabela 6 que em $50 \%$ dos trabalhos, o objeto de custos foram equipes básicas de saúde da família; 20\% custearam equipes básicas e ampliadas de saúde da família; 20\% compararam o modelo tradicional da atenção básica (UBS) com a estratégia saúde da família (PSF) e $10 \%$ selecionou exclusivamente uma única atividade da atenção básica à saúde, a atividade - imunização.

Tabela 6 - Distribuição dos objetos de custos conforme tipo de atenção à saúde. São Paulo - 2010

\begin{tabular}{ll|ll}
\hline Tipo de atenção & Número & $\%$ \\
\hline PSF - equipe básica & & 5 & 50 \\
PSF - eq. Básica e eq. & 2 & 20 \\
Ampliada & & 2 & \\
PSF X UBS & 01 & 1 & 20 \\
Atenção básica & & & 10 \\
atividade & $\mathbf{1 0}$ & $\mathbf{1 0 0}$ \\
\hline Total & & \\
\hline
\end{tabular}

Quanto ao local onde esses objetos foram custeados, pode-se identificar também nas sínteses que os municípios na faixa populacional com mais 1 milhão de habitantes está presente em $50 \%$ dos estudos; as faixas com menos de 5 mil habitantes e com mais de 100 mil habitantes estão presentes em 30\% dos estudos cada uma delas; as faixas de 30 a 50 mil e de $50 \mathrm{mil}$ a $100 \mathrm{mil}$ aparecem em 20\% dos trabalhos cada uma delas; e as faixas de 5 a 10mil e de 10 a 30mil aparecem apenas em 10\% dos trabalhos cada uma delas.

Também podemos avaliar que $30 \%$ dos trabalhos tiveram como local de realização do estudo município com cobertura de até $10 \%$ da população pela estratégia saúde da família; $20 \%$ dos municípios com cobertura de até $20 \%$; $30 \%$ dos trabalhos municípios com até $40 \%$; $20 \%$ dos trabalhos municípios com cobertura de até $85 \%$, e $10 \%$ dos trabalhos utilizaram municípios com 100\% de cobertura pela estratégia saúde da família. 
Vale ressaltar que não citamos aqui as coberturas dos municípios estudados no trabalho 4, por não haver citação da cobertura dos municípios selecionados pela pesquisa.

Também não citamos o trabalho 9, pois o município selecionado não cita a estratégia saúde da família na sua estrutura.

Avaliar esses dados é de extrema importância, pois como foi citado no referencial teórico, o incentivo financeiro para cada município é calculado de acordo com o tamanho populacional e diferenciado pela proporção da população coberta pelo PSF, nos municípios cadastrados com esse modelo.

\subsection{CLASSIFICAÇÃO DOS CUSTOS E DOS SISTEMAS DE CUSTEIO}

Talvez a maior dificuldade encontrada em analisar os trabalhos foi como comparar os dados apresentados, já que as terminologias não foram as mesmas em todos os trabalhos, o que leva à conclusão de que cada autor tem um entendimento próprio sobre o conceito de custos.

Neste tópico, tentamos despretensiosamente, identificar como cada conceito foi entendido por cada autor, como cada conceito foi descrito ou quais foram os termos utilizados.

No Quadro 3 apresentamos como a terminologia sobre custos foi utilizada nos trabalhos. 
Quadro 3 - Conceito de custos. São Paulo - 2010

\begin{tabular}{|c|c|c|c|c|c|c|c|c|c|c|}
\hline & 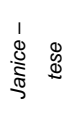 & 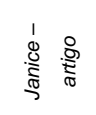 & 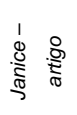 & गे & $\frac{\sqrt{7}}{0}$ & 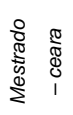 & $\frac{1}{3}$ & $\begin{array}{l}\stackrel{8}{8} \\
1 \\
\& \\
\stackrel{\pi}{\pi} \\
\infty\end{array}$ & $\begin{array}{ll}\frac{1}{10} & 0 \\
0 & 0 \\
1 & 0 \\
0 & 0 \\
0 & 0\end{array}$ & 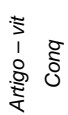 \\
\hline Material de consumo & $C D$ & $C D$ & $\mathrm{NI}$ & C & C & $\mathrm{CR}$ & $\mathrm{CR}$ & $C D$ & $\mathrm{NI}$ & $C D$ \\
\hline $\begin{array}{l}\text { Folha de Pagamento do PSF - } \\
\text { salários + encargos }\end{array}$ & $C D$ & $C D$ & $\mathrm{NI}$ & C & C & C & C & $C D$ & $\mathrm{NI}$ & $C D$ \\
\hline Exames e diagnósticos & $\mathrm{CD}$ & CD & $\mathrm{NI}$ & C & $\mathrm{C}$ & $\mathrm{C}$ & $\mathrm{C}$ & $\mathrm{NI}$ & $\mathrm{NI}$ & $\mathrm{NI}$ \\
\hline Material medico hospitalar & $\mathrm{CD}$ & $\mathrm{NI}$ & NUI & C & $\mathrm{C}$ & $\mathrm{NI}$ & $\mathrm{NI}$ & $\mathrm{CD}$ & $\mathrm{NI}$ & $\mathrm{CD}$ \\
\hline Medicamentos & $\mathrm{CD}$ & $\mathrm{NI}$ & $\mathrm{NI}$ & C & C & $\mathrm{C}$ & $\mathrm{C}$ & $\mathrm{CD}$ & $\mathrm{NI}$ & CD \\
\hline Vacinas & $\mathrm{NI}$ & $\mathrm{NI}$ & $\mathrm{NI}$ & C & $\mathrm{C}$ & $\mathrm{C}$ & $\mathrm{C}$ & $\mathrm{NI}$ & $\mathrm{NI}$ & $\mathrm{NI}$ \\
\hline Depreciação & $\mathrm{Cl}$ & $\mathrm{NI}$ & $\overline{\mathrm{NI}}$ & $\overline{\mathrm{NI}}$ & C & $\overline{C R}$ & $\overline{C R}$ & $\mathrm{NI}$ & $\mathrm{NI}$ & $\mathrm{NI}$ \\
\hline Aluguel & $\mathrm{Cl}$ & $\mathrm{Cl}$ & $\overline{\mathrm{NI}}$ & C & $\overline{C G}$ & $\mathrm{CR}$ & CR & CD & $\mathrm{NI}$ & $\mathrm{Cl}$ \\
\hline Energia elétrica & $\mathrm{Cl}$ & $\mathrm{Cl}$ & $\mathrm{NI}$ & $\mathrm{C}$ & CG & CR & $\mathrm{CR}$ & CD & $\mathrm{NI}$ & $\mathrm{Cl}$ \\
\hline Água & $\mathrm{Cl}$ & $\mathrm{Cl}$ & $\mathrm{NI}$ & $\mathrm{C}$ & CG & $\mathrm{CR}$ & $\mathrm{CR}$ & CD & $\mathrm{NI}$ & $\mathrm{Cl}$ \\
\hline Telefone & $\mathrm{Cl}$ & $\mathrm{Cl}$ & $\mathrm{NI}$ & C & CG & $\mathrm{CR}$ & $\mathrm{CR}$ & $\mathrm{CD}$ & $\mathrm{NI}$ & $\mathrm{Cl}$ \\
\hline Publicidade & $\mathrm{Cl}$ & $\mathrm{NI}$ & $\mathrm{NI}$ & $\mathrm{NI}$ & $\mathrm{NI}$ & $\mathrm{NI}$ & $\mathrm{NI}$ & $\mathrm{NI}$ & $\overline{\mathrm{NI}}$ & $\overline{\mathrm{NI}}$ \\
\hline $\begin{array}{llll}\text { veículos } & - & \text { despesas } & \text { com } \\
\text { veículos próprios e/ou } & \text { com } \\
\text { locação } & & & \\
\end{array}$ & $\mathrm{Cl}$ & $\mathrm{NI}$ & $\mathrm{NI}$ & C & C & $\mathrm{CR}$ & CR & $\mathrm{Cl}$ & $\mathrm{NI}$ & $\mathrm{Cl}$ \\
\hline Obras e instalações & $\mathrm{Cl}$ & $\mathrm{NI}$ & $\mathrm{NI}$ & C & $\overline{C G}$ & $\mathrm{CR}$ & $\mathrm{CR}$ & $\mathrm{NI}$ & $\overline{\mathrm{NI}}$ & $\mathrm{Cl}$ \\
\hline $\begin{array}{llll}\text { Equipamentos } & \text { e } & \text { material } \\
\text { permanente } & & \\
\end{array}$ & $\mathrm{Cl}$ & $\mathrm{NI}$ & $\mathrm{NI}$ & C & CG & $\mathrm{CR}$ & $\mathrm{CR}$ & $C D$ & $\mathrm{NI}$ & $\mathrm{Cl}$ \\
\hline $\begin{array}{l}\text { Salários e encargos de } \\
\text { profissionais administrativos e de } \\
\text { apoio - limpeza, segurança, } \\
\text { same }\end{array}$ & $\mathrm{CA}$ & $\mathrm{NI}$ & $\mathrm{NI}$ & c & $\mathrm{CA}$ & $\mathrm{CR}$ & $\mathrm{CR}$ & $\mathrm{NI}$ & $\mathrm{NI}$ & $\mathrm{Cl}$ \\
\hline Salários equipe odonto & $\mathrm{NI}$ & $\mathrm{NI}$ & $\mathrm{NI}$ & $\mathrm{NI}$ & $\mathrm{C}$ & $\mathrm{CR}$ & $\mathrm{CR}$ & $\mathrm{NI}$ & $\mathrm{NI}$ & $\mathrm{CD}$ \\
\hline
\end{tabular}

$$
\begin{aligned}
& \mathrm{C}=\text { custo } \\
& \mathrm{CD}=\text { custo direto } \\
& \mathrm{CI}=\text { custo indireto } \\
& \mathrm{CA}=\text { custo administrativo } \\
& \mathrm{CR}=\text { custo rateado } \\
& \mathrm{CG}=\text { custo geral } \\
& \mathrm{NI}=\text { não informado }
\end{aligned}
$$

$\mathrm{Na}$ tabela 7 observa-se que $80 \%$ dos trabalhos analisados utilizaram o sistema de custeio por absorção e $20 \%$ a metodologia de custeio baseado em atividades - ABC. 
Tabela 7 - Distribuição pelo método de custeio utilizado. São Paulo - 2010

\begin{tabular}{l|l|l|l}
\hline Método de custeio & $\%$ & Número & Trabalhos \\
\hline Custeio por absorção & $80 \%$ & 8 & $1,2,3,4,5,6,7,10$ \\
Custeio por metodologia & $20 \%$ & 2 & 8,9 \\
ABC & & & \\
\hline Total & $\mathbf{1 0 0 \%}$ & 10 & \\
\hline
\end{tabular}

Como descrito anteriormente, para a aferição de custos pelo método de custeio por absorção há necessidade de separar os centros de custos em produtivos, de apoio e administrativo; estabelecer os critérios de rateio e aferir os custos diretos e indiretos de cada centro de custos, e ratear os serviços de apoio e administrativo e despesas gerais para os produtivos. Na seqüência são propostas planilhas para a aferição desses custos.

Apenas 2 dos 08 trabalhos que utilizaram o sistema de custeio por absorção, explicitaram todos esses princípios, detalhando todos os passos da metodologia aplicada. Isso dificultou o entendimento de como os custos foram constituídos com diferentes itens. Diante desses fatos não há possibilidade de comparação entre os custos aferidos nos estudos.

Maior atenção foi dada às planilhas para a aferição dos custos. No trabalho 1 foram utilizadas as seguintes planilhas de sistema de apuração de custo: folha de pagamento; material de consumo; outros serviços e encargos; exames e diagnósticos; depreciação; produção; custos indiretos e total dos centros de custos. Essas planilhas estão apresentadas no Anexo A.

Os trabalhos 2 e 3 utilizaram o sistema de custeio por absorção pois, segundo os autores foi considerado um sistema de custeio integral, apropriando todos os custos incorridos para a produção de um bem ou serviço, considerando os custos diretos, indiretos, fixos e variáveis. Eles não apresentaram nenhuma planilha. 
O trabalho 4 descreve detalhadamente todos os passos utilizados e necessários para o sistema por absorção. Para a aferição total utilizou planilhas de apuração de custo para cada centro de custo próprio, identificados por categorias de dispêndios: a) recursos humanos, para equipes básicas e ampliadas; b) recursos materiais - medicamentos, vacinas, materiais de enfermagem, material odontológico, transporte e ativo fixo e c) estrutura: aluguel, despesas administrativas e gerais.

O estudo criou as seguintes planilhas de levantamento de custos, de acordo com essas categorias: planilha de salários e encargos; planilha de medicamentos e vacinas; planilha de material e equipamentos de enfermagem e odontologia; planilha de exames realizados pelo PSF; planilha de despesas de transporte; planilha de despesas administrativas, serviços diversos e despesas gerais; planilha da soma dos custos da equipe. Todas as planilhas estão apresentadas no Anexo B.

A metodologia utilizada para a aferição de custos no trabalho 5 foi 0 método de custeio por absorção, por duas razões: a precariedade dos sistemas de custeamento nas áreas de saúde dos municípios investigados impedia o uso de qualquer metodologia mais sofisticada e por outras pesquisas realizadas no Brasil sobre os custos no PSF, com as quais o estudo pretende dialogar.

Para a análise foi considerada a equipe do PSF e não a unidade de PSF para a valoração total dos custos, porque a lógica de incentivo do PSF é construída sobre o número de equipes implantadas e em funcionamento, e não sobre o número de unidades de saúde existentes.

Para a aferição dos custos totais por equipe, os dados foram distribuídos em uma tabela de itens de custo da seguinte forma: salários e encargos sociais da equipe; material permanente da unidade (depreciação); equipamento odontológico (depreciação); material de consumo da enfermagem; material de consumo odontológico; medicamentos; vacinas; exames laboratoriais; despesas de transporte; despesas gerais; despesas administrativas. 
No item despesas gerais considerou-se os valores referentes a aluguel de imóvel ou depreciação, água, luz, telefone, material de escritório, material administrativo e de limpeza, adaptação e reforma do imóvel.

A pesquisa utilizou todos os passos da metodologia do sistema de custeio por absorção.

No trabalho 6, para o cálculo dos custos de todas as atividades foi utilizado o método de custeio por absorção, identificando todos os recursos empregados. No estudo os custos foram classificados em diretos e indiretos, definindo os critérios de rateio dos custos indiretos.

Para a aferição dos custos o estudo identificou e classificou os centros de custos da seguinte forma:

- assistenciais (que realizam as atividades finalísticas): equipes do PSF, equipes de odontologia, equipe de ginecologia e equipe de pediatria;

- de apoio assistencial: SAME, acolhimento (atividades de enfermagem), esterilização, lavanderia e farmácia;

- de apoio geral: serviços gerais, manutenção, transporte e almoxarifado;

- administrativo e de gastos gerais: coordenação e gastos com telefonia, energia elétrica e água.

Para a aplicação da metodologia o autor encontrou algumas dificuldades, devido à precariedade de registro de alguns itens. O gasto com medicação foi estimado a partir da lista de compras do Ministério da Saúde. Não foram mensurados os gastos com exames laboratoriais, informática, nem o custo de apoio administrativo e de manutenção que eram realizados por intermédio das secretarias estadual e municipal de saúde.

No trabalho 7 foi utilizado o método de custeio por absorção, pois para os autores, este era o método adequado para o cálculo do custo global da atuação de cada equipe do PSF, definindo cada equipe como um departamento 
produtivo dentro de cada unidade de saúde em que estava inserida, e também como um centro de custo produtivo.

A metodologia utilizada no trabalho 8 foi o sistema de custeio - $A B C$ para a determinação dos custos do PSF do município selecionado, o cálculo do custo por equipes do PSF e por famílias atendidas.

Para o cálculo do custo total neste trabalho, os custos foram divididos da seguinte forma:

- Custos diretos: despesas com pessoal, outros materiais de consumo, equipamentos e material permanente, água, energia elétrica, aluguel de imóveis, medicamentos e material médico, manutenção, conservação, limpeza;

- custos indiretos: transportes da equipe do PSF (Médicos); gasto com a alimentação das equipes.

Após a identificação destes custos através do método $A B C$, foi identificada a ausência, na atividade do PSF, dos custos com encargos sociais, que depois de somados aos salários das equipes gerou um aumento significativo nos custos do PSF.

No trabalho 9 , após a análise da estrutura do município selecionado, foi escolhido para exemplificar a aplicabilidade do sistema de custeio ABC um dos programas de saúde da Secretaria Municipal de Saúde e Promoção Social, após o detalhamento dos Programas da Área da Saúde.

A SMS foi selecionada por apresentar uma estrutura organizada, sendo possível detectar os controles dos recursos utilizados, devido à exigência do Ministério da Saúde de prestação de contas mensais e anuais, com percentuais de metas pactuadas e indicadores.

Para se chegar à atividade escolhida, foram definidas as atividades de uma Unidade Básica de Saúde, divididas essas atividades em subfunções de governo, e posteriormente desmembrando as subfunções em procedimentos. 
Para cada procedimento relacionado, foram atribuídas as atividades desenvolvidas.

Após a escolha do programa de imunização, para o rastreamento dos custos, foi elaborado um dicionário das atividades do programa, com as atividades desenvolvidas por cada profissional - enfermeiro e auxiliar de enfermagem.

Com todos os passos da metodologia de custeio $A B C$ descritos neste estudo, foi possível a visualização e análise das atividades executadas dentro do programa de imunização, identificando que os dados fornecidos servem de subsídio para tomada de decisão para o gestor, e que o método pode ser aplicado em outros programas, desde que eles sejam bem estruturados.

No trabalho 10, o processo de apuração de custos iniciou-se com o acompanhamento contábil e com a sistematização das informações de caráter material, patrimonial e pessoal, de maneira que estas informações pudessem ser computadas mensalmente nos respectivos centros de custos. $\mathrm{Na}$ apuração dos dados brutos, foram discriminados os custos diretos e indiretos para todas as despesas, e para os custos com pessoal, foram apurados também os fixos (vencimentos, insalubridade, ajuda de custo, salário família) e variáveis (serviços extras, produtividade e plantão extra). Considerou-se como custos diretos aqueles relacionados à pessoal, medicamentos e material médicohospitalar. Considerou-se como custos indiretos aqueles relacionados à administração e manutenção das unidades de saúde, que foram: pessoal, material de consumo, despesas administrativas (água, energia, aluguel de imóveis e veículos). 


\subsection{ANÁLISE DOS RESULTADOS DOS ESTUDOS}

Apesar de não podermos comparar os resultados dos estudos por utilizarem conceitos e métodos com interpretações próprias, mostraremos a seguir alguns dados auferidos em cada trabalho.

\subsubsection{Avaliação de custo per capita}

Observamos na Tabela 8 os valores de custo per capita mensal encontrados nos trabalhos.

Tabela 8 - Valor do custo com saúde per capita/mensal de acordo com os estudos - $R \$ 1,00$. São Paulo - 2010

\begin{tabular}{|c|c|c|c|c|c|c|c|c|}
\hline & $\begin{array}{l}P S F \\
1998\end{array}$ & $\begin{array}{l}\text { PSF } \\
2000\end{array}$ & $\begin{array}{l}P S F \\
2000^{*}\end{array}$ & $\begin{array}{l}P S F \\
2002\end{array}$ & $\begin{array}{l}\text { UBS } \\
2002\end{array}$ & $\begin{array}{l}\text { PSF } \\
2005\end{array}$ & $\begin{array}{l}P S F \\
2006\end{array}$ & $\begin{array}{l}\text { UBS } \\
2006\end{array}$ \\
\hline + 1 milhão & $7,28^{1,3}$ & & & $\begin{array}{l}8,65^{2} \\
10,99^{3}\end{array}$ & $10,01^{2}$ & & & \\
\hline Até 5.000 & & $9,07^{4}$ & $8,95^{4}$ & & & & & \\
\hline 5-10 mil & & $5,15^{4}$ & $7,75^{4}$ & $4,53^{5^{*}}$ & & & & \\
\hline $10-30 \mathrm{mil}$ & & $4,54^{4}$ & $8,07^{4}$ & & & & & \\
\hline $30-50 \mathrm{mil}$ & & $3,85^{4}$ & $6,08^{4}$ & & & $\begin{array}{l}3,27^{8} \\
4,17^{8}\end{array}$ & $\begin{array}{l}3,36^{8} \\
4,26^{8}\end{array}$ & \\
\hline $50-100 \mathrm{mil}$ & & $5,70^{4}$ & $6,79^{4}$ & $6,21^{5^{*}}$ & & & & \\
\hline$+100 \mathrm{mil}$ & & $5,52^{4}$ & $8,27^{4}$ & $5,42^{5^{*}}$ & & & $\begin{array}{l}3,60^{10} \mathrm{zu} \\
6,28^{10} \quad \mathrm{zr}\end{array}$ & $3,73^{10}$ \\
\hline Brasil & & $5,11^{4}$ & $8,01^{4}$ & & & & & \\
\hline
\end{tabular}

* Valor para equipes ampliadas

Referências sobrescritas equivalem aos trabalhos estudados 
No trabalho 01 o valor encontrado per capita mensal para o ano de 1998 foi $R \$ 7,28$.

No trabalho 02 as autoras apresentaram a comparação entre dois modelos de atenção, o PSF e o modelo tradicional; o custo per capita mensal ficou em $\mathrm{R} \$ 8,65$ para o PSF e $\mathrm{R} \$ 10,01$ para o modelo tradicional.

A autora utilizou como base para seu estudo para comparação do custo per capta os seguintes indicadores de efetividade:

- de oferta $=$ total de atendimentos percapita

- de qualidade $=$ total de atendimentos de pré-natal realizados

- de acesso/utilização = cobertura vacinal

No trabalho 03 os autores avaliaram a evolução do custo do PSF no período de 1998 a 2002, identificando um aumento em torno de 33,51\% no período, aumentando o custo per capita mensal do PSF em 1998 de $R \$ 7,28$ para $\mathrm{R} \$ 10,99$ em 2002.

De acordo com o que foi analisado e observado nos dados do trabalho 4, os municípios que se encontram nos extremos das faixas populacionais, ou seja, pequenos com menos de 5 mil habitantes e grandes com mais de 100 mil habitantes, possuem custos per capita consideravelmente mais elevados que os municípios que se encontram nas outras faixas populacionais.

Observa-se que os municípios que se encontram na faixa de 30 a 50 mil habitantes são os que possuem menor custo per capita.

Esses dados podem ser observados nas duas faixas de atendimento, tanto para os custos das equipes básicas como os das equipes ampliadas. Um valor que chamou a atenção foi o custo per capita para equipes ampliadas em municípios de menos de $5 \mathrm{mil}$ habitantes, que apresentou valor um pouco menor que o custo para as equipes básicas, algo próximo de 1,5\% menor, podendo nos levar a considerar como sem alteração de custo. 
Já para as outras faixas populacionais os custos per capita para as equipes ampliadas apresentaram diferenças muito maiores, e para algumas faixas populacionais ultrapassaram o dobro do custo, como apresentamos abaixo na Tabela 9.

Tabela 9 - Distribuição aumento do custo per capita para equipes ampliadas.

São Paulo - 2010

\begin{tabular}{l|l}
\hline Faixa populacional & Variação do custo em relação a equipe básica \\
\hline Até 5.000 & $-1,5 \%$ \\
$5-10 \mathrm{mil}$ & $+50,6 \%$ \\
$10-30 \mathrm{mil}$ & $+77,7 \%$ \\
$30-50 \mathrm{mil}$ & $+58 \%$ \\
$50-100 \mathrm{mil}$ & $+19,1 \%$ \\
$+100 \mathrm{mil}$ & $+49,1 \%$ \\
Brasil & $+56,7 \%$ \\
\hline
\end{tabular}

$\mathrm{Na}$ Tabela 9 observamos o quanto aumentou o custo per capita para os municípios, com as equipes ampliadas em relação às básicas, mostrando que a média nacional foi de um aumento de $56,7 \%$, elevando o custo per capita de $R \$$ 5,11 para $\mathrm{R} \$ 8,01$. Notamos em especial o acréscimo para os municípios da faixa populacional de 10 a 30 mil, com aumento de $77,7 \%$ no custo, passando de $R \$ 4,54$ para $R \$ 8,06$. A faixa que apresentou menor elevação dos custos foi a dos municípios entre 50 a 100 mil habitantes, cujo acréscimo foi de $19,1 \%$, menos da metade da média nacional, elevando o custo de $R \$ 5,70$ para $R \$$ 6,79 .

O estudo mostra o quanto o gasto com recursos humanos eleva o custo do programa de equipes básicas para equipes ampliadas, como vemos no Quadro 4, considerando os custos per capita a nível nacional. A elevação do custo é da ordem de $56,4 \%$. 
Quadro 4 - Apresentação dos custos das equipes

\begin{tabular}{|c|c|c|c|}
\hline \multicolumn{2}{|c|}{ Equipe Básica } & \multicolumn{2}{c|}{ Equipe Ampliada } \\
\hline Total & Custo per capita & Total & Custo per capita \\
\hline $\mathrm{R} \$ 17.903,00$ & $\mathrm{R} \$ 5,11$ & $\mathrm{R} \$ 28.322,00$ & $\mathrm{R} \$ 7,99$ \\
\hline
\end{tabular}

Fonte: Relatório: FGV/EPOS - 2001

Levando em consideração apenas às despesas do subconjunto de uma equipe odontológica, a média encontrada no estudo com os dados de 56 equipes ampliadas em todo o território nacional, foi o valor de $R \$ 5.156,00$, que dividido pelo número de 3.450 pessoas atendidas em média por uma equipe de saúde da família, esse valor foi acrescido de $R \$ 1,49$ por habitante por mês no custo do programa.

Contudo, segundo a Portaria no. 1444/2000 uma equipe odontológica deve atender 6900 e não 3450, e com isso o acréscimo ao custo da equipe básica será de $R \$ 0,75$ habitante/mês.

No trabalho 5 o custo médio per capita mensal ficou em $R \$ 5,39$, sendo que os custos nos municípios selecionados individualmente ficaram em $R \$ 5,42$ no município de grande porte, $R \$ 6,21$ no município de médio porte, e $R \$ 4,53$ no município de pequeno porte. A média da população cadastrada por equipe era respectivamente de $3.524,2.753$ e 3.201 pessoas.

Segundo o trabalho 8, os valores encontrados per capita foram por família atendida, porém, para efeito de comparação com os outros trabalhos, dividimos o valor por 4 , por ser a média de pessoas em cada família neste estudo, chegando ao valor per capita de $R \$ 3,32$ e $R \$ 3,42$ para os anos de 2005 e 2006 respectivamente, sem a inclusão dos encargos sociais aos salários dos profissionais. Com a correta aferição dos gastos, os custos passaram para $R \$ 4,17$ e $R \$ 4,26$.

Neste trabalho observamos que com 19 equipes no município para uma população atendida pelo PSF de aproximadamente 39.500 habitantes, cada 
equipe seria responsável por uma média de 526 famílias, com aproximadamente 2104 pessoas, bem abaixo do observados, nos outros estudos, em que a média de pessoas atendidas por equipe fica em torno de 3.000 a 3.500 pessoas.

Para o trabalho 10 apurou-se um custo médio per capita de $R \$ 4,54$, com base nas informações do SIAB, sendo $R \$ 3,73$ com relação ao custo total de um centro de saúde, $R \$ 3,60$ com relação aos custos totais de uma USF zona urbana e $R \$ 6,28$ com relação aos custos totais de uma USF Zona rural. A diferença de custo de um centro de saúde em relação a uma unidade de saúde da família se deve, entre outros fatores, à população cadastrada. Em um centro de saúde, a população média cadastrada é de 14.299 habitantes. Em uma USF zona urbana, a população adstrita é de 13.354 e numa USF zona rural, a população é de 5.021 habitantes, o que eleva o custo per capita.

Não foram citados nesta análise os trabalhos 6,7 e 9, por não terem realizado a aferição de custo per capita.

\subsubsection{Avaliação de repasse das verbas financeiras e do gasto municipal}

Observa-se na Tabela 10 que $3(30 \%)$ dos estudos não informaram a porcentagem referente ao município para a manutenção do PSF. A minoria, 1 (10\%) verificou que o município arcava com 30\% dos gastos totais. Os outros 6 (60\%) estão divididos igualitariamente em 3 intervalos: 2 (20\%) identificaram que os municípios arcam com até $40 \%$ dos gastos totais, 2 (20\%) com até $50 \%$ e $2(20 \%)$ com até $90 \%$ dos gastos totais. 
Tabela 10 - Distribuição de acordo com o gasto do município com os serviços de saúde. São Paulo - 2010

\begin{tabular}{l|l|l|l}
\hline Gasto do município & Número & $\%$ & Trabalhos \\
\hline Não informado & 3 & 30 & $2,5,9$ \\
Até 40\% & 2 & 20 & 6,7 \\
Até 50\% & 2 & 20 & 4,8 \\
Até 90\% & 2 & 20 & 1,3 \\
Até 30\% & 1 & 10 & 10 \\
\hline Total & $\mathbf{1 0}$ & $\mathbf{1 0 0}$ & \\
\hline
\end{tabular}

No trabalho 1 o município não recebia incentivos fixos do PSF, e desta forma o gasto do município com o programa podia chegar até a $90 \%$, e os repasses eram feitos do município diretamente para as associações comunitárias, que faziam a contratação dos membros das equipes através do regime de CLT.

Os profissionais contratados eram os médicos, enfermeiros, auxiliares de enfermagem e agentes comunitários de saúde. Os outros funcionários das unidades de saúde eram funcionários da Secretaria municipal de saúde e não há informação sobre a equipe de apoio para a unidade, como, gerente, administrativos e limpeza.

O estudo informa que as unidades de PSF estudadas atendiam $8 \%$ da população, o que equivale a 104.000 habitantes. Se o município recebesse o repasse de incentivo teria o valor de receita de $104.000 \times 10,00 /$ ano $=R \$$ 1.040.000,00 referente ao PAB Fixo. Referente ao PAB variável, o município ainda teria o valor de 2.200,00/ano por ACS, que seria equivalente a 28 equipes x 4 acs $=112$ ACS, $112 \times 2.200,00=246.400,00$ de repasse para os ACS. Esses repasses somariam $R \$ 1.286 .000,00$ o que cobriria $23 \%$ do custo total destas equipes, que neste ano gerou em torno de $\mathrm{R} \$ 5.671 .856,67$. 
O estudo 4 levou em consideração os valores de repasse do Ministério da Saúde para os municípios estudados, de acordo com o Financiamento da estratégia.

Ao aderir ao programa, o município recebe um auxílio para implantação por equipe de $\mathrm{R} \$ 10.000,00$, pago em duas parcelas. Por equipe implantada o município recebe um valor de $R \$ 28.008,00$ a $R \$ 54.000,00$ por equipe por ano de acordo com a cobertura populacional pelo PSF.

Também fazia parte o pagamento do PAB variável de $R \$ 2.200,00$ por ACS por ano e o PAB fixo de $\mathrm{R} \$ 10,00$ por habitante/ano. Considerando uma média de 3.450 pessoas cadastradas por equipe, cada equipe recebia por ano o valor de $\mathrm{R} \$ 34.500,00$.

Para o incentivo da farmácia básica, o Ministério repassava o valor de $\mathrm{R} \$$ 1,00 por habitante/ano, e o município e o Estado em contrapartida entravam com $R \$ 0,50$ cada um.

Os custos das vacinas e dos exames foram considerados como custos do Ministério da Saúde, e não dos municípios.

Desta forma, o ministério da saúde repassaria como financiamento para o PSF (anual):

- R\$28.008 a R \$ 54.000 (PAB Variável do PSF)

- $R \$ 8.800$ a $R \$ 13.200$ (4 a 6 ACS)

- $R \$ 34.500-P A B$ Fixo

- R\$ 3.450,00 - farmácia básica

- custo médio das vacinas: $\mathrm{R} \$ 2.532,00$ por ano

- custo médio dos exames: $R \$ 13.584,00$ por ano

Total mínimo: $\mathrm{R} \$ 90.874,00$

Total máximo: $\mathrm{R} \$ 121.266,00$ 
Considerou-se um custo médio anual de $R \$ 214.836,00$, com a parte financiada pelo Ministério de $\mathrm{R} \$ 121.266,00$, ou seja, $56,4 \%$, cabendo ao Estado e ao município 43,5\% dos custos da equipe básica do PSF. É importante ressaltar que nesses valores não estão incluídos o financiamento de implantação de cada equipe.

Nos trabalhos 6 e 7 os autores relatam que o município arca com 39,20\% para a manutenção de cada equipe do PSF. Eles informam, ainda, que considerando o repasse federal e apenas o gasto com salários e encargos, 0 repasse federal arcaria com $97,57 \%$ do gasto com salários se considerar apenas os profissionais da equipe do PSF, e 80,49\% do gasto com esses profissionais somados ao do pessoal dos centros de custo de apoio.

De acordo com o trabalho 8, o município recebeu em 11 meses de 2005 o valor de $R \$ 110.700,00$. Considerando os valores de incentivo e financiamentos para o funcionamento do PSF teríamos:

População $=39.408 \times 10,00 / 12=32.840,00$

Cobertura até $50 \mathrm{mil}$ com $85 \%=64.800,00$

ACS $19 \times 4 \times 200,00=15.200,00$

Total: $112.840,00$

O trabalho informa, ainda, que o município arcou em 2005 com 42,23\% e com 46,01\% em 2006, equivalendo a um valor de $R \$ 963.368,04$ e $R \$$ 1.072.281,09 respectivamente em cada ano.

O trabalho 9 apresenta os gastos do municípios com cada estrutura funcional do governo, apresentando um gasto de aproximadamente $22 \%$ das despesas totais do município com a Secretaria Municipal de Saúde, apresentando um gasto de aproximadamente 15\% na Atenção Básica.

No trabalho 10 para o calculo da receita, utilizou-se as informações do Fundo Nacional de Saúde (FNS), transferências automáticas e regulares Fundo-a-Fundo, os incentivos do estado para o PSF, que corresponde a $20 \%$ 
do incentivo federal, e os recursos do fundo municipal de saúde, que correspondiam as transferências de folha realizadas mensalmente. Estratificando essas receitas, temos a seguinte composição das receitas:

- PAB Fixo per capita

- PAB Variável - ACS

- PAB Variável - Saúde Bucal

- PAB Variável - Saúde da Família

- Incentivo PACS/PSF Estado

- Recursos do Fundo Municipal de Saúde

Desses incentivos citados acima, os incentivos federais correspondiam em média a $67 \%$ da receita do total das unidades; os incentivos estaduais correspondiam em média a $3 \%$ das unidades e os recursos do tesouro municipal correspondiam em media a $30 \%$ da receita total das unidades, indicando a dependência do financiamento federal.

As estimativas do montante de receitas apontavam que o financiamento cobria $76 \%$ dos custos de um centro de saúde, $84 \%$ dos custos das USF Zona Urbana e $89 \%$ das USF Zona Rural.

Para a estimativa dos custos de uma ESF, foram considerados o valor dos salários, encargos e benefícios de ACS, auxiliares de enfermagem, enfermeiro, médico e odontólogo. A diferença de uma unidade da zona urbana para a zona rural era explicada pelos valores dos benefícios sociais (ajuda de custo, auxilio alimentação e gratificações), além dos custos com veículos pertinentes à zona rural.

Nos estudos 2,3 e 5 não há a discussão sobre os repasses para os municípios. 


\subsubsection{Avaliação com gasto de pessoal}

Observamos na Tabela 11 que 40\% dos trabalhos apresentaram que o gasto com recursos humanos era responsável por até $70 \%$ do custo total, $40 \%$ era responsável por mais que $75 \%$ do gasto total, e $20 \%$ não informaram.

Tabela 11 - Distribuição dos trabalhos de acordo com o gasto com recursos humanos em relação ao custo total. São Paulo - 2010

\begin{tabular}{l|l|l|l}
\hline $\begin{array}{l}\text { Gasto com recursos humanos em relação ao } \\
\text { custo direto }\end{array}$ & Número & $\%$ & Trabalhos \\
\hline Até 70\% & 4 & 40 & $1,3,4,5$ \\
Acima de $75 \%$ & 4 & 40 & $6,7,8,10$ \\
Não informado & 2 & 20 & 2,9 \\
\hline Total & $\mathbf{1 0}$ & $\mathbf{1 0 0}$ & \\
\hline
\end{tabular}

No trabalho 01, para a avaliação do sistema de apuração de custos com a folha de pagamento, foram consideradas as despesas com salários, INSS, vale transporte, vale alimentação, imposto de renda, FGTS e PIS. Foram considerados neste trabalho os gastos com os funcionários da equipe, os funcionários de apoio administrativo e de gerência não foram considerados.

Já no estudo 2 não foram avaliadas as despesas com pessoal em relação ao custo total.

O trabalho 3 observou que a despesa com pessoal foi a mais significativa, passando de 63,31\% em 1998 para 65,53\% em 2002.

O trabalho 4 informa que o gasto com salários e encargos para o programa equivale a $65,73 \%$ para os municípios com equipes básicas, e a $71,76 \%$ para os municípios com equipes ampliadas. 
O trabalho 5 encontrou na média do estudo que o gasto com salários e encargos equivalem a $66,3 \%$ do custo total com PSF.

Para o cálculo de salários e encargos, foi levado em consideração o tipo de contratação dos profissionais (CLT, concursados, contrato/prestação de serviços). No caso dos profissionais CLT, foram calculados $27,5 \%$ de INSS, $8,5 \%$ de FGTS, 13 ‥ Salário e férias. No caso dos concursados, os itens foram os mesmos, variando a porcentagem de INSS para $21 \%$ e excluindo o FGTS. Para os contratados/prestadores de serviços, foram considerados os salários brutos.

Os custos com pessoal da coordenação, como SAME, limpeza, segurança e motorista foram considerados como despesas administrativas.

Os Trabalhos 6 e 7 informaram que o gasto com salários e encargos com o programa equivale a $75,42 \%$ do custo com a equipe para o programa. Para a aferição de gastos com pessoal, foram considerados os gastos diretos da prefeitura municipal, que teve variação de acordo com a vinculação do funcionário: se direta ou por intermédio de cooperativas e empresas de prestação de serviços profissionais.

O trabalho 8 identificou que o gasto com pessoal equivaleu, sem os encargos sociais somados, a 82,27\% e 79,45\% nos anos de 2005 e 2006; com a soma dos encargos sociais, essa proporção aumentou respectivamente para $85 \%$ e $83,5 \%$.

O estudo 9 não apresenta o gasto total do município com pessoal em saúde, por não ter sido escopo do trabalho, porém, avaliando o custo do procedimento imunização, identificamos que aproximadamente $38 \%$ do custo do procedimento se refere ao tempo gasto exclusivamente pelos profissionais de enfermagem para a realização do procedimento.

O estudo 10 demonstrou que o determinante dos custos totais das Unidades de saúde é a conta de pessoal, onde a somatória dos salários, encargos e benefícios representam até $91,58 \%$ dos custos totais. 
O estudo demonstrou que uma parcela significativa dos custos das unidades era absorvida pelos custos diretos, atingindo um percentual de $85 \%$ nas USF Zona Urbana, e pelos custos fixos com pessoal, que representam até $99 \%$ dos custos totais com a folha de pagamento e até $91 \%$ dos custos totais das unidades de saúde.

\subsubsection{Avaliação do custo de procedimentos}

$\mathrm{Na}$ tabela 12 observamos os valores encontrados nos estudos referentes ao custo por procedimento.

Neste item fica clara a impossibilidade de comparação, pois a seleção dos procedimentos foi realizada com características próprias em cada estudo, por cada pesquisador.

Tabela 12 -Valor encontrado por procedimento realizado. São Paulo, 2010

\begin{tabular}{c|c|c}
\hline Trabalho & Procedimentos & Valor \\
\hline 1 & Atendimentos & 12,36 \\
2 & - & $\mathrm{NI}$ \\
3 & Atendimentos & 18,00 \\
4 & Atendimentos & 13,85 \\
5 & Atendimentos & 11,30 \\
6 & Atendimentos & 34,20 \\
7 & - & $\mathrm{NI}$ \\
8 & - & $\mathrm{NI}$ \\
9 & Imunização & 17,97 \\
10 & Atendimentos & 8,35 \\
\hline
\end{tabular}

No trabalho 01 foram considerados, para a aferição de custo médio de procedimentos, todos os atendimentos realizados nas unidades de PSF: consultas e procedimentos médicos, e a AVEIANM - ações de vigilância epidemiológica, imunizações e atos não médicos. Segundo o estudo as 
informações foram levantadas do SIAB - Sistema de Informações da Atenção Básica. Foi considerada também a quantidade de exames solicitados por cada equipe. O custo variou entre $R \$ 9,13$ a $R \$ 15,58$, com custo médio de $R \$ 12,36$.

No trabalho 03 as autoras consideraram para o cálculo de procedimento todos os atendimentos realizados, chegando ao valor de $R \$ 18,00$, considerando a atualização dos valores de 1998 para 2002 pelo INPC-IBGE, o custo médio anual tinha se mantido constante.

O valor encontrado no trabalho 4 , de $R \$ 13,85$ por procedimento realizado, foi definido pela divisão do custo total das equipes pelo número total de atendimentos no período, sem distinção de equipes básicas e ampliadas e nem de região em que a equipe se encontrava. Foram incluídos para esse cálculo os todos procedimentos descritos na relação de procedimentos da atenção básica do SUS - aplicação de vacinas, procedimentos de enfermagem, atividades em grupo, ações médicas, ações de odontologia, procedimentos por outros profissionais de nível superior e procedimentos básicos em vigilância sanitária.

Para o cálculo do custo por procedimento, no trabalho 5, foram considerados: consultas médicas, consultas de enfermagem, consultas de outros profissionais de nível superior, visitas domiciliares dos ACS e de outros profissionais. O valor médio encontrado para o custo por procedimento foi de $\mathrm{R} \$ 11,30$. Os valores individuais do estudo, nos três municípios, ficaram da seguinte forma: $R \$ 13,47$ no município de grande porte, $R \$ 11,89$ no município de médio porte e de $\mathrm{R} \$ 8,35$ no município de pequeno porte. Ainda é importante ressaltar outra informação apresentada no estudo, que foi a diferenciação do custo por procedimento no município de grande porte quando avaliadas as unidades da zona urbana e da zona rural. Neste caso, as unidades da zona urbana tiveram um custo médio por procedimento de $R \$ 11,71$ e as unidades da zona rural tiveram um custo médio de $R \$ 45,83$; esse valor muito mais alto se deve pelo número muito mais baixo de atendimentos realizados, 
que na média em zona rural ficou em 491 atendimentos/mês, enquanto na zona urbana a média foi de 1.514 atendimentos/mês.

Para a aferição do custo por procedimento no trabalho 06 foi analisado o conjunto de ações desenvolvidas pelo médico - visitas domiciliares, consultas de pré-natal e outras consultas realizadas na unidade, e as ações realizadas pelo enfermeiro - visitas domiciliares, consultas de pré-natal e outras consultas e atendimento para coleta de material para exame de prevenção de câncer de colo uterino. Não foram incluídas outras atividades desenvolvidas na unidade, como por exemplo, procedimentos de enfermagem e atividades educativas.

No trabalho 6 a pesquisa identificou que, caso a meta de consultas tivesse sido alcançada, o custo de $R \$ 34,20$ cairia para $R \$ 7,48$. O estudo ainda avaliou que o custo de visita domiciliar pelo médico ficou em $R \$ 150,74$, sendo que esse custo poderia ser de $R \$ 25,91$, caso a meta de produção tivesse sido alcançada.

Os autores citam que a melhor média alcançada para o conjunto de atividades pelo médico e pela enfermeira de uma das unidades estudadas foi de $36,22 \%$ da produção esperada pelas metas estipuladas. Na outra unidade estudada, a melhor equipe atingiu $47,7 \%$ das metas esperadas. No estudo das oito equipes estudadas, uma atingiu $32,01 \%$ na primeira unidade, e outra da segunda unidade $41,92 \%$. Todas as quatro equipes restantes apresentaram produtividade abaixo de $30 \%$ das metas esperadas.

Neste estudo fica clara a ociosidade em mais de $50 \%$ das equipes, e como se faz importante uma maior precisão na avaliação e no planejamento do curto ao longo prazo, sobre a manutenção e atuação destas equipes.

Entendemos, então, a necessidade de análises críticas sobre 0 planejamento de alternativas para a otimização destes serviços, com melhoria da produtividade e da qualidade do serviço prestado, sem o aumento de gastos, aliado a alternativas de diminuição de custos sem a perda desta produtividade, com a alocação adequada dos recursos. 
No trabalho 9 a pesquisa foi o detalhamento de como aferir o custo de um procedimento, no caso deste estudo foi o procedimento imunização. Para esta aferição foram definidos os direcionadores de recursos e atividades. Foi identificado que a mão-de-obra é o principal recurso para a realização do procedimento, e os recursos de materiais de consumo não foram significativos, por serem distribuídos diretamente pelo Ministério da Saúde, através da Diretoria Regional de Saúde da região.

O estudo definiu o custo de mão-de-obra e encargos por minuto dos profissionais envolvidos na atividade, no caso enfermeiros e auxiliares de enfermagem. Posteriormente foram levantados os procedimentos e atividades realizados na sub-função administração, e alocada no procedimento imunização. Após a aferição do gasto total da subfunção administração, o valor foi dividido pelo número de procedimentos realizados, até se chegar ao valor unitário.

O estudo apresentou então o custo do procedimento imunização de $R \$$ 17,97 , sendo que $R \$ 6,87$ refere-se à realização técnica do procedimento e $R \$$ 11,10 refere-se à alocação de custos da subfunção administração.

No trabalho 10, o custo médio encontrado por procedimento nos três municípios foi de $R \$ 8,35$, sendo que os custos individuais ficaram em: $R \$ 6,26$ para um centro de saúde, $R \$ 8,03$ para uma USF zona urbana e $R \$ 10,75$ para uma USF zona rural. Como dito anteriormente, o custo se difere pela população cadastrada em cada unidade, aproximadamente 14 mil habitantes no centro de saúde, 13 mil na USF zona urbana e 5 mil na USF zona rural.

Nos trabalhos 2, 7 e 8 não foi citada aferição de custo dos procedimentos.

Para a definição de procedimentos, percebemos que na maioria dos estudos, foram consideradas as consultas médicas, consultas de enfermagem, consultas de outros profissionais de nível superior, visitas domiciliares dos ACS e outros profissionais. Não foram levadas em consideração todas as atividades 
desenvolvidas pelos profissionais na unidade, como descrito na Relação de Procedimentos da Atenção Básica do Ministério da Saúde - SIA/SUS, como, por exemplo, procedimentos de enfermagem (medicação, vacina, curativos, coleta de exames, inalação), grupos educativos, entre outros. Apenas 02 estudos informam claramente, terem utilizados as informações para o cálculo por procedimentos seguindo as informações desta relação.

A maioria dos estudos sobre custos em atenção básica (90\%) utilizaram ou realizaram a aferição dos custos, em unidades com estratégia de saúde da família.

Isso pode nos mostrar que talvez haja uma lógica de pensamento sobre a responsabilidade do Estado, nestes casos, dos municípios, em que pela cultura não se faz um controle adequado dos custos em saúde, já que no modelo tradicional da atenção básica, podemos pensar que não há como controlar os gastos.

A lógica pode ser de que o município tem que prover sua população com os atendimentos básicos de consulta médica, atendimento de enfermagem, distribuição de medicamentos, e os gastos para essa atenção vêm basicamente do recolhimento de impostos para o provimento dos custos com recursos humanos, materiais e insumos, que são aqueles que não podem ser cortados.

Após análise dos estudos, identificou-se que o ideal seria que as equipes de PSF fossem estruturadas e tivesse um padrão uniforme, o que refletiria numa homogeneidade de custos. Nesse caso, todos os municípios deveriam seguir rigorosamente as orientações do Ministério da Saúde, com a composição das equipes da seguinte forma: 01 médico generalista, 01 enfermeira, 01 auxiliar de enfermagem e no mínimo 04 ACS's. Toda a equipe deveria trabalhar em regime integral e com registro de trabalho.

Os salários deveriam ser uniformes, garantidas as especificidades de cada região e/ou município. Contudo, as equipes não se enquadram nesse modelo rígido, com equipes menores ou maiores, e com uma considerável 
diversidade salarial, de acordo com as condições dos municípios, e a forma de contratação dos profissionais.

Essa diversidade de composição e remuneração é extrapolada para outros fatores, como despesas com transportes, gastos com remoção de pacientes para outros municípios, por exemplo, que aumentaram os custos em municípios sem recursos secundários e terciários, o que não acontece nos grandes centros urbanos.

Com essa diversidade, a criatividade dos secretários de saúde deve aflorar para se adaptar às necessidades de expandir o programa.

Seria desejável que cada município estruture um sistema de custo, não somente para seu programa de saúde da família, mas para todas suas atividades relacionadas à saúde, e também para todas as suas funções do município.

Para atingir esse fim, seria necessário que o município montasse os seguintes sistemas auxiliares de apoio:

- sistema orçamentário e de controle do orçamento realizado;

- sistema de controle de custeio de materiais;

- sistema de controle dos veículos de transporte;

- sistema de controle de patrimônio;

- sistema de apuração das despesas gerais e administrativas.

Também seria desejável condicionar parte dos incentivos financeiros do PSF à existência de um sistema de custeio das atividades de assistência médica do município.

Outro aspecto importante é que estudos de descrição e análise de custos de programas e serviços de saúde constituem-se em importante ferramenta para a análise de viabilidade financeira e para um melhor gerenciamento do sistema de saúde. Foi consenso que, mesmo os municípios que apresentam 
maior nível de organização, ainda não estão preparados para a produção de informações que possibilitem sua utilização, quer seja para a composição dos custos do PSF, quer seja, para a sua utilização como instrumento aplicado para conferir maior eficiência ao sistema de saúde.

Verificou-se que praticamente todos os pesquisadores citaram a inexistência de centros de custeio organizados nos municípios, demandando mais tempo do que o previsto para se chegar às informações necessárias.

Alguns identificaram a necessidade de se fortalecer, junto aos municípios, uma cultura de apuração de custos que permita, com o tempo, monitorar, acompanhar e avaliar, sistematicamente, a aplicação dos recursos em saúde, criando as condições necessárias para uma maior eficiência dos sistemas municipais, seu gerenciamento e gestão.

Esses estudos permitem que o planejamento da instalação de novas equipes de PSF seja realizado com maior precisão, além de possibilitar planejar alternativas para aumento da produtividade, com qualidade sem aumento de gastos, bem como diminuição de custos, sem a perda da produtividade.

Os resultados dessas pesquisas podem subsidiar a atuação de gerentes e gestores nos vários níveis, identificando os obstáculos e mostrando aos profissionais de saúde essas informações sobre os custos de suas atividades, motivando-os a se empenhar com mais intensidade nessas reformas de otimização dos recursos e de maior produtividade.

Os estudos apresentaram idéias acerca da gestão de custos no setor governamental, e a sua possibilidade de sua aplicabilidade no setor público, analisando se os recursos transferidos pelo SUS ao PSF são suficientes para atender de forma satisfatória a população. 


\section{CONCLUSÃO}

Dos dez estudos analisados observou-se que:

* Os 10 (dez) trabalhos analisados foram escritos por profissionais com diferentes formações, sendo 04 contadores, 02 economistas, 02 administradores hospitalar, 02 médicos, 01 administrador, 01 psicólogo e 01 tecnólogo em processamento de dados.

* Em relação ao tipo de publicação, foram encontrados 03 artigos em revista, 02 artigos apresentados em congressos, 02 dissertações de mestrado, sendo 01 em saúde pública e 01 em engenharia de produção, 01 tese de doutorado em saúde coletiva, 01 relatório de pesquisa governamental nacional e 01 relatório de pesquisa governamental estadual.

- A maioria dos trabalhos (80\%) foram selecionados após busca no site Google e 20\% estavam indexados na fonte LILACS.

* Conforme a distribuição ano de publicação, os trabalhos foram publicados entre os anos de 2000 e 2009.

* Metade dos trabalhos utilizou como objeto de custo para aferição equipes básicas de PSF; outros objetos de custo utilizados foram equipes ampliadas de PSF, unidades básicas de saúde e a atividade imunização.

- A grande maioria dos trabalhos (80\%) utilizou a metodologia de aferição de custos por absorção, sendo que apenas 2 descreveu e utilizou toda a metodologia proposta por esse modelo.

- Dois trabalhos $(20 \%)$ utilizaram a metodologia $A B C$, como metodologia para aferição dos custos, porém apenas 01 trabalhou descreveu e apresentou detalhadamente todos os passos da metodologia. 
* As amostras eram de municípios de todo o território nacional, com menos de 5 mil habitantes a municípios com mais de 1 milhão de habitantes.

* Os valores de custo per capita mensal encontrados variou de $R \$ 3,27$ a R\$10,99. Quando avaliado o aumento dos custos das equipes básicas de PSF para equipes ampliadas, foi observado um aumento de até $77,7 \%$ com o acréscimo da equipe de odontologia.

* Os gastos dos municípios com os serviços de saúde variaram de $30 \%$ a $90 \%$.

* Os gastos com recursos humanos são responsáveis por cerca de $70 \%$ a $75 \%$ dos custos totais encontrados.

* Dos trabalhos que aferiram o custo médio por procedimentos, através da metodologia de custeio por absorção os valores encontrados variaram de $R \$ 8,35$ a $R \$ 34,20$.

* O estudo que identificou o custo do procedimento imunização através da metodologia $A B C$ encontrou o valor de $R \$ 17,97$. 


\section{CONSIDERAÇÕES FINAIS}

O crescimento dos gastos públicos na saúde, relacionado aos problemas de financiamento, intensificaram a necessidade de conhecimento sobre custos.

Ainda é pequena a disseminação de métodos adequados para a mensuração de custos, como importante ferramenta para o gerenciamento, controle, tomada de decisão, análise e escolha de programas e estabelecimento de políticas.

Este trabalho vem mostrar a importância da aplicação de um sistema de custeio na atenção básica, para identificar os principais custos, e quais podem ser otimizados para melhorar a eficiência e eficácia dos serviços públicos de saúde.

Para tanto, torna-se inevitável que os sistemas contábeis sejam mais sofisticados, porém devem ser práticos e confiáveis. A contabilidade não pode ser mais entendida como uma necessidade real apenas para o fisco, mas é essencial como ferramenta de gestão.

Após a leitura intensa de todos os trabalhos, além das referências que foram utilizadas para a conceituação teórica sobre o tema, concluímos que ainda há muito sobre o tema a ser avaliado, analisado e discutido.

Esta pesquisa apresenta como limitações a não exploração de todas as fases da metodologia dos modelos de sistema de custeio utilizados nos trabalhos, além da limitação na avaliação criteriosa sobre as definições utilizadas por cada autor em relação às definições de custos e sistemas de custeio.

Podemos concluir que o objetivo principal proposto foi alcançado, descrevendo após busca intensa, identificando e analisando os trabalhos encontrados na literatura nacional sobre aferição de custos em unidades básicas de saúde, caracterizando suas peculiaridades, avanços e dificuldades. 
Recomenda-se, por fim, propor um modelo de aferição de custos na atenção básica, considerando seus aspectos mais relevantes, buscando aprimorar a utilização de técnicas de custos, em especial a forma de coleta das informações em todos os níveis de atenção, desde um procedimento realizado em uma unidade básica de saúde, até o custo total de uma secretaria municipal de saúde. 


\section{REFERÊNCIA BIBLIOGRÁFICA}

ANSELMI, M. L.; NAKAO, J. R. S. A enfermagem no processo de gestão econômica dos serviços de saúde: Limites e possibilidades. Rev. Bras. Enferm., Brasília, v. 52, n. 2, p. 223-232, abr/jun. 1999.

BRASIL. Constituição (1988). Constituição da República Federativa do Brasil. Brasília, DF: Senado Federal, 1988.

Lei ${ }^{\circ} .8080,19$ de setembro de 1990. Dispõe sobre as condições para a promoção, proteção e recuperação da saúde, a organização e o funcionamento dos serviços correspondentes e dá outras providências. Diário Oficial da União, Brasília, DF, 20 set. 1990.

Lei n. 8142, 28 de dezembro de 1990. Dispõe sobre a participação da comunidade na gestão do Sistema Único de Saúde (SUS) e sobre as transferências intergovernamentais de recursos financeiros na área e dá outras providências. Diário Oficial da União, Brasília, DF, 31 dez. 1990.

5 PIOLA, S. F.; VIANNA, S. M (orgs). Saúde no Brasil: Algumas questões sobre o Sistema Único de Saúde(SUS). Comissão Econômica para a América Latina e o Caribe: Escritório no Brasil. Documento CEPAL/IPEA, 77 p., 2009.

CASTRO, J. D. A utilização do sistema de custeio por absorção para avaliar custos da atenção básica de saúde: reformulações e aprimoramentos metodológicos. 2000. 167 p. Tese (Doutorado em Saúde Coletiva) - Faculdade de Ciências Médicas, UNICAMP, Campinas.

ROCHA, J. S. Y.; CACCIA-BAVA, M. D. C. G. G. A atenção básica na construção da saúde. Ciência \& Saúde Coletiva, Rio de Janeiro, v. 14, Supl.1, p. 1340-1343, set/out, 2009.

SAMPAIO, L. F. R.; LIMA, P. G. A. Informações para Tomadores de Decisão em Saúde Pública - Tema: Apoio ao Programa Saúde da Família. 75 p. São Paulo: BIREME/OPAS/OMS, 2002.

CAVAlCANTI, M. D. L. T. Comentários sobre a Estratégia de Saúde da Família e o SUS, suscitados pelo texto de Sousa e Hamann. Ciência \& Saúde Coletiva, Rio de Janeiro, v. 14, n. Supl. 1, p 1338-1340, set/out, 2009. 
ROCHA FILHO, F. D. S.; SILVA, M. G. C. Análise de custos com pessoal e produtividade de equipes do programa de saúde da família em Fortaleza, Ceará. Ciência \& Saúde Coletiva, Rio de Janeiro, v. 14, n. 3, p. 919-928, mai/jun 2009.

JERICO, M. D. C. Aplicação do custeio baseado em atividades em centro de material esterilizado. 2008. 197 p. Tese (Doutorado em Enfermagem) - Escola de Enfermagem, Universidade de São Paulo, São Paulo.

SANTANA, E. D. M. et al. Avaliação econômica do Programa de Saúde da Família (PSF) em municípios do Estado da Bahia: um estudo de custos. Relatório de pesquisa. Salvador: UFBA/ISC. Acordo de Cooperação Técnica Brasil-Reino Unido, MS/IPEA/DFID, 2003.

BRASIL. Ministério da Saúde. Projeto Reforsus - CNPq "Determinação do custo do programa de saúde da família - PSF". Relatório Final: Consórcio FGV - EPOS Health Consultants, 2001.

WITT, R. R. Competências da Enfermeira na atenção básica: Contribuição à construção das funções essenciais de saúde pública. 2005. 336 p. Tese (Doutorado em Enfermagem) - Escola de Enfermagem de Ribeirão Preto, Universidade de São Paulo, Ribeirão Preto.

CARVAlHO, A. I., et al. Políticas de saúde e organização Setorial do País. In: Curso de especialização autogestão em saúde. Rio de Janeiro: FIOCRUZ, 2001, v.1, p.111-131.

BRASIL, CONASS. Mecanismos e Critérios de Transferências de Recursos federais para Estados e Municípios. In: O Financiamento da Saúde. Brasília: CONASS, 2007, v. 3, p. 128-152. (Coleção Progestores - Para entender o SUS.)Disponível em: http://www.conass.org.br. Acesso em 02 fev. 2011.

LIMA, L. D. D.; ANDRADE, C. L. T. D. Condições de financiamento em saúde nos grandes municípios do Brasil. Cad. Saúde Pública, Rio de Janeiro, v. 25, n. 10, p. 2237-2248, out, 2009.

CASTRO, J. D.; MARINHO, M. E. Os custos do Programa de Saúde da Família de Porto Alegre - 1998 e 2002. Rev Bras Med Fam e Com, Rio de Janeiro, v. 2, n. 8, p. 298-306, jan/mar 2007.

RIBEIRO, J. A.; PIOLA, S. F.; SERVO, L. M. Financiamento e gasto das políticas sociais: o caso do Ministério da Saúde, 1995 a 20005. Bahia Análise \& Dados, Salvador, v. 16, n. 2, p. 289-301, set, 2006. 
BRASIL. Ministério da Saúde. Gestão Financeira do Sistema Único de Saúde. 66 p. Brasília, DF: Ministério da Saúde, 2003. (Série A. Normas e Manuais Técnicos).

Ministério da Saúde. Portaria GM no 2.203, de 05 de novembro de 1996. Aprova a Norma Operacional Básica do SUS - NOB-SUS 01/96, que redefine o modelo de gestão do Sistema Único de Saúde, constituindo, por conseguinte, instrumento imprescindível à viabilização da atenção integral à saúde da população e ao disciplinamento das relações entre as três esferas de gestão do Sistema. Diário Oficial da União, Brasília, DF, 1996.

Ministério da Saúde. Portaria GM no 373, de 27 de fevereiro de 2002. Aprova a Norma Operacional da Assistência à Saúde - NOAS-SUS 01/2002 que amplia as responsabilidades dos municípios na Atenção Básica; estabelece o processo de regionalização como estratégia de hierarquização dos serviços de saúde e busca de maior equidade; cria mecanismos para o fortalecimento da capacidade de gestão do Sistema Único de Saúde e procede à atualização dos critérios de habilitação de estados e municípios. Diário Oficial da União, Brasília, DF, 2002.

BRASIL, CONASS. O Financiamento da Atenção Básica. In: Atenção Primária e promoção da Saúde. Brasília: CONASS, 2007, v. 8, p. 130-152. (Coleção Progestores - Para entender o SUS.) Disponível em: http://www.conass.org.br. Acesso em 02 fev. 2011.

BODSTEIN, R. Atenção Básica na agenda da saúde. Ciência \& Saúde Coletiva, Rio de Janeiro, v. 7, n. 3, p. 401-411, 2002.

BRASIL. Ministério da Saúde. Portaria GM n ${ }^{\circ}$ 545. Estabelece normas e procedimentos reguladores do processo de descentralização da gestão das ações e serviços de saúde, através da Norma Operacional Básica - SUS 01/93. Diário Oficial da União, Brasília, DF, 20 mai. 1993. Ministério da Saúde. Portaria GM no 1.882, de 18 de dezembro de 1997. Estabelece o Piso da Atenção Básica - PAB e a sua composição. Diário Oficial da União, Brasília, DF, 22 dez. 1997, Seção I, p. 10.

- Ministério da Saúde. Portaria GM nº. 2007, de 1 de setembro de 2009. Define o valor mínimo da parte fixa do Piso de Atenção Básica (PAB), para efeito do cálculo do montante de recursos a ser transferido do Fundo Nacional de Saúde aos Fundos de Saúde dos Municípios e do Distrito Federal, e divulga os valores anuais e mensais da parte fixa do $\mathrm{PAB}$, por município e para o Distrito Federal. Diário Oficial da União, Brasília, DF, 02 set. 2009, n 168, seção 1, p. 45 . 
- Ministério da Saúde. Portaria GM no. 398, de 04 de abril de 2003. Define o Piso de Atenção Básico Ampliado. Diário Oficial da União, Brasília, DF, 04 de abril de 2003.

MARTINS, E. Contabilidade de custos. 9a . São Paulo: Atlas, 2008.

CASTILHO, V. Gerenciamento de custos: análise de pesquisas produzidas por enfermeiras. 2008. 107 p. Tese (Livre-Docência) - Escola de Enfermagem, Universidade de São Paulo, São Paulo.

BRASIL. Ministério da Saúde. Programa Nacional de Gestão de Custos Manual Técnico de Custos - conceitos e metodologia. 76 p. Brasília, DF: Ministério da Saúde, 2006 (Série A, Normas e Manuais Técnicos).

MELlo, G. Sistema de Custos na Administração Pública - Análise da Implantação do Método ABC em um Município de Pequeno Porte. 2006. 123 p. Dissertação (Mestrado em Engenharia de Produção) - Engenharia de Produção, Universidade Federal de Itajubá, Itajubá.

BEULKE, R.; BERTÓ, D. J. Gestão de custos e resultado na saúde. Hospitais, clínicas, laboratórios e congêneres. 4.ed. rev., atual. e ampliada. São Paulo: Saraiva, 2008.

COUTO, P. A. Avaliação economica da atenção básica no município de Vitória da Conquista - Bahia. In: VIII Encontro ABRES, 2007 "Democracia, universalidade e economia da saúde". PUC, São Paulo, 2007. Disponível: http://www.abresbrasil.org.br/pdf/11.pdf. Acesso em 29 mar. 2011.

ALMEIDA, D. A. D. Vacinação contra influenza em idosos e fatores relacionados à sua adesão: revisão integrativa da literatura e análise do conceito. 2009. 131 p. Dissertação (Mestrado em Enfermagem) - Escola de Enfermagem de Ribeirão Preto, Universidade de São Paulo, Ribeirão Preto.

LULIO, F. R. M. O uso de sistemas informatizados para o dimensionamento de pessoal de enfermagem: uma revisão integrativa da literatura. 2009.83 p. Dissertação (Mestrado em Enfermagem) - Escola de Enfermagem de Ribeirão Preto, Universidade de São Paulo, Ribeirão Preto.

POMPEO, D. A. Diagnóstico de enfermagem náusea em pacientes no período pós-operatório imediato: revisão integrativa da literatura. 2007. 184 p. Dissertação (Mestrado em Enfermagem) - Escola de Enfermagem de Ribeirão Preto, Universidade de São Paulo, Ribeirão Preto.

CASTRO, J. D. et al. Custo-efetividade: comparação entre o modelo "tradicional " e o Programa de Saúde da Família. Rev. Bras. Med. Fam. e Com., Rio de Janeiro, v. 3, n. 10, p. 91-98, jul/set 2007. 
ROCHA FILHO, F. Análise de custos e produtividade de equipes do Programa de Saúde da Família em Fortaleza - Ceará em 2004. 2005. 140 p. Dissertação (Mestrado em Saúde Pública). Centro de Ciências da Saúde, Universidade Estadual do Ceará, Fortaleza.

BARBOSA, E. S.; RÊGO, T. F.; REZENDE, I. C. C. O custo do Programa de Saúde da Família: um estudo de caso do município de Sapé/PB. In: XV Congresso Brasileiro de Custos. Curitiba, 2008. (Anais) 


\section{APÊNDICES}

10.1 APÊNDICE A - Planilha de análise dos estudos

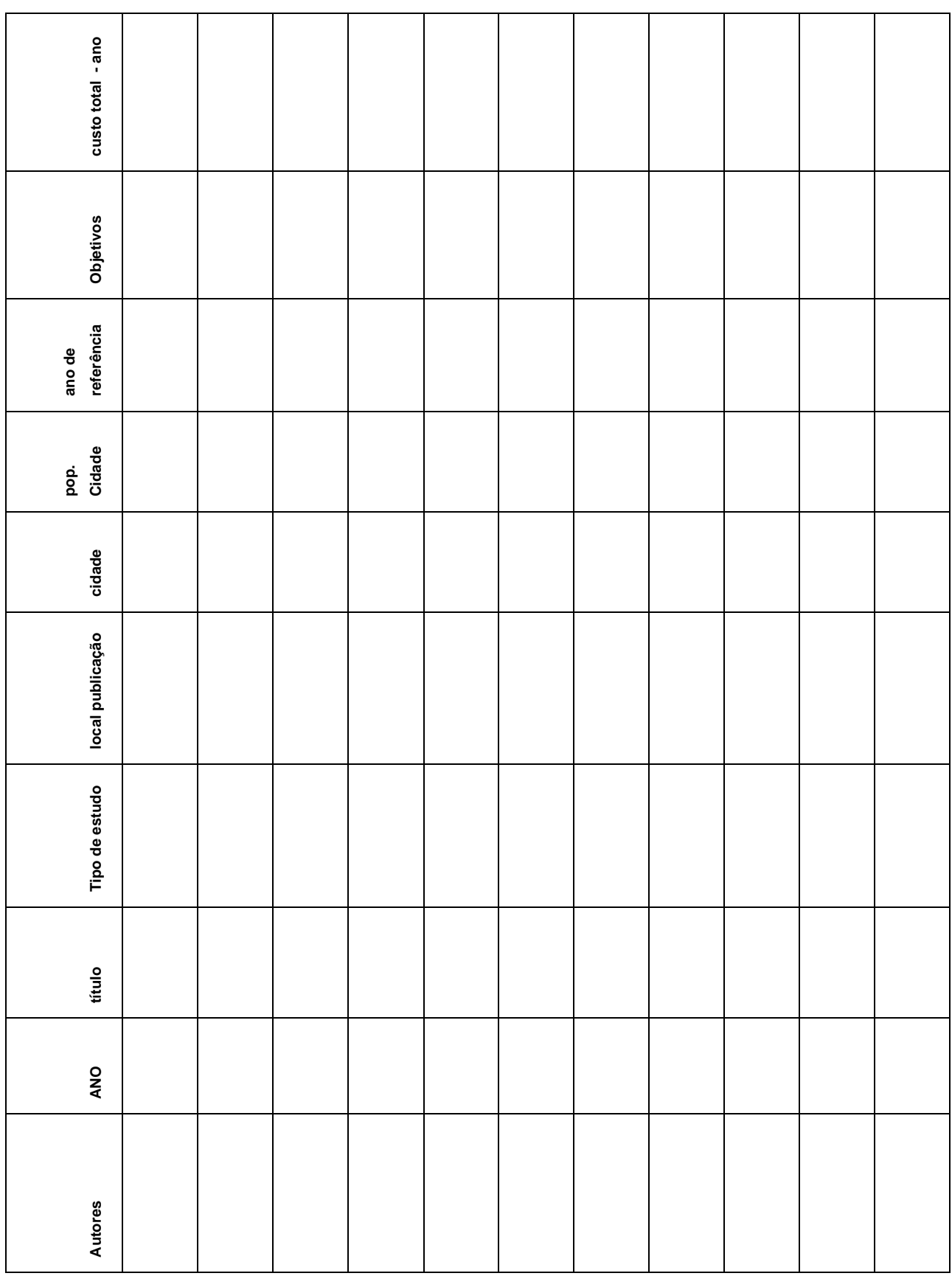


119

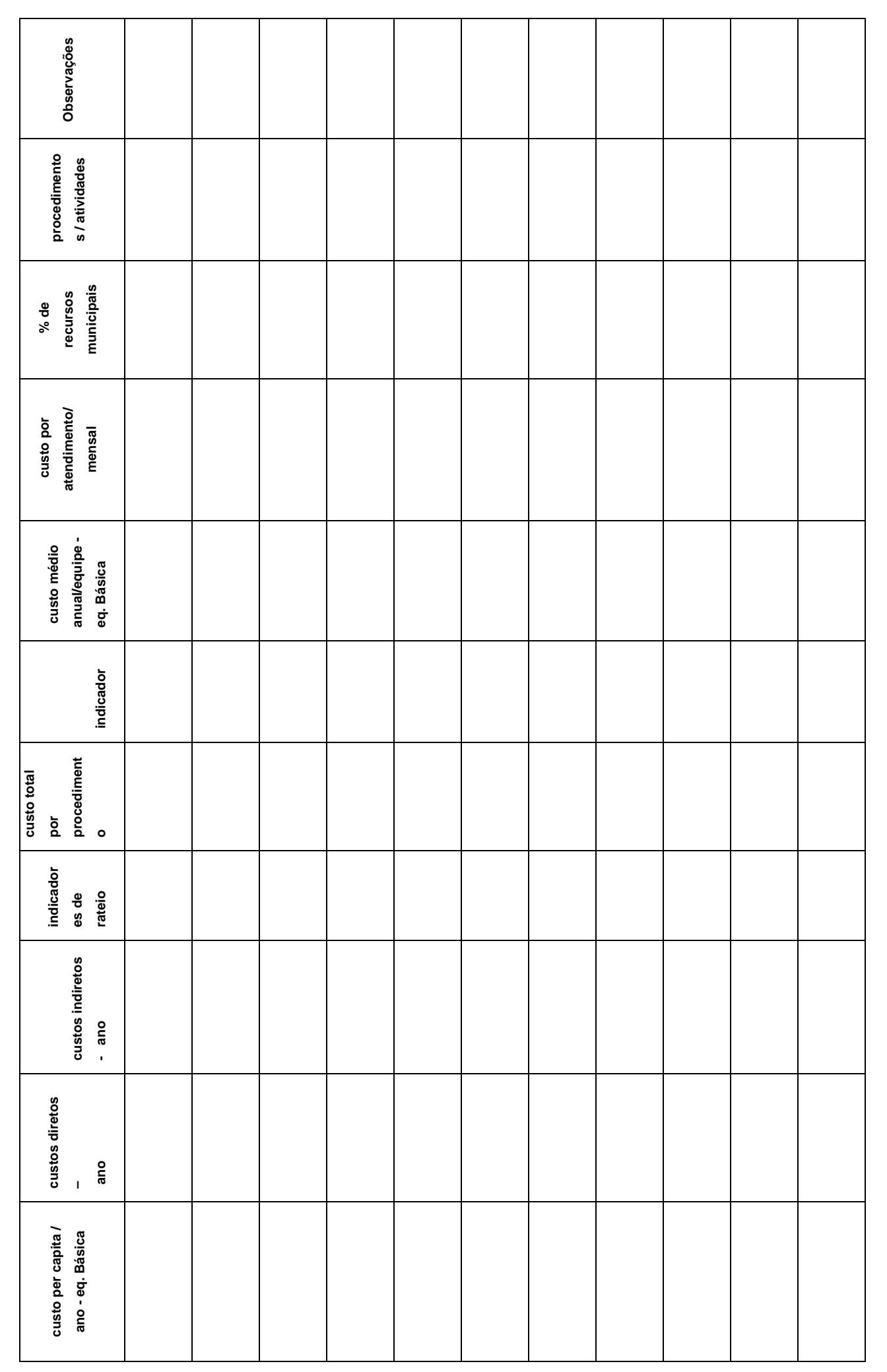


10.2 APÊNDICE B - Artigos componentes da amostra

1. Castro, JD. A utilização do sistema de custeio por absorção para avaliar custos da atenção básica de saúde: reformulações e aprimoramentos metodológicos. 2000. Tese (Doutorado) - Saúde Coletiva da Faculdade de Ciências Médicas, UNICAMP, Campinas.

2. Castro, JD; Marinho, ME. Os custos do Programa de Saúde da Família de Porto Alegre - 1998 e 2002. Rev Bras Med Fam e Com, Rio de Janeiro, v. 2, n. 8, p. 298-306, jan/mar 2007.

3. Castro, JD, et al. Custo-Efetividade:comparação entre o modelo "tradicional " e o Programa de Saúde da Família. Rev Bras Med Fam e Com, v. 3, n. 10, p. 8 , jul/set 2007.

4. Brasil. Ministério da Saúde. Projeto Reforsus - CNPq "Determinação do custo do programa de saúde da família - PSF". Relatório Final: Consórcio FGV EPOS Health Consultants 2001.

5. Santana, EDM, et al. Avaliação econômica do Programa de Saúde da Família (PSF) em municípios do Estado da Bahia: um estudo de custos. Relatório de pesquisa. Salvador: UFBA/ISC (Acordo de Cooperação Técnica Brasil-Reino Unido, MS/IPEA/DFID 2003.

6. Rocha Filho, FS. Análise de custos e produtividade de equipes do Programa de Saúde da Família em Fortaleza - Ceará em 2004. 2005. 140 (Mestrado em Saúde Pública). Centro de Ciências da Saúde Universidade Estadual do Ceará, Fortaleza. 
7. Rocha Filho, FS; Silva, MGC. Análise de custos com pessoal e produtividade de equipes do programa de saúde da família em Fortaleza, Ceará. Ciência \& Saúde Coletiva, v. 14, n. 3, p. 919-928, 2009.

8. Barbosa, ES; Rêgo, TF; Rezende ICC. O custo do Programa de Saúde da Família: um estudo de caso do município de Sapé/PB. XV Congresso Brasileiro de Custos. Curitiba, PR, Brasil 2008.

9. Mello, G. Sistema de Custos na Administração Pública - Análise da Implantação do Método ABC em um Município de Pequeno Porte. 2006. 123 (Mestrado em Engenharia de produção). Engenharia de produção, Universidade Federal de Itajubá, Itajubá.

10. Couto, PA. Avaliação economica da atenção básica no município de Vitória da Conquista - Bahia. VIII Encontro ABRES, 2007 "Democracia, universalidade e economia da saúde". PUC/São Paulo 2007. 


\section{ANEXOS}

11.1 ANEXO A - Planilhas utilizadas no trabalho 1.

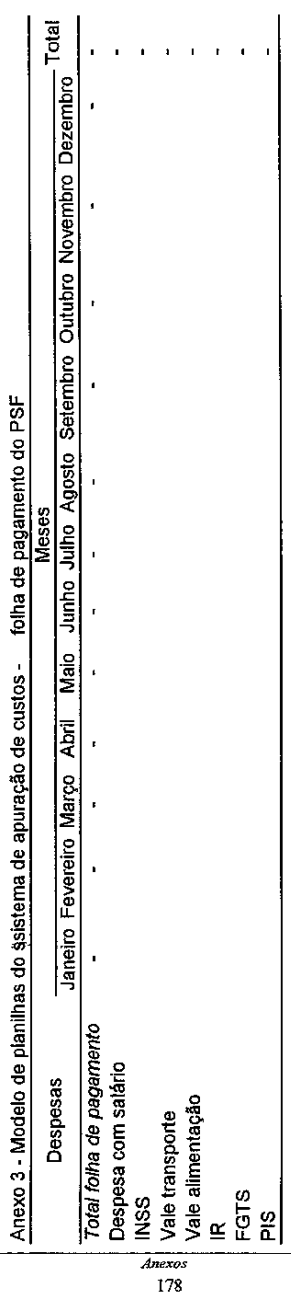




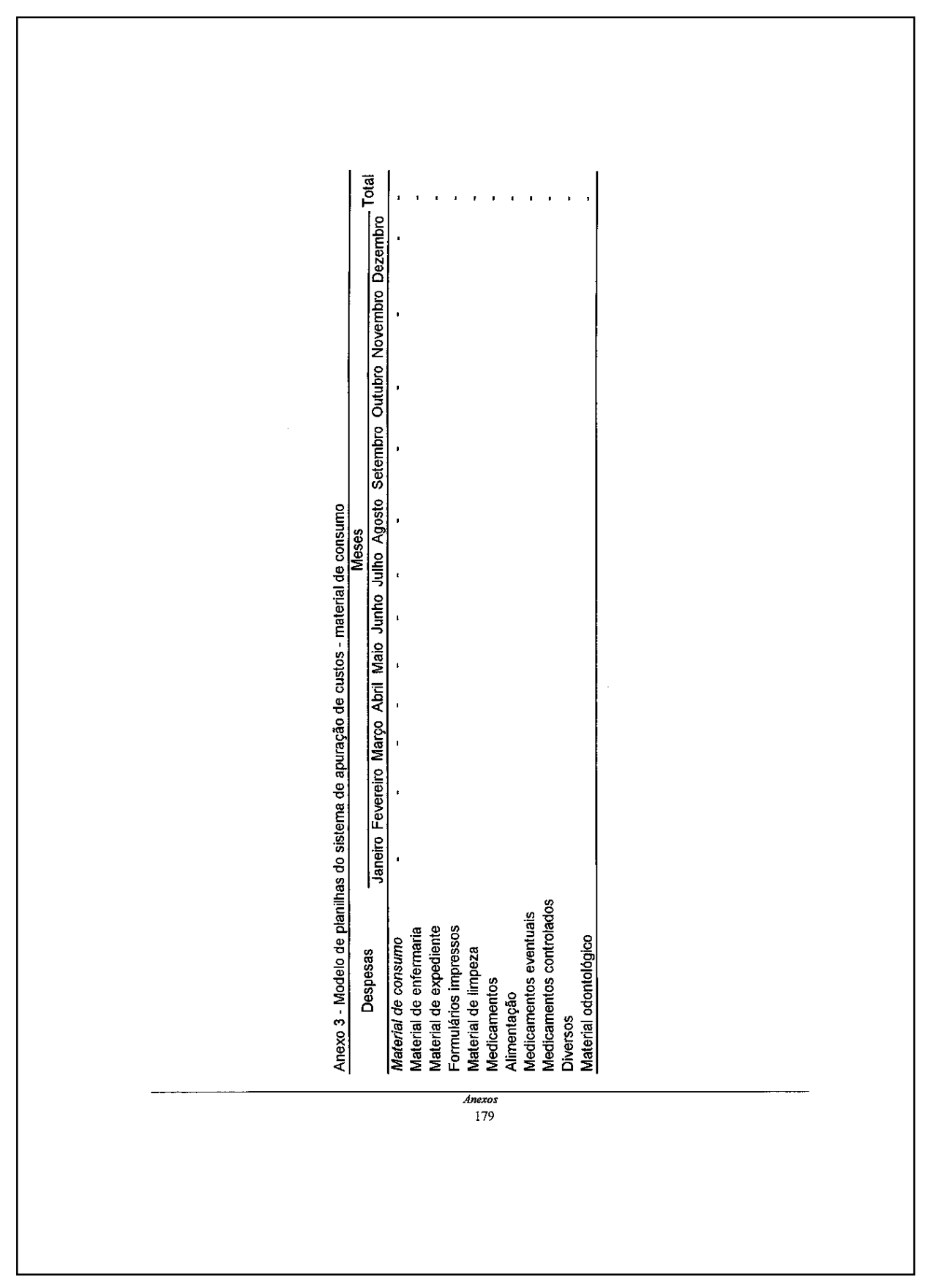




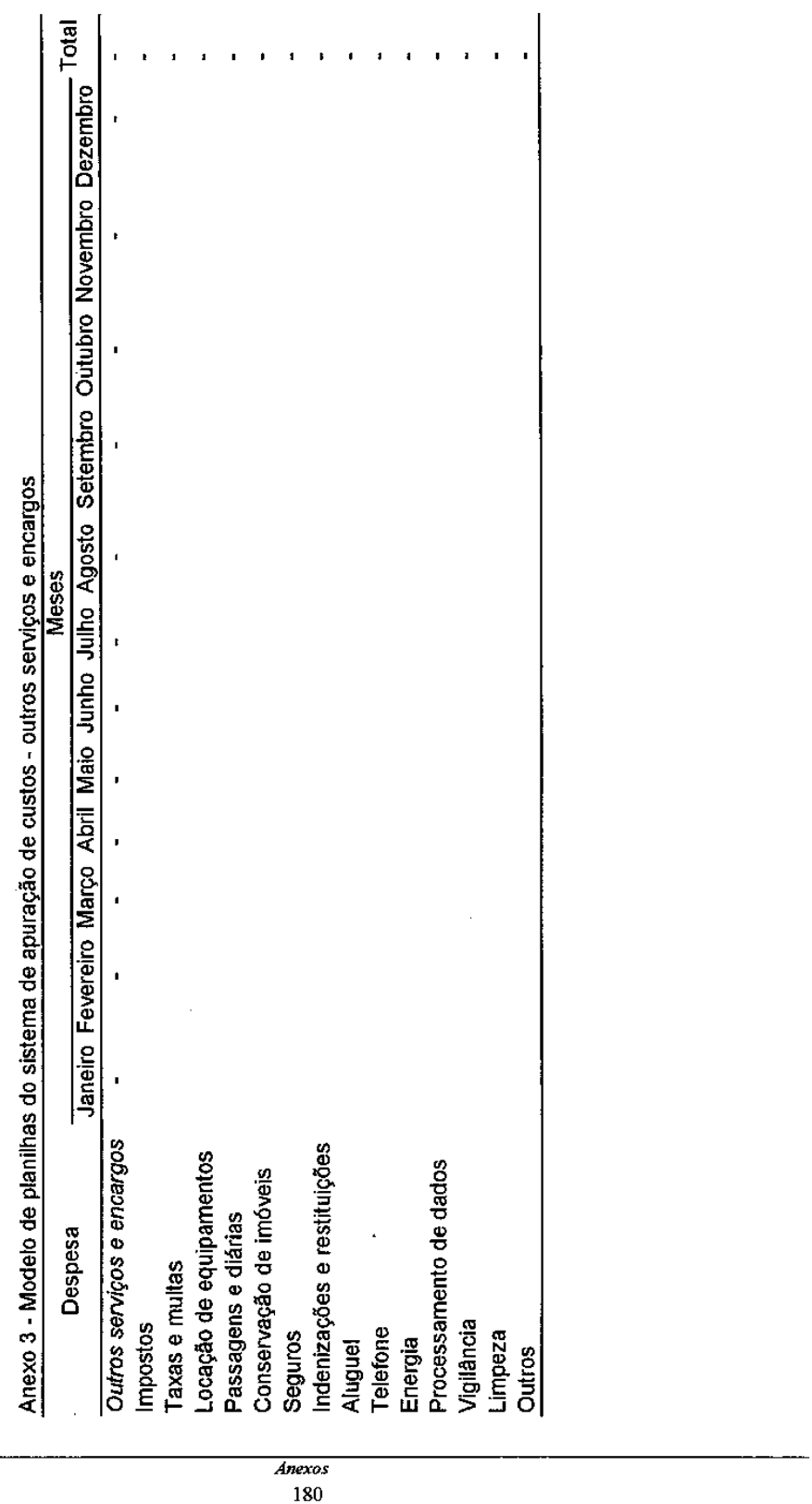




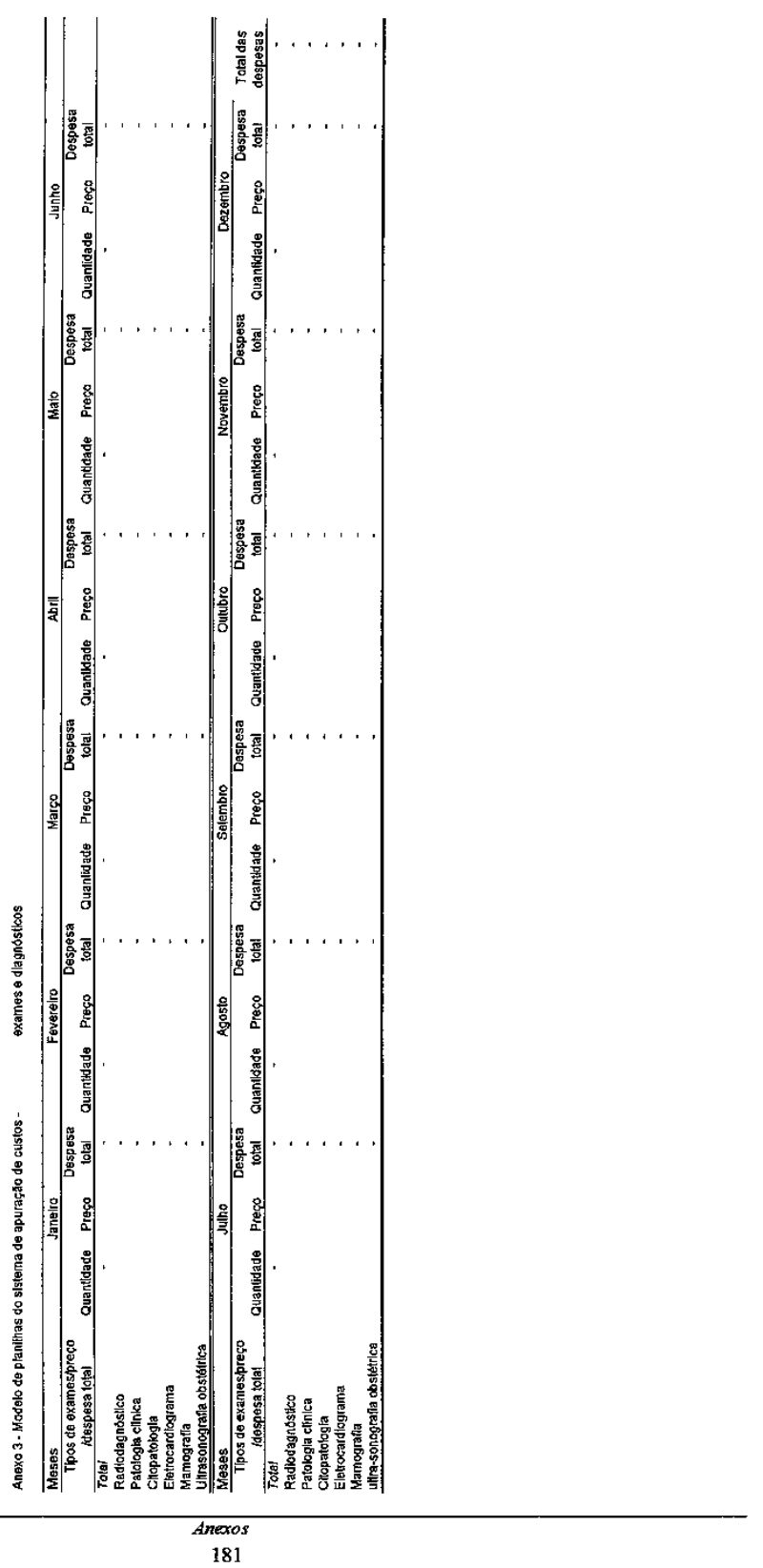




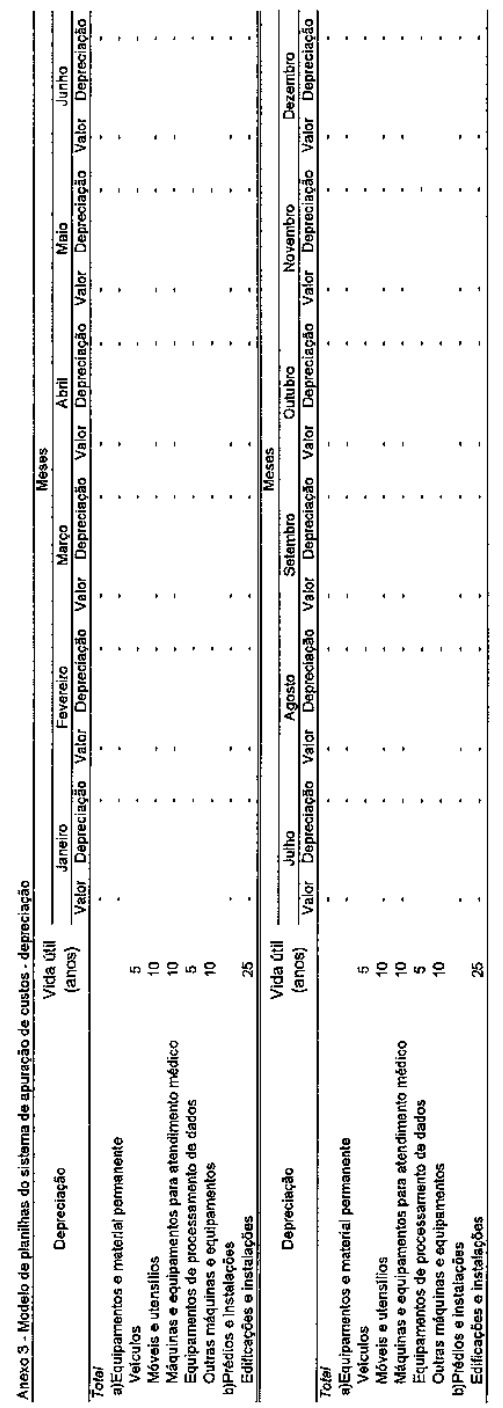

Anexos
182 


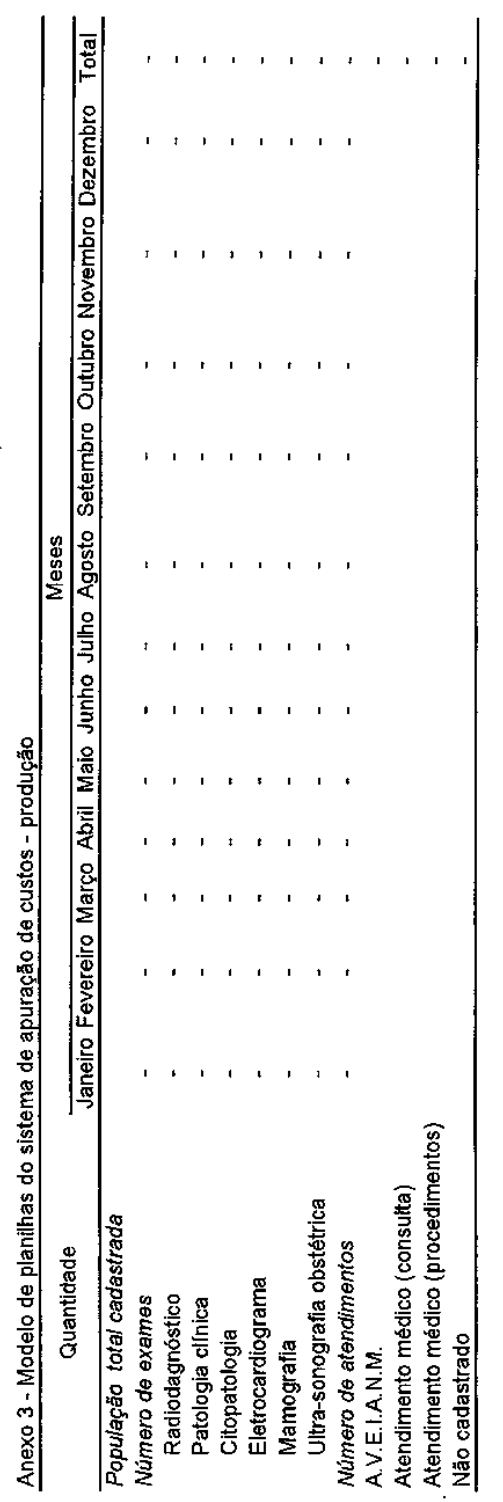




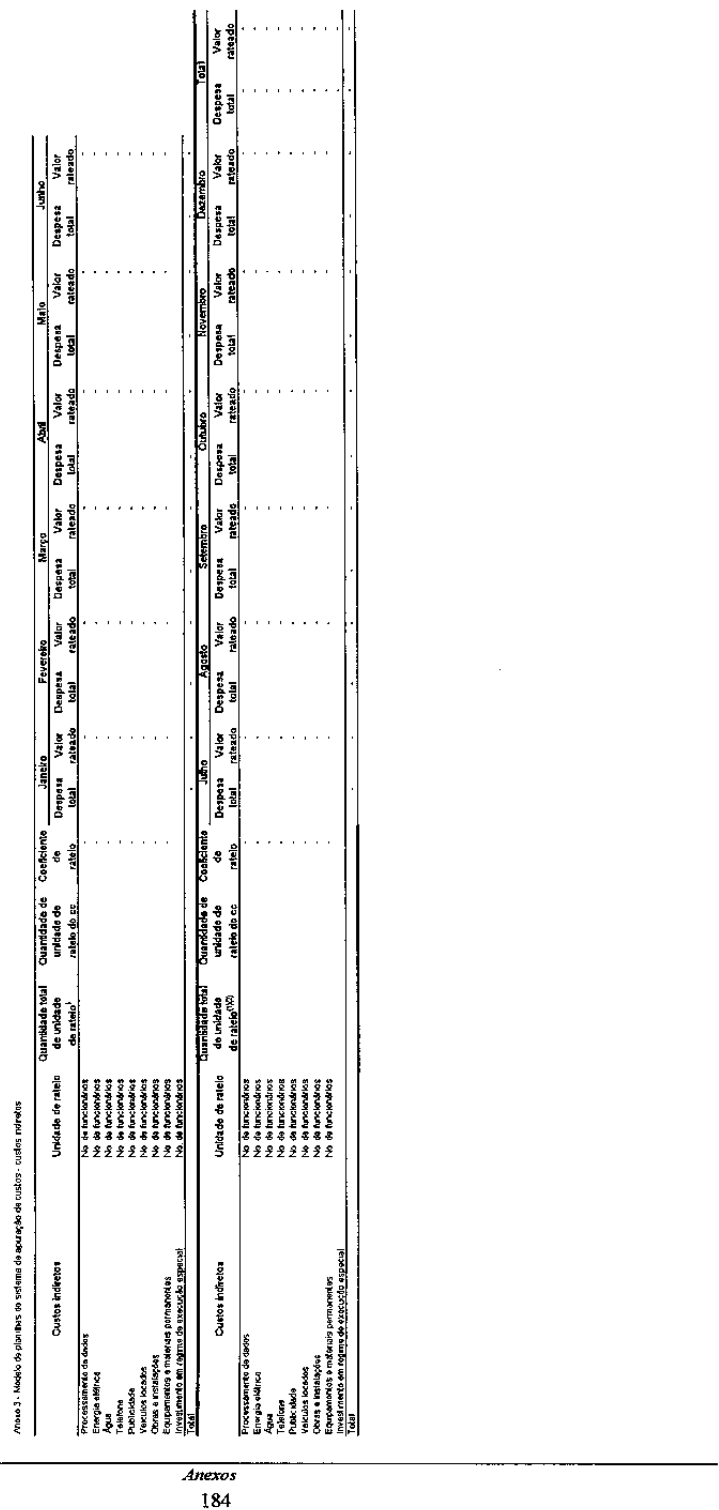




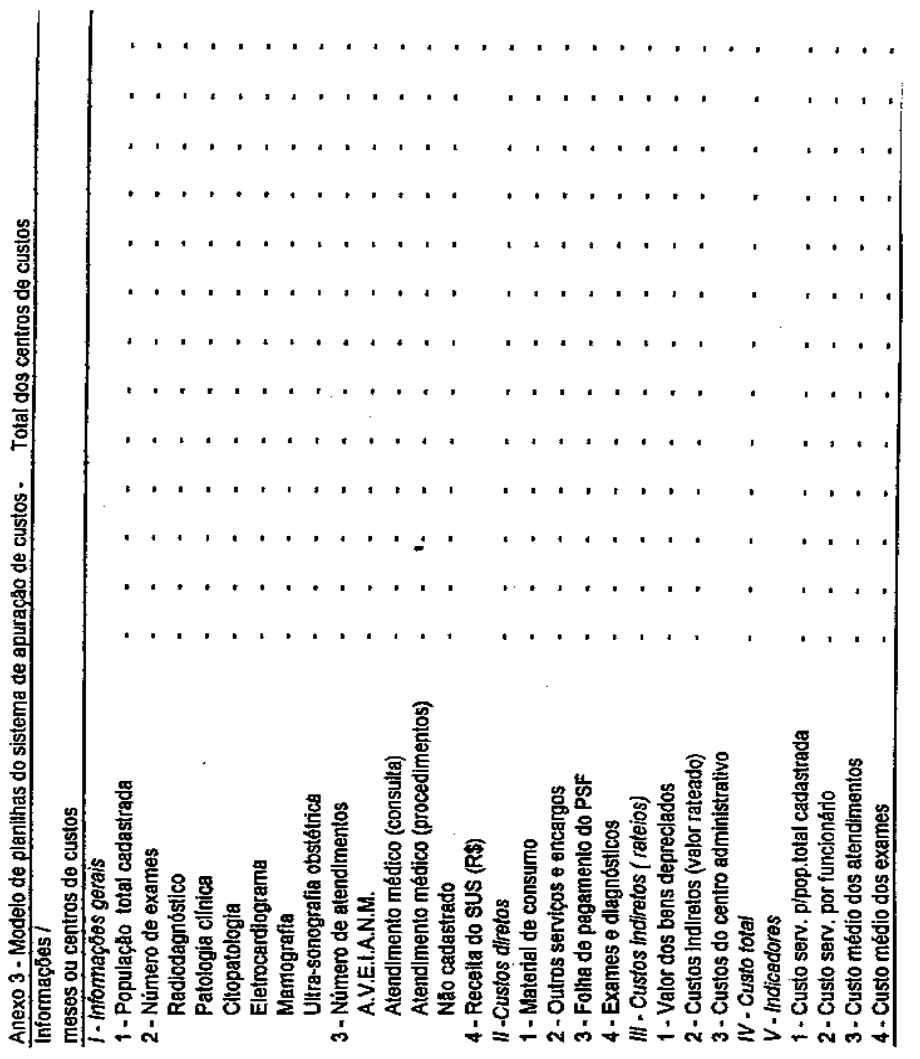


11.2 ANEXO B - Planilhas utilizadas no trabalho 4.

ANEXO A - QUESTIONÁRIO GERAL (COVTINUAÇÃO)

8.Indique a composição de cada equipe, básica/ completa ou ampliada, anotando o número de profissionais atuando em cada equipe. Use o mesmo número de identificaçắo da questẫo 7.

COMPOSIÇÃ́O DAS EQUIPES DO P.S.F.

\begin{tabular}{|c|c|c|c|c|c|c|c|c|c|c|}
\hline $\begin{array}{l}\text { Número de } \\
\text { identificaçẩo da } \\
\text { equipe }\end{array}$ & Médico & Enfermeiro & $\begin{array}{l}\text { Auxiliar de } \\
\text { Enfermagem }\end{array}$ & $\begin{array}{l}\text { Agente } \\
\text { Comunitário } \\
\text { de Saúde }\end{array}$ & Odontólogo & Psicólogo & $\begin{array}{c}\text { Assistente } \\
\text { Social }\end{array}$ & Nutricionista & $\begin{array}{c}\text { Outros } \\
\text { Profissionais } \\
\text { da Área } \\
\text { Médica }\end{array}$ & $\begin{array}{c}\text { Outros } \\
\text { Profissionais } \\
\text { Administrativos }\end{array}$ \\
\hline \multicolumn{11}{|l|}{1} \\
\hline \multicolumn{11}{|l|}{2} \\
\hline 3 & & & & & & & 1 & & & \\
\hline \multicolumn{11}{|l|}{4} \\
\hline \multicolumn{11}{|c|}{0} \\
\hline \multicolumn{11}{|l|}{6} \\
\hline \multicolumn{11}{|l|}{7} \\
\hline \multicolumn{11}{|l|}{8} \\
\hline \multicolumn{11}{|l|}{9} \\
\hline \multicolumn{11}{|l|}{10} \\
\hline \multicolumn{11}{|l|}{11} \\
\hline \multicolumn{11}{|l|}{13} \\
\hline \multicolumn{11}{|l|}{14} \\
\hline \multicolumn{11}{|l|}{15} \\
\hline \multicolumn{11}{|l|}{16} \\
\hline \multicolumn{11}{|l|}{17} \\
\hline \multicolumn{11}{|l|}{18} \\
\hline \multicolumn{11}{|l|}{19} \\
\hline \multicolumn{11}{|l|}{20} \\
\hline Comentários: & & & & & & & & & & \\
\hline
\end{tabular}


ANEXOB

(CONTINUAÇÃO)

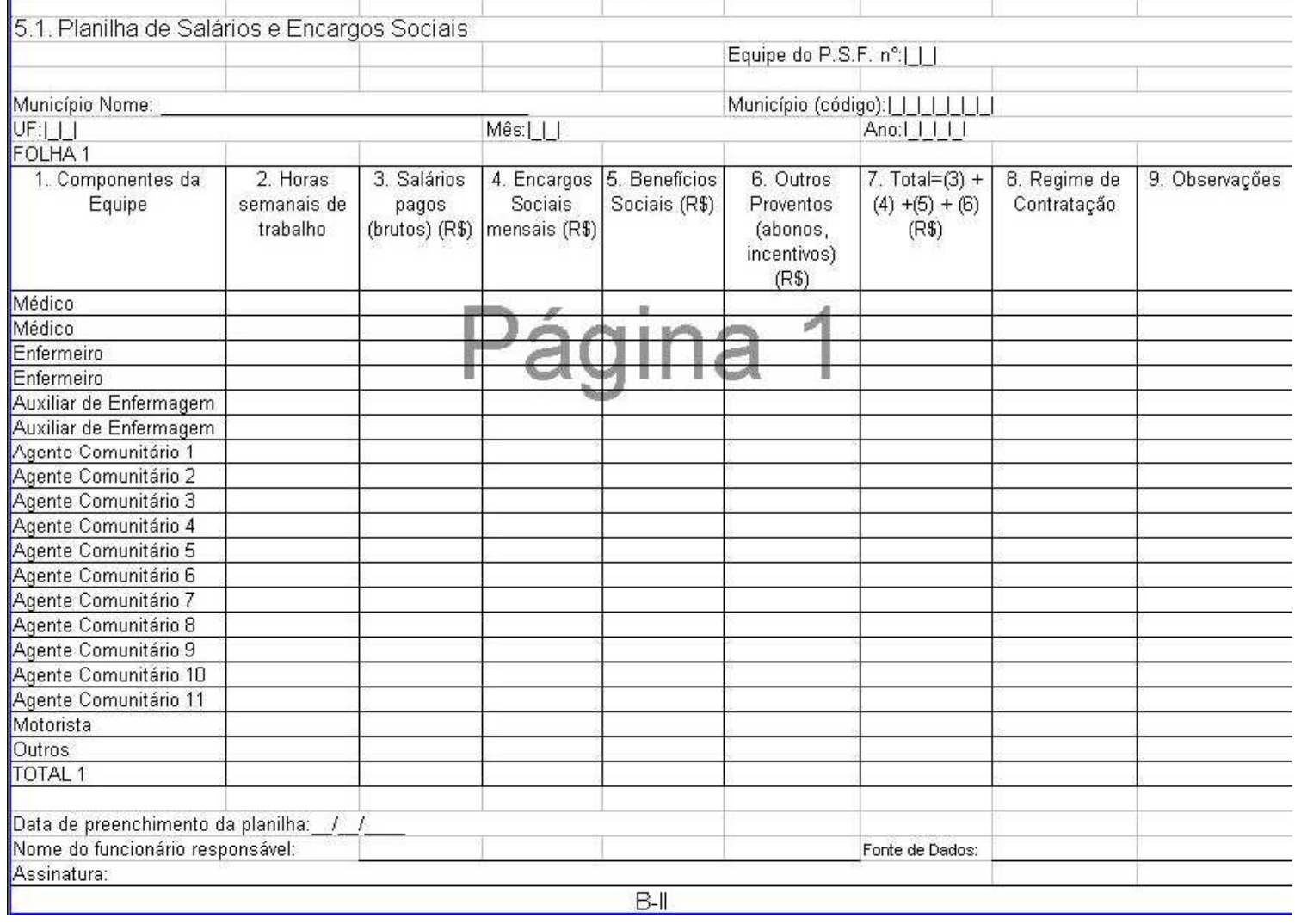




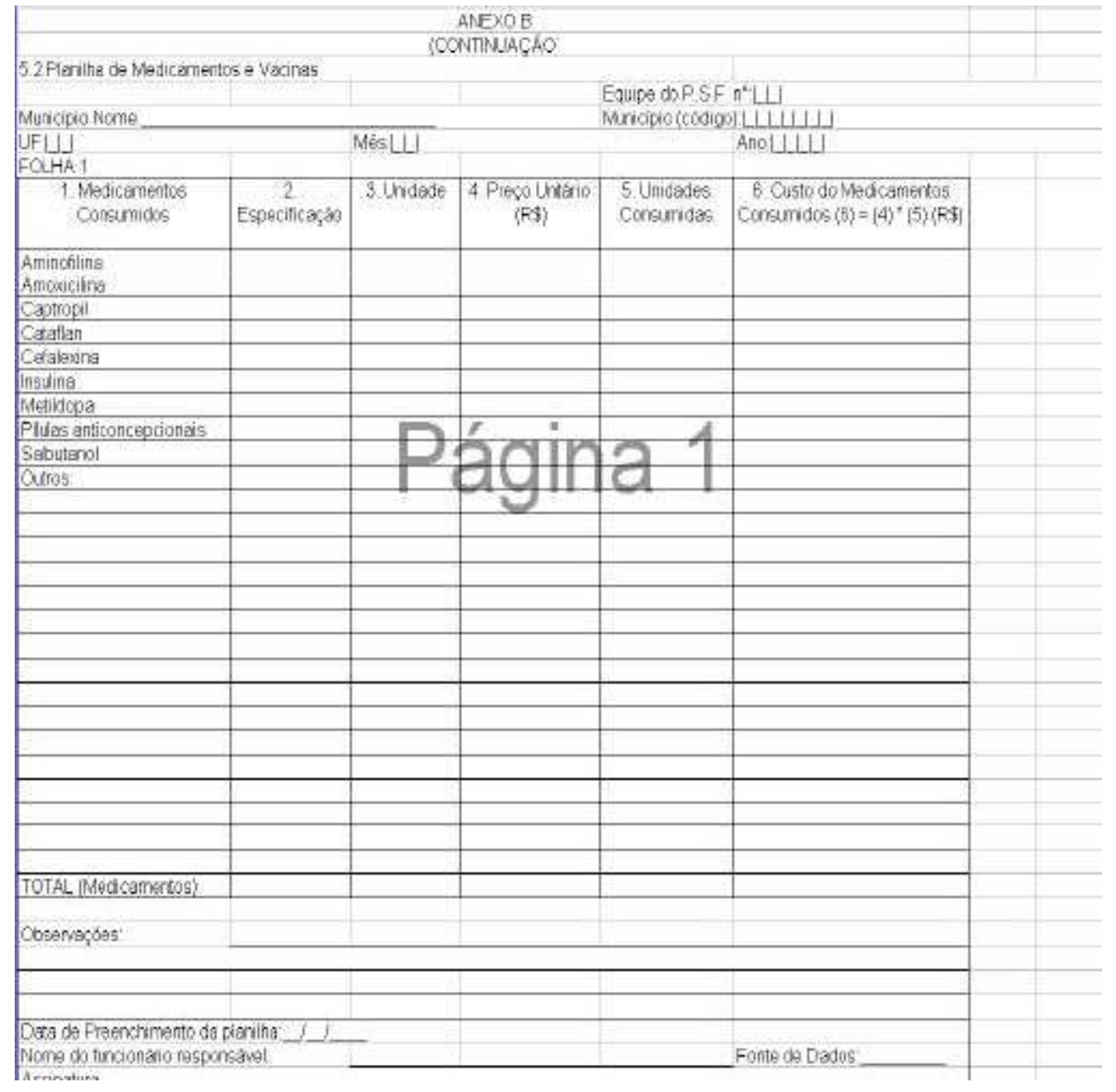


ANEXO B

(CONTINUAÇÃO)

\subsection{Planilha de Medicamentos e Vacinas}

\begin{tabular}{|c|c|c|c|c|c|}
\hline \multirow{2}{*}{\multicolumn{3}{|c|}{ Nome do Município: }} & \multirow{3}{*}{ Mês:|_I_I } & \multicolumn{2}{|c|}{ Equipe do P.S.F. nI_I_I } \\
\hline & & & & \multirow{2}{*}{\multicolumn{2}{|c|}{ 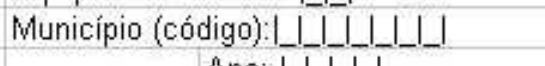 }} \\
\hline & & & & & \\
\hline \multicolumn{6}{|l|}{ FOLHA 2} \\
\hline 1. Vacinas Consumidas & $\begin{array}{c}2 . \\
\text { Especificação }\end{array}$ & $\begin{array}{c}3 . \\
\text { Unidade }\end{array}$ & $\begin{array}{l}\text { 4. Preço } \\
\text { Unitário } \\
(\mathrm{R} \$)\end{array}$ & $\begin{array}{l}\text { 5. Unidades } \\
\text { Consumidas }\end{array}$ & $\begin{array}{c}\text { 6. Custos dos } \\
\text { Medicamentos } \\
\text { Consumidos }(6)=(4) \text { * }\end{array}$ \\
\hline \multicolumn{6}{|l|}{ Vacina DT Adulto } \\
\hline \multicolumn{6}{|l|}{ Vacina DT Infantil } \\
\hline \multicolumn{6}{|l|}{ Vacina Antipólio - SABIN } \\
\hline \multicolumn{6}{|l|}{ Vacina Tríplice/DPT } \\
\hline \multicolumn{6}{|l|}{ Vacina Anti-Sarampo } \\
\hline \multicolumn{6}{|l|}{ Vacina $\mathrm{BCG}$} \\
\hline \multicolumn{6}{|l|}{ Vacina Anti-Hepatite B } \\
\hline \multicolumn{6}{|l|}{ Vacina Toxóide Tetânico } \\
\hline \multicolumn{6}{|l|}{ Vacina Tríplice Viral/MMR } \\
\hline \multicolumn{6}{|l|}{ Outras } \\
\hline & & & & & \\
\hline & & & & & \\
\hline & & & & & \\
\hline & & & & & \\
\hline & & & & & \\
\hline & & & & & \\
\hline & & & & & \\
\hline & & & & & \\
\hline & & & & & \\
\hline & & & & & \\
\hline \multicolumn{6}{|c|}{ TOTAL (medicamentos e vacinas) } \\
\hline & & & & & \\
\hline \multicolumn{6}{|c|}{ Observaçốes: } \\
\hline \multicolumn{6}{|c|}{ Data de preenchimento da planilha: } \\
\hline Nome do funcionário responsável: & & & & Fonte de Dados & \\
\hline Assinatura: & & & & & \\
\hline
\end{tabular}




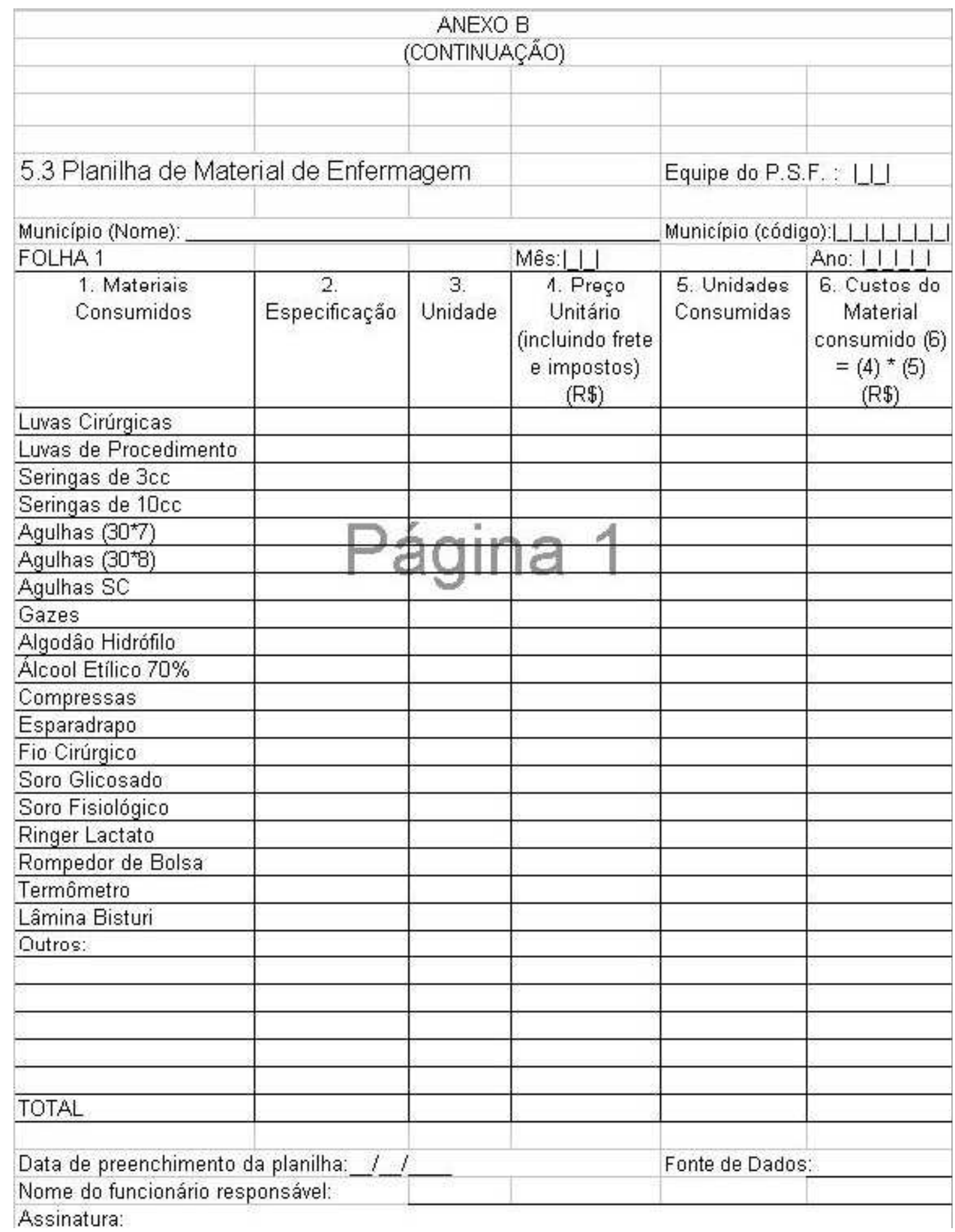




\begin{tabular}{|c|c|c|c|c|c|}
\hline \multicolumn{6}{|c|}{ ANE $\triangle O B$ B (CONTINUAÇÃO) } \\
\hline \multicolumn{4}{|c|}{ 5.3 Planilha de Equipamento de Enfermagem } & \multicolumn{2}{|c|}{ Equipe do P.S.F. : I_I_I } \\
\hline \multicolumn{4}{|c|}{ Municipio (Nome): } & \multirow{2}{*}{\multicolumn{2}{|c|}{ 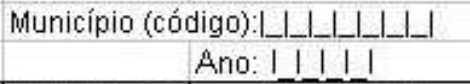 }} \\
\hline FOLHA2 & UF: I_I_I & & & & \\
\hline 1. Materiais Permanentes & $\begin{array}{c}2 . \\
\text { Especificaçã̃o }\end{array}$ & $\begin{array}{c}3 . \\
\text { Unidade }\end{array}$ & $\begin{array}{l}\text { 4. Preço Unitário } \\
\text { (incluindo frete e } \\
\text { impostos) (RS) }\end{array}$ & $\begin{array}{c}\text { 5. Unidades } \\
\text { existentes }\end{array}$ & $\begin{array}{l}\text { 6. Custos do } \\
\text { Equipamento } \\
\text { Existente }(6)=(4) \text { * } \\
\text { (5) }(\mathrm{R} \$)\end{array}$ \\
\hline \multicolumn{6}{|l|}{ Estetoscópio Clínico Adulto } \\
\hline \multicolumn{6}{|l|}{ Estetoscópio Clínico Infantil } \\
\hline \multicolumn{6}{|l|}{ Balança de Adulto } \\
\hline \multicolumn{6}{|c|}{\begin{tabular}{|l|l} 
Balança Infantil & \\
\end{tabular}} \\
\hline \multicolumn{6}{|c|}{ Material para Retirada de Pontos e Sutura: } \\
\hline \multicolumn{6}{|c|}{\begin{tabular}{l|l} 
A. Pinça de Kocher & \\
\end{tabular}} \\
\hline \multicolumn{6}{|l|}{ B. Pinça Dente de Rato } \\
\hline \multicolumn{6}{|l|}{ C. Cabo de Bisturi } \\
\hline \multicolumn{6}{|l|}{ D. Tesoura } \\
\hline \multicolumn{6}{|l|}{ E. Porta Agulha } \\
\hline Estetoscópio de Pinard & 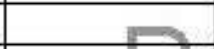 & y & & & \\
\hline \multicolumn{6}{|l|}{ Nebulizadorilnalador } \\
\hline \multicolumn{6}{|l|}{ Aparelho de Pressẫo } \\
\hline \multicolumn{6}{|l|}{ Foco de Luz } \\
\hline \multicolumn{6}{|l|}{ Otoscópio } \\
\hline \multicolumn{6}{|l|}{ Lanterna } \\
\hline \multicolumn{6}{|l|}{ Sonar Doppler } \\
\hline \multicolumn{6}{|l|}{ Glicosímetro } \\
\hline \multicolumn{6}{|l|}{ Ambú } \\
\hline \multicolumn{6}{|l|}{ Material para Parto: } \\
\hline \multicolumn{6}{|l|}{ A. Pinça de Kocher } \\
\hline \multicolumn{6}{|l|}{ B. Pinça Dente de Rato } \\
\hline C. Cabo de Bisturi & & & & & \\
\hline D. Tesoura & & & & & \\
\hline E. Porta Agulha & & & & & \\
\hline F. Pinça Cheron & & & & & \\
\hline G. Bandeja ou Caixa Inox & & & & & \\
\hline Oftalmoscópio & & & & & \\
\hline Laringoscópio & & & & & \\
\hline Refrigerador & & & & & \\
\hline Autoclave & & & & & \\
\hline Estufa & & & & & \\
\hline Outros & & & & & \\
\hline Data de preenchimento da $p$ & anilha: 1 & & & Fonte de Dado & \\
\hline Nome do funcionário respon & ável: & & & & \\
\hline
\end{tabular}




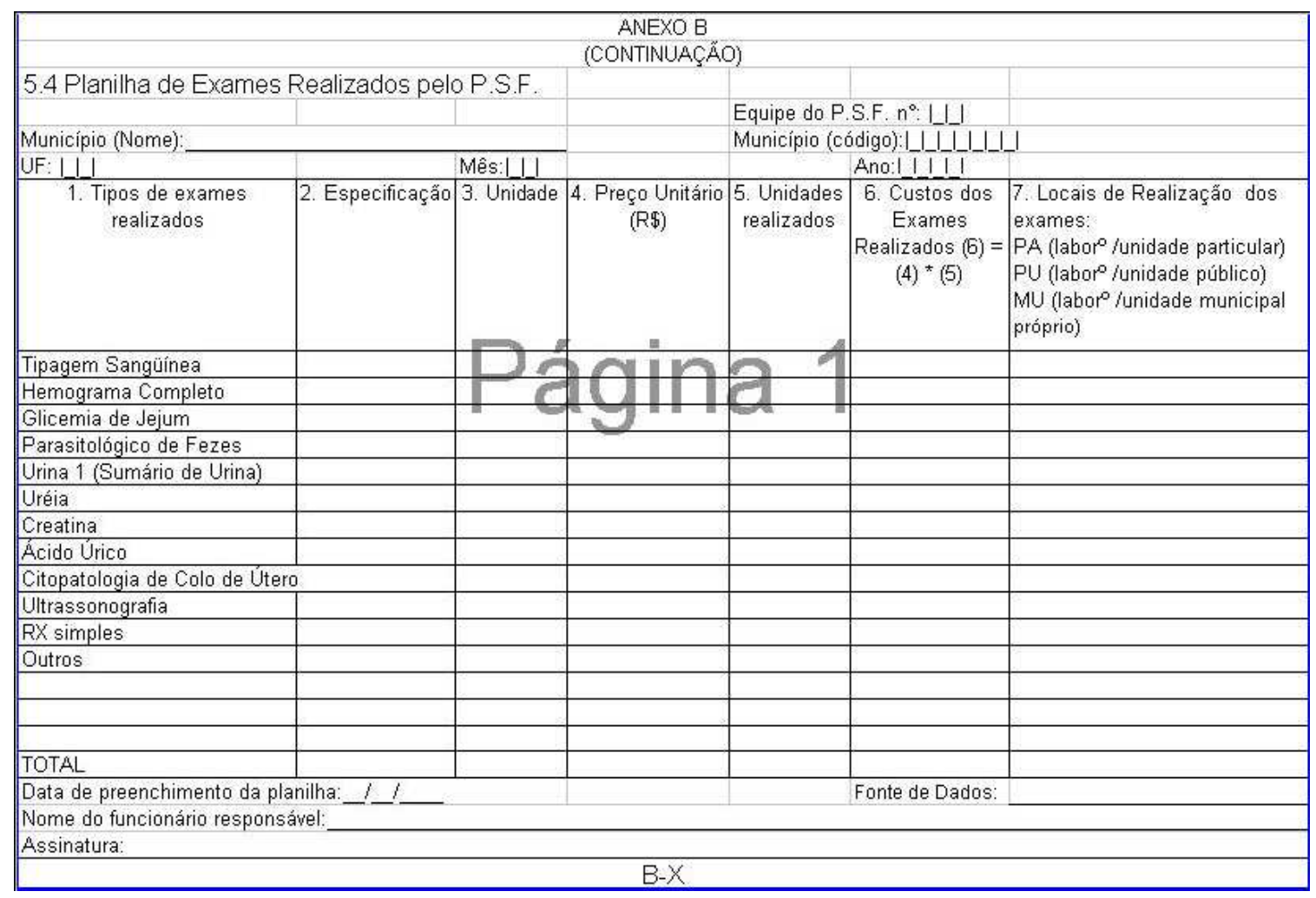




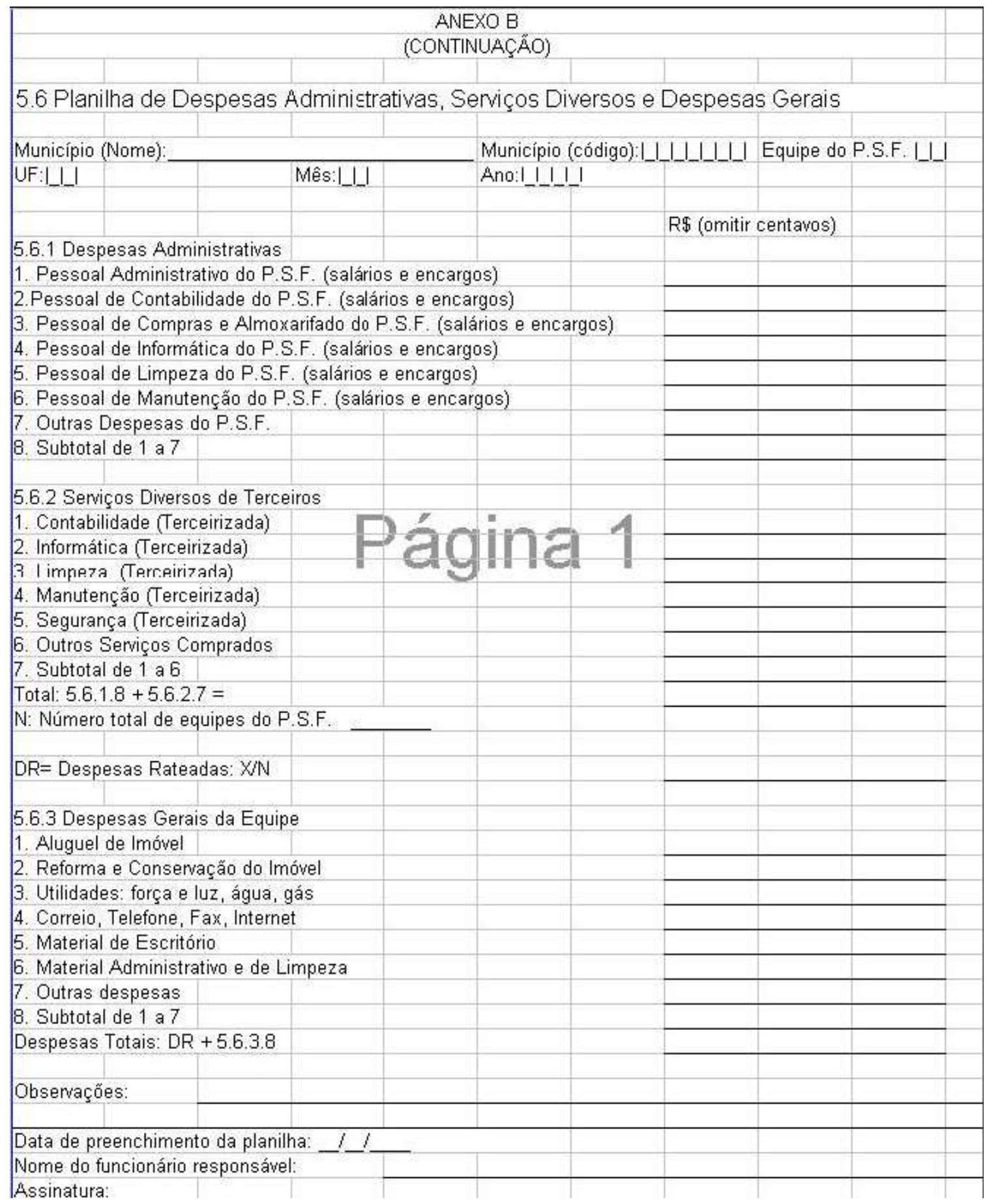




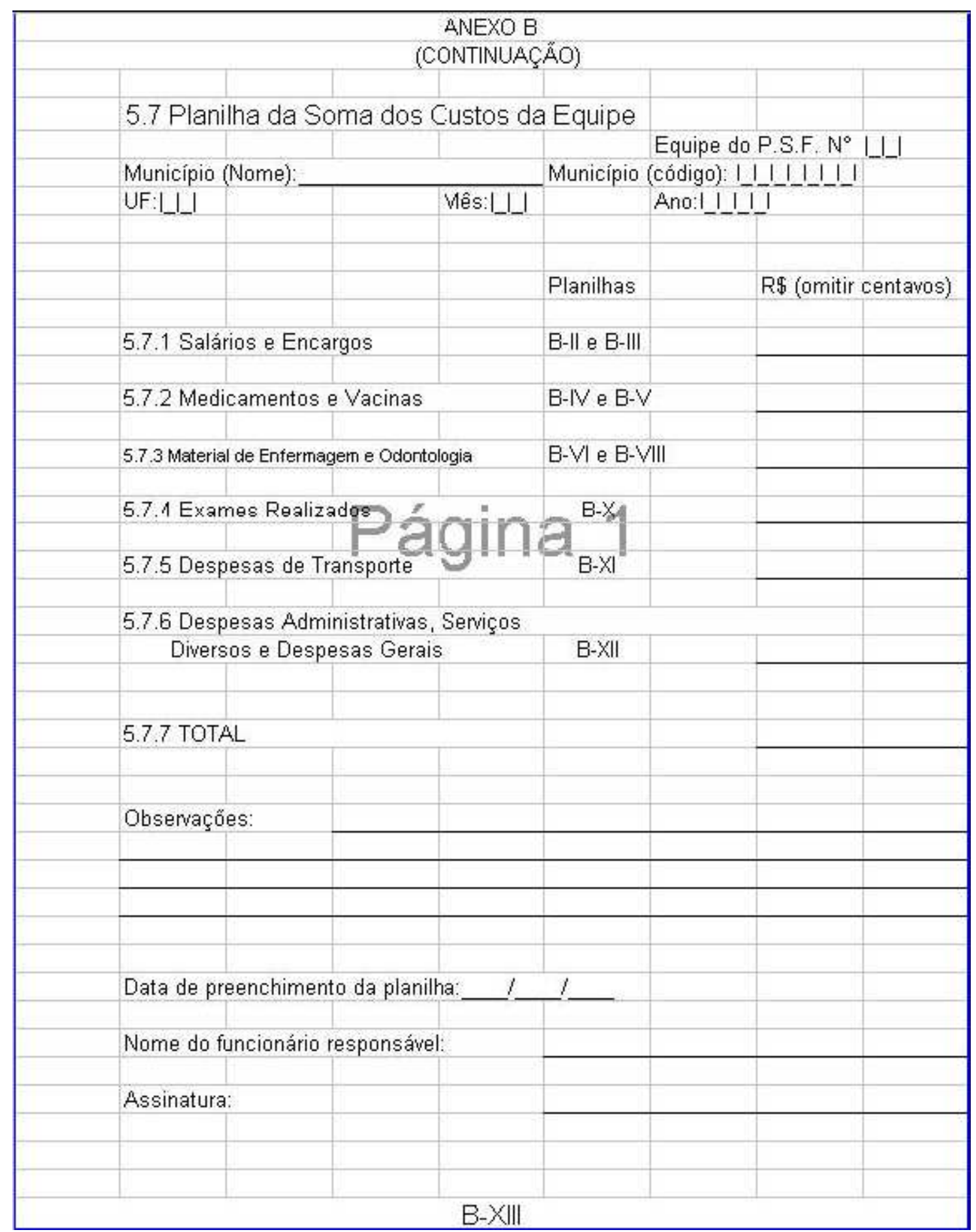

